\title{
DISCLAIMER
}

This report was prepared as an account of work sponsored by an agency of the United States Government. Neither the United States Government nor any agency thereof, nor any of their employees, makes any warranty, express or implied, or assumes any legal liability or responsibility for the accuracy, completeness, or usefulness of any information, apparatus, product, or process disclosed, or represents that its use would not infringe privately owned rights. Reference herein to any specific commercial product, process, or service by trade name, trademark, manufacturer, or otherwise does not necessarily constitute or imply its endorsement, recommendation, or favoring by the United States Government or any agency thereof. The views and opinions of authors expressed herein do not necessarily state or reflect those of the United States Government or any agency thereof.

\section{Use of MCNP for Characterization of Reactor Vessel Internals Waste from Decommissioned Nuclear Reactors}

\author{
E. F. Love \\ K. A. Pauley \\ B. D. Reid
}

Published September 1995

Battelle, Pacific Northwest Laboratories Richland, Washington 9935

\section{Idaho National Engineering Laboratory National Low-Level Waste Management Program Lockheed Idaho Technologies Company Idaho Falls, Idaho $\mathbf{8 3 4 1 5}$}

Prepared for the

U.S. Department of Energy

Assistant Secretary for Environmental Management

Under DOE Idaho Operations Office

Contract DE-ACO7-94ID13223 


\section{DISCLAIMER}

Portions of this document may be illegible in electronic image products. Images are produced from the best available original document. 


\begin{abstract}
This study describes the use of the Monte Carlo Neutron-Photon (MCNP) code for determining activation levels of irradiated reactor vessel internals hardware. The purpose of the analysis is to produce data for the Department of Energy's Greater-Than-Class C Low-Level Radioactive Waste Program. An MCNP model was developed to analyze the Yankee Rowe reactor facility. The model incorporates reactor geometry, material compositions, and operating history data acquired from Yankee Atomic Electric Company. In addition to the base activation analysis, parametric studies were performed to determine the sensitivity of activation to specific parameters. A component sampling plan was also developed to validate the model results, although the plan was not implemented.
\end{abstract}

The calculations for the Yankee Rowe reactor predict that only the core baffle and the core support plates will be activated to levels above the Class $\mathrm{C}$ limits. The parametric calculations show, however, that the large uncertainties in the material compositions could cause errors in the estimates that could also increase the estimated activation level of the core barrel to above the Class $\mathrm{C}$ limits. Extrapolation of the results to other reactor facilities indicates that in addition to the baffle and support plates, core barrels may also be activated to above Class $\mathrm{C}$ limits; however the classification will depend on the specific operating conditions of the reactor and the specific material compositions of the metal, as well as the use of allowable concentration averaging practices in packaging and classifying the waste. 


\section{ACKNOWLEDGMENTS}

The authors of this report wish to acknowledge the support of the Yankee Atomic Electric Company (YAEC) during this study. YAEC employees provided significant information and assistance in developing this report. Without their participation, this study would not have been possible. 


\section{CONTENTS}

ABSTRACT $\ldots \ldots \ldots \ldots \ldots \ldots \ldots \ldots \ldots \ldots \ldots \ldots \ldots \ldots \ldots \ldots \ldots$

ACKNOWLEDGMENTS $\ldots \ldots \ldots \ldots \ldots \ldots \ldots \ldots \ldots \ldots \ldots \ldots \ldots \ldots \ldots$

1. INTRODUCTION $\ldots \ldots \ldots \ldots \ldots \ldots \ldots \ldots \ldots \ldots \ldots \ldots \ldots \ldots$

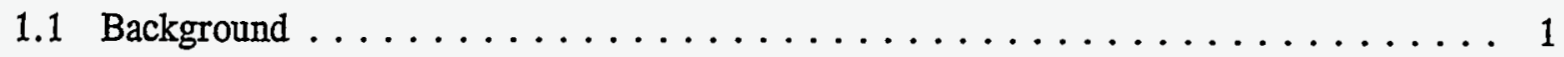

1.2 General Description of Vessel Decommissioning Wastes . . . . . . . . . . . . 3

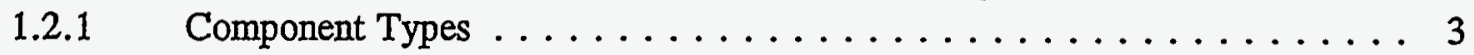

1.2.2 Component Masses and Volumes . . . . . . . . . . . . . 3

1.2.3 Current Uncertainty in GTCC Volume Estimates . . . . . . . . . . . . . 4

1.2.4 Impacts of GTCC LLW on the Waste Management System . . . . . . . 4

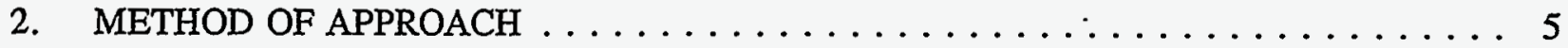

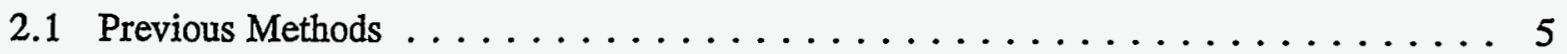

2.1.1 Direct Assay Method . . . . . . . . . . . . . . . . 5

2.1.2 Activation Analysis $\ldots \ldots \ldots \ldots \ldots \ldots \ldots \ldots \ldots \ldots \ldots \ldots \ldots \ldots$

2.2 Monte Carlo Method Using MCNP $\ldots \ldots \ldots \ldots \ldots \ldots \ldots \ldots$

2.3 Advantages/Disadvantages of MCNP Analysis Compared to Other Methods . . . . . . 8

2.4 Objectives of Current Analysis $\ldots \ldots \ldots \ldots \ldots \ldots \ldots \ldots \ldots \ldots \ldots \ldots \ldots \ldots \ldots \ldots$

2.4.1 Model Development . . . . . . . . . . . . . . . . 10

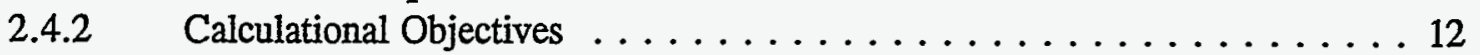

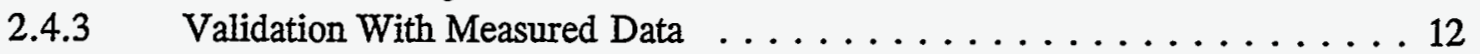

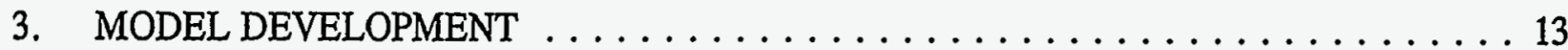

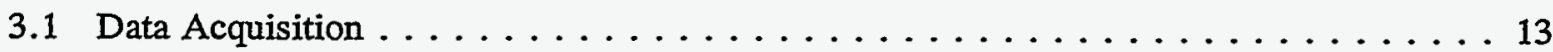

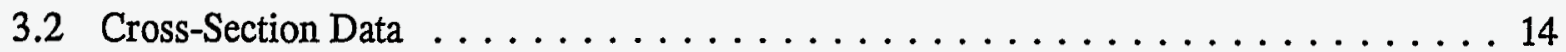

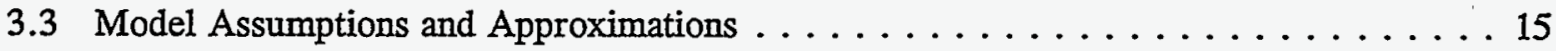

3.3.1 Reactor Physical Characteristics .................. 15

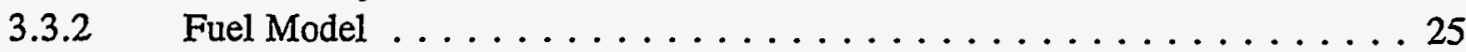

3.3.3 Component Geometry Model . . . . . . . . . . . . . . . 31

3.3.4 Material Compositions . . . . . . . . . . . . . . . . 49

3.3.5 Irradiation History and Cooling Time $\ldots \ldots \ldots \ldots \ldots \ldots \ldots \ldots \ldots \ldots \ldots$ 
3.3.6 MCNP Tally Structure $\ldots \ldots \ldots \ldots \ldots \ldots \ldots \ldots \ldots \ldots$

4. CALCULATIONAL RESULtS $\ldots \ldots \ldots \ldots \ldots \ldots \ldots \ldots \ldots \ldots \ldots \ldots \ldots \ldots \ldots$

4.1 Predicted Activation Levels $\ldots \ldots \ldots \ldots \ldots \ldots \ldots \ldots \ldots \ldots \ldots \ldots \ldots \ldots \ldots \ldots$

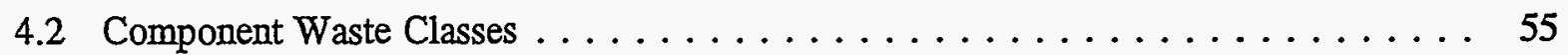

4.3 Monte Carlo Statistics $\ldots \ldots \ldots \ldots \ldots \ldots \ldots \ldots \ldots \ldots \ldots$

4.4 Calculational Difficulties/Problem Areas $\ldots \ldots \ldots \ldots \ldots \ldots \ldots \ldots \ldots$

4.5 Extrapolation of Results to Other PWRS $\ldots \ldots \ldots \ldots \ldots \ldots \ldots \ldots \ldots$

4.6 Validation With Measured Data $\ldots \ldots \ldots \ldots \ldots \ldots \ldots \ldots \ldots \ldots \ldots \ldots \ldots \ldots$

5. CONCLUSIONS $\ldots \ldots \ldots \ldots \ldots \ldots \ldots \ldots \ldots \ldots \ldots \ldots \ldots \ldots \ldots \ldots \ldots \ldots \ldots$

5.1 Analysis Conclusions for Yankee Rowe $\ldots \ldots \ldots \ldots \ldots \ldots \ldots \ldots$

5.2 Extrapolation of Results to Other PWRS ............... 63

5.3 Generic Applicability of the Analysis Methodology $\ldots \ldots \ldots \ldots \ldots \ldots$

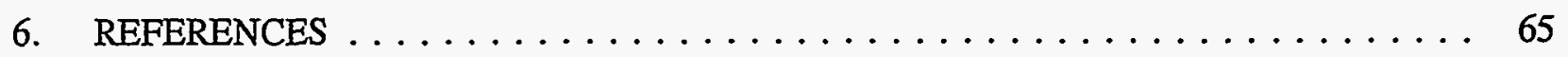

Appendix A-Parametric Studies $\ldots \ldots \ldots \ldots \ldots \ldots \ldots \ldots \ldots \ldots \ldots \ldots \ldots \ldots \ldots \ldots \ldots$

Appendix B-Draft Component Sampling Plan for Yankee Rowe Reactor $\ldots \ldots \ldots \ldots \ldots$ B-1

Appendix C-Comparison to DORT/ACTIV Calculations $\ldots \ldots \ldots \ldots \ldots \ldots \ldots$ C-1

FIGURES

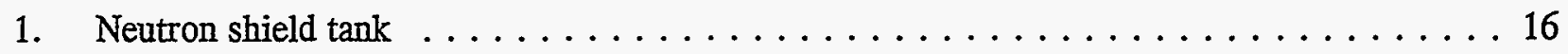

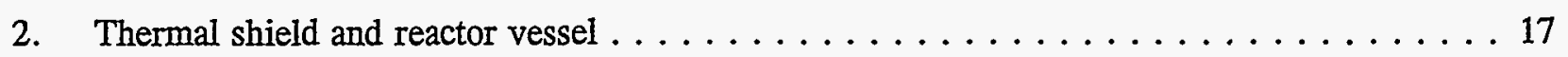

3. Lower core support plate and control rod shrouds $\ldots \ldots \ldots \ldots \ldots \ldots \ldots \ldots$

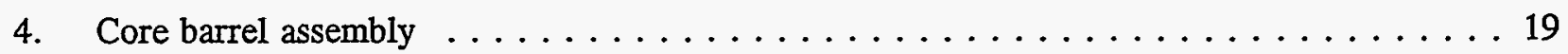

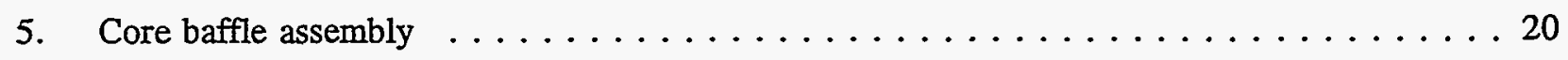

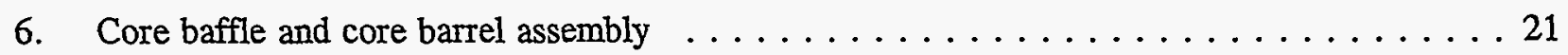

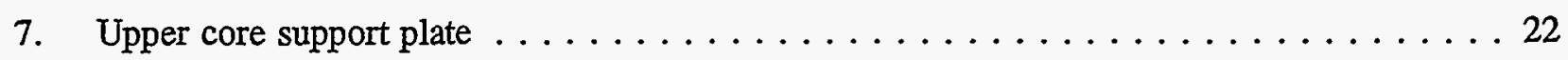




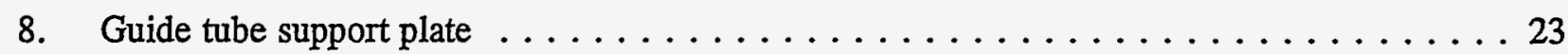

9. Yankee Rowe reactor radial section (Reference 12$) \ldots \ldots \ldots \ldots \ldots \ldots \ldots$

10. Illustration of Yankee Rowe axial section $\ldots \ldots \ldots \ldots \ldots \ldots \ldots \ldots \ldots \ldots \ldots \ldots \ldots$

11. Typical Yankee Rowe core loading pattern $\ldots \ldots \ldots \ldots \ldots \ldots \ldots \ldots \ldots \ldots \ldots$

12. Typical Yankee Rowe radial power profile $\ldots \ldots \ldots \ldots \ldots \ldots \ldots \ldots \ldots$

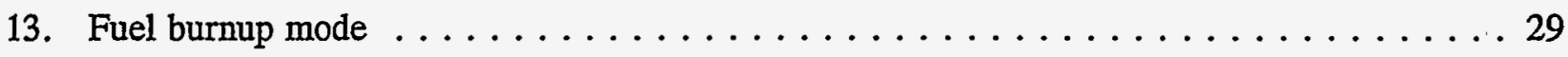

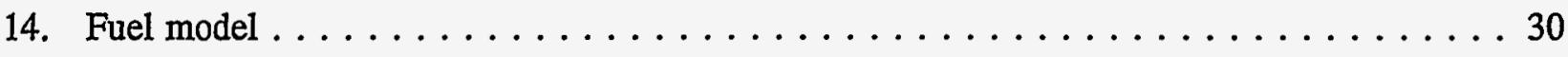

15. Axial view of Yankee Rowe MCNP model $\ldots \ldots \ldots \ldots \ldots \ldots \ldots \ldots \ldots$

16. Radial view of Yankee Rowe MCNP model-axial height of $595 \mathrm{~cm} \ldots \ldots \ldots \ldots 36$

17. Radial view of Yankee Rowe MCNP model-axial height of $570 \mathrm{~cm} \ldots \ldots \ldots 37$

18. Radial view of Yankee Rowe MCNP model-axial height of $567 \mathrm{~cm} \ldots \ldots \ldots \ldots 38$

19. Radial view of Yankee Rowe MCNP model-axial height of $564 \mathrm{~cm} \ldots \ldots \ldots 39$

20. Radial view of Yankee Rowe MCNP model-axial height of $559 \mathrm{~cm} \ldots \ldots \ldots \ldots . \ldots 40$

21. Radial view of Yankee Rowe MCNP model-axial height of $555 \mathrm{~cm} \ldots \ldots \ldots \ldots 41$

22. Radial view of Yankee Rowe MCNP model-axial height of $550 \mathrm{~cm} \ldots \ldots \ldots \ldots 2$

23. Radial view of Yankee Rowe MCNP model-axial height of $543 \mathrm{~cm} \ldots \ldots \ldots \ldots . \ldots 4$

24. Radial view of Yankee Rowe MCNP model-axial height of $542 \mathrm{~cm} \ldots \ldots \ldots \ldots 44$

25. Radial view of Yankee Rowe MCNP model-axial height of $540.5 \mathrm{~cm} \ldots \ldots \ldots \ldots$

26. Radial view of Yankee Rowe MCNP model-axial height of $527 \mathrm{~cm} \ldots \ldots \ldots \ldots 46$

27. Radial view of Yankee Rowe MCNP model-axial height of $500 \mathrm{~cm} \ldots \ldots \ldots \ldots$. . . 47

28. Radial view of Yankee Rowe MCNP model-axial height of $450 \mathrm{~cm} \ldots \ldots \ldots \ldots$

29. Radial reactor relative flux levels exterior to the active core $\ldots \ldots \ldots \ldots \ldots \ldots$

B-1. Yankee Rowe radial view-active core mid-plane $\ldots \ldots \ldots \ldots \ldots \ldots$ B-4

B-2. Yankee Rowe radial view $-50 \%$ above active core mid-plane $\ldots \ldots \ldots \ldots \ldots$ B-5 
B-3. Yankee Rowe radial view-top of active core $\ldots \ldots \ldots \ldots \ldots \ldots \ldots \ldots \ldots$ B-6

B-4. Yankee Rowe axial view $\ldots \ldots \ldots \ldots \ldots \ldots \ldots \ldots \ldots \ldots \ldots \ldots \ldots \ldots \ldots \ldots$

\section{TABLES}

1. Isotopes governing Class $\mathrm{C}$ waste classification and their half-lives $\ldots \ldots \ldots \ldots 2$

2. Parent reactions for GTCC isotopes of interest $\ldots \ldots \ldots \ldots \ldots \ldots \ldots \ldots \ldots$

3. Elemental constituents of carbon steel and stainless steel $304 \ldots \ldots \ldots \ldots \ldots$

4. Activated metal isotope activity limits for Class $\mathrm{C}$ waste $\ldots \ldots \ldots \ldots \ldots \ldots \ldots$

5. MCNP base case activation calculation for long-lived isotopes $\left(\mathrm{Ci} / \mathrm{m}^{3}\right) \ldots \ldots \ldots 53$

6. MCNP base case activation calculations for short-lived isotopes $\ldots \ldots \ldots \ldots \ldots 4$

7. MCNP base case activation calculations for ${ }^{60} \mathrm{Co} \ldots \ldots \ldots \ldots \ldots \ldots \ldots$

8. Production rate ratios of activation products $\ldots \ldots \ldots \ldots \ldots \ldots \ldots \ldots \ldots$

9. MCNP base case sum-of-the-fractions calculations for long-lived isotopes $\ldots \ldots \ldots 58$

10. MCNP base case sum-of-the-fractions calculation for short-lived isotopes. . . . . . . 59

A-1. Isotopic constituents of stainless steel $304 \ldots \ldots \ldots \ldots \ldots \ldots \ldots \ldots \ldots \ldots$

A-2. Isotopic constituents of carbon steel $\ldots \ldots \ldots \ldots \ldots \ldots \ldots \ldots \ldots \ldots \ldots \ldots \ldots$

A-3. Concentration ranges of GTCC parent elements in carbon steel $\ldots \ldots \ldots \ldots \ldots$ A-7

A-4. Concentration ranges of GTCC parent elements in stainless steel $\ldots \ldots \ldots \ldots \ldots$ A-7

A-5. Concentration parametric calculations for long-lived isotopes $\ldots \ldots \ldots \ldots \ldots$ A-9

A-6. Concentration parametric calculations for short-lived isotopes $\ldots \ldots \ldots \ldots \ldots$ A-10

A-7. Concentration parametric calculations for ${ }^{60} \mathrm{Co} \ldots \ldots \ldots \ldots \ldots \ldots \ldots$

A-8. Concentration parametric sum-of-the-fractions calculations for long-lived isotopes . . . A A-11

A-9. Concentration parametric sum-of-the fractions calculations for short-lived isotopes . . . A-12

A-10. Increased core barrel size activation calculations for long-lived isotopesdecayed values 
A-11. Increased core barrel size activation calculations for short-lived isotopes-

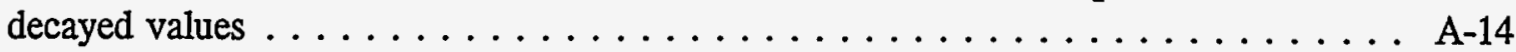

A-12. Increased core barrel size activation calculations for ${ }^{80} \mathrm{Co}$-decayed values $\ldots \ldots \ldots$ A-14

A-13. Increased core barrel size sum-of-the-fractions calculations for long-lived isotopes . . . A-14

A-14. Increased core barrel size sum-of-the-fractions calculations for short-lived isotopes . . A A-15

A-15. Reactor exposure parametric for long-lived isotopes-activation at 30 EFPY $\ldots \ldots$ A-17

A-16. Reactor exposure parametric for short-lived isotopes-activation at 30 EFPY . . . . . A-18

A-17. Reactor exposure parametric for ${ }^{60} \mathrm{Co}$ at $30 \mathrm{EFPY} \ldots \ldots \ldots \ldots \ldots \ldots \ldots$ A-18

A-18. Reactor exposure parametric for long-lived isotopes-sum-of-the-fractions at

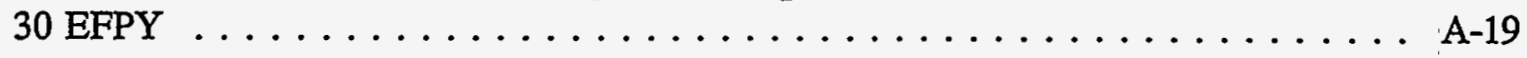

A-19. Reactor exposure parametric for short-lived isotopes-sum-of-the-fractions at

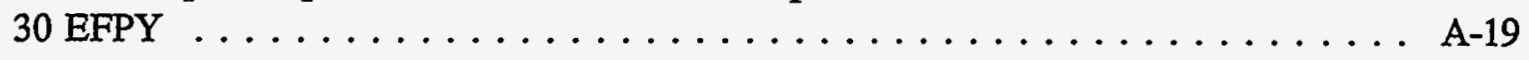

B-1. Proposed sample location list and location description for the Yankee Rowe reactor . . B B

C-1. Activation calculations for long-lived isotopes $\ldots \ldots \ldots \ldots \ldots \ldots \ldots$ C-4

C-2. Comparison of DORT/ACTIV and MCNP scaling factors $\ldots \ldots \ldots \ldots \ldots$ C-5

C-3. Comparison of production ratios of activation products $\ldots \ldots \ldots \ldots \ldots \ldots$ C-7

C-4. Comparison of sums-of-the-fractions calculations for long-lived isotopes $\ldots \ldots \ldots \ldots$ C-9

C-5. Comparison of sums-of-the-fractions calculations for short-lived isotopes $\ldots \ldots \ldots$ C-10 


\section{Use of MCNP for Characterization of Reactor Vessel Internals Waste from Decommissioned Nuclear Reactors}

\section{INTRODUCTION}

\subsection{Background}

The decommissioning of commercial nuclear power reactors will require the disposal of relatively large volumes of activated metals. These metals will consist of reactor vessel internal components such as core baffles, core barrels, thermal shields, pressure vessels, and core support structures. Reactor vessels and internal components must be characterized to determine their waste classification and disposal requirements placed on these materials. Structural components in operating nuclear reactors are activated when their constituent materials absorb neutrons. How these materials are disposed of during reactor decommissioning depends on the activity levels of the materials. Waste classification, which defines the disposal requirements, is presented in Title 10 of the Code of Federal Regulations Part 61 (10 CFR 61). ${ }^{1}$

Low-level radioactive waste is classified into three distinct categories under $10 \mathrm{CFR} 61$. These categories, Class A, B, and C, are determined by the concentrations of a relatively few radionuclides, with $\mathrm{C}$ being the most restrictive. Waste that is determined to exceed Class $\mathrm{C}$ limits is referred to as Greater-Than-Class C Low-Level Radioactive Waste (GTCC LLW) and is generally deemed to be unacceptable for disposal in a shallow land burial site. Under the Low-Level Waste Policy Act Amendments of 1985 (Public Law 99-240), the responsibility for disposal of GTCC LLW rests with the Department of Energy (DOE).

The classification of radioactive waste depends on how the wastes are packaged. Containers, and not the individual pieces or components, are classified as Class $\mathrm{A}, \mathrm{B}$, or $\mathrm{C}$. The waste container classification is based on the volume-averaged radionuclide concentrations of the pieces and components within the container. The volume used for averaging is the total displaced water volume of the activated metal, not the container volume. It is important to note that an individual piece of activated metal may be above Class $\mathrm{C}$ limits, but once it is placed into a container filled with other activated metal, the container may be within Class $\mathrm{C}$ limits. This method, which allows for some dilution of the radioactive material concentrations, is commonly called concentration averaging. Unlimited dilution of waste is not allowed, however. For predominantly gamma-emitting nuclides, the radionuclide concentration of the most activated piece (or component) must be within a factor of 1.5 of the container's average concentration. Additionally, for predominantly beta-emitting nuclides, the radionuclide concentration of the most activated piece (or component) must be within a factor of 10 of the container's average concentration.

The specific isotopes of concern to GTCC LLW classification are listed in 10 CFR 61. The long-lived isotopes are ${ }^{14} \mathrm{C},{ }^{59} \mathrm{Ni},{ }^{94} \mathrm{Nb},{ }^{99} \mathrm{Tc},{ }^{129} \mathrm{I},{ }^{241} \mathrm{Pu},{ }^{242} \mathrm{Cm}$, and alpha emitting transuranics with half-lives greater than 5 years. The short-lived isotopes are ${ }^{63} \mathrm{Ni},{ }^{90} \mathrm{Sr}$, and ${ }^{137} \mathrm{Cs}$. These isotopes and their half-lives are listed in Table 1. Radionuclides such as ${ }^{60} \mathrm{Co}$ and ${ }^{55} \mathrm{Fe}$, while important to the economics of waste disposal, do not affect waste classification. For reactor vessel internals, the 
Table 1. Isotopes governing Class $\mathrm{C}$ waste classification and their half-lives.

\begin{tabular}{cl}
\hline Isotope & \multicolumn{1}{c}{ Half-life } \\
\hline${ }^{14} \mathrm{C}$ & $5.73 \times 10^{3} \mathrm{y}$ \\
${ }^{59} \mathrm{Ni}$ & $7.6 \times 10^{4} \mathrm{y}$ \\
${ }^{94} \mathrm{Nb}$ & $2.0 \times 10^{4} \mathrm{y}$ \\
${ }^{99} \mathrm{Tc}$ & $2.13 \times 10^{5} \mathrm{y}$ \\
${ }^{129} \mathrm{I}$ & $1.57 \times 10^{7} \mathrm{y}$ \\
${ }^{241} \mathrm{Pu}$ & $14.4 \mathrm{y}$ \\
${ }^{242} \mathrm{Cm}$ & $162.8 \mathrm{~d}$ \\
${ }^{63} \mathrm{Ni}$ & $100 \mathrm{y}$ \\
${ }^{90} \mathrm{Sr}$ & $29.1 \mathrm{y}$ \\
${ }^{137} \mathrm{Cs}$ & $30.17 \mathrm{y}$ \\
\hline
\end{tabular}

major isotopes of concern are ${ }^{14} \mathrm{C},{ }^{59} \mathrm{Ni},{ }^{94} \mathrm{Nb},{ }^{99} \mathrm{Tc}$, and ${ }^{63} \mathrm{Ni}$. These elements have parent isotopes that are commonly found in reactor structural materials. The other isotopes listed in Table 1 are fission products or transuranics, and will only exist as surface contaminants on reactor vessel internals. This results in small quantities relative to the concentrations of the other isotopes listed in Table 1 that are in the components and are of interest to this study.

The purpose of this report is to describe the model development and results from a Monte Carlo analysis method that may be used for characterizing the activated metals from reactor decommissioning waste. This Monte Carlo analysis method would enable DOE to project the quantities of GTCC LLW arising from decommissioning of reactor vessel internals.

The characterization method uses the Monte Carlo Neutron-Photon (MCNP) computer code ${ }^{2}$ to predict the concentrations of 10 CFR 61 radionuclides in the components of interest. This report describes the details of the MCNP model and the model analysis techniques. Additionally, preliminary sampling and laboratory analysis plans have been developed that would serve to validate the code results. The sampling and laboratory analysis are not within the scope of this report. However, a draft sampling and analysis plan has been developed to outline the tasks required for validation.

The reactor vessel and internal components are referred to as far-core components because they are typically located more than several neutron mean-free paths from the active fuel region of the core. Because these components are relatively far from the core, the analytical methods used to calculate activation of their materials are necessarily more complex than those used to calculate activation of components in the active fuel region of the core.

Disposal costs for GTCC LLW are expected to be considerably higher than for other classes of waste because GTCC LLW is generally not acceptable for near-surface disposal. As indicated earlier, the responsibility for disposal of GTCC LLW lies with the DOE, but no disposal facility presently 
exists that routinely accepts GTCC LLW. DOE is currently considering options for the management and ultimate disposal of GTCC LLW. Therefore, it is important to have an accurate assessment of the volumes of GTCC LLW that will need to be handled by such a disposal facility so that credible waste disposal planning can be performed. Of particular concern are those far-core components that are potentially GTCC LLW and have large dimensions and volumes that pose unique concerns. These large far-core components currently have significant uncertainties associated with their waste classification.

Projections of the component sizes and volumes of GTCC LLW from future reactor decommissioning will be critical input into the planning for the transportation, packaging, handling, and ultimate disposal of these wastes. Provisions to accommodate relatively large components, such as pressure vessels or core barrels, will be particularly important. The size and volume of the components that the disposal facility must be designed to handle will have large economic implications for the facility. There is strong incentive to reduce the uncertainties in the waste classification of reactor decommissioning waste.

\subsection{General Description of Vessel Decommissioning Wastes}

\subsubsection{Component Types}

All reactor vessel internal components must be disposed of as radioactive waste. The types of components that will cause the most concern are the large, bulky components which may be difficult to handle and dispose of merely due to their size. For pressurized water reactors (PWRs), these components include the core baffle, core barrel, thermal shield, pressure vessel, and upper and lower support plates. For boiling water reactors (BWRs), the core shroud, pressure vessel, jet pumps, and steam separators and dryers are typical components. Since most U.S. reactors have relatively unique designs, there may be other core support structures depending on the particular reactor in question. The listed components will generally be found in all reactors; however, their specific configurations will vary with reactor design.

Of specific concern to GTCC LLW estimates are the larger components, such as the core baffles and core barrels, which may be GTCC LLW. If these components are GTCC LLW, their size may impose expensive design requirements on a disposal site. Clear identification of those components that are likely to be GTCC LLW is desirable for incorporation into the design of a disposal facility.

\subsubsection{Component Masses and Volumes}

The masses and volumes of the components listed above are all relatively large. However, the two may not be directly proportional to each other. In the case of the radial components (core barrel, baffle, etc.), components may be cut into manageable pieces and, therefore, the total volume would be approximately the metal volume. Conversely, items like the support plates are relatively thick with many holes in them, and these holes will take up volume even if the plates are cut into smaller pieces. Reference 3 estimates the masses and volumes of LLW, and specifically the GTCC LLW, that could be generated from decommissioned LWRs. 


\subsubsection{Current Uncertainty in GTCC Volume Estimates}

Most of the GTCC LLW that DOE must handle is likely to come from nuclear power reactors. A previous estimate of nuclear power reactors' unpackaged waste metal volume activated to above the Class $\mathrm{C}$ limits has indicated that about $75 \%$, or $627 \mathrm{~m}^{3}$, will be from decommissioning wastes. ${ }^{3} \mathrm{~A}$ large uncertainty exists in this estimate, however. The estimate assumes that reactor core barrels are activated to above Class $\mathrm{C}$ limits. There are indications that core barrels may not be activated that high, in which case the volume estimate could be reduced to about $340 \mathrm{~m}^{3}$, or $62 \%$ of the nuclear reactor unpackaged metal LLW above the Class C limits. Such a large uncertainty could be considered unreasonably high for repository planning purposes.

\subsubsection{Impacts of GTCC LLW on the Waste Management System}

Proper planning is needed to accommodate the expected volume of GTCC LLW. The waste components that may be GTCC LLW are of considerable mass and volume. If a disposal facility is not designed to accept these components and their volumes, the system could incur large costs to upgrade it to handle these wastes. The most costly option would be to build a separate repository specifically for GTCC LLW.

By characterizing the nature of the GTCC LLW far in advance of repository construction, the size and weight of the GTCC LLW components that must be handled can be estimated, and the repository can be properly designed. Investing in the characterization of GTCC LLW in advance can better define the design parameters of the repository and eliminate the potential for costly repository design changes in the future. 


\section{METHOD OF APPROACH}

\subsection{Previous Methods}

Industry commonly uses two different methods for characterizing irradiated hardware prior to disposal. ${ }^{4}$ The two methods are generically referred to as the direct assay method and the activation analysis method. The direct assay method uses a combination of gamma scanning, direct sampling, underwater radiation profiling, and radiochemical analysis to determine the 10 CFR 61 radionuclide content of the waste. The activation analysis method uses a form of activation analysis in conjunction with underwater radiation profiling. Both methods employ two distinct steps: (a) estimating the ${ }^{60} \mathrm{Co}$ content in the waste, and (b) determining the scaling factors to calculate the concentration of the remainder of the radionuclides.

The primary application of these characterization methods has been to evaluate nonfuel assembly core components and spent fuel assembly hardware in and near the core. Previously, there has been less of a need to evaluate the components associated with reactor decommissioning waste. Presently, some of the oldest commercial reactors are being shut down, resulting in an increased interest in the issues surrounding reactor decommissioning. In addition, projections of reactor decommissioning waste are needed by DOE to perform accurate waste disposal planning.

\subsubsection{Direct Assay Method}

The direct assay method involves a combination of steps, including gamma ray spectroscopy, component sampling and laboratory analysis, and contact dose profiling. Together, these provide a detailed characterization of a limited number of preselected components. The remainder of the waste components are subjected only to dose rate profiling. These components are then characterized by using dose-to-curie conversion factors and radionuclide concentration scaling factors that were obtained from the measured samples. Dose-to-curie factors and radionuclide scaling factors are applied to each waste component to determine the 10 CFR 61 radionuclide concentrations for waste classification. As a practical matter, the activated components have typically cooled sufficiently long enough that the dose rate is dominated by ${ }^{60} \mathrm{Co}^{5}$

The direct assay method provides a pragmatic means of characterizing existing reactor decommissioning waste, though it has large uncertainties. The methodology has been employed in the field to characterize reactor internal components. However, there is little experience in using this method to characterize large, thick-walled components. While the direct assay method can be applied to characterizing existing waste components, it is less suited for projecting the waste classification of future waste components. The methodology can provide a current characterization of a component, but significant uncertainties are introduced when extrapolating this information to project the waste classification of a component at end-of-life. Additionally, it is difficult to extrapolate the results of direct assay analysis of a component in one reactor to a similar component in a different reactor

primarily due to design differences and, to a lesser degree, the differing reactor operating histories. 


\subsubsection{Activation Analysis}

Activation analysis is a method by which the concentrations of the 10 CFR 61 radionuclides are calculated analytically. The results of these calculations are typically correlated to measured data from dose rate profiling. Several variations of the activation analysis method have been used for waste characterization. All methods require key input data for the performance of the activation calculations. The required data includes material compositions, irradiation history and cooling time, and geometry data to determine neutron flux magnitude and spectrum.

Code methodologies have generally used one of two methods to calculate activation of materials in the reactor core. One method employs one- or two-dimensional transport calculations, coupled with one-neutron energy group activation codes, to perform activation predictions. The results from these analyses that have been compared by others with the limited available experimental data from far-core components indicate significant differences between measured and calculated results. ${ }^{6}$

The second code methodology involves the use of shielding codes, coupled with assumed material compositions and measured dose rates, to estimate ${ }^{60} \mathrm{Co}$ concentrations. Radiation dose profiles due to gamma energy fields are measured for all of the waste components. Shielding codes are then employed to calculate the ${ }^{60} \mathrm{Co}$ dose-to-curie factors. From these, the ${ }^{60} \mathrm{Co}$ concentration is determined for each component. Activation codes are then used to calculate scaling factors for determining the concentrations of the $10 \mathrm{CFR} 61$ radionuclides relative to ${ }^{60} \mathrm{Co}$. For some components that have been well characterized in the past, the scaling factors for determining concentrations of 10 CFR 61 radionuclides relative to ${ }^{60} \mathrm{Co}$ can be obtained from published data bases.

Activation analysis methods have been employed successfully for characterizing waste components that have been irradiated in the active fuel region of the core. An understanding of how the concentration of ${ }^{60} \mathrm{Co}$ parents relate to other impurities is requisite to using this methodology. The flux spectrum seen by these in-core components is well understood. Codes used to calculate component activation generally assume a core average flux spectrum since this is acceptable for most activation calculations of interest. However, the neutron flux spectrum seen by far-core components is significantly different than the core average flux spectrum. The neutrons seen by far-core components are largely a result of high energy neutrons slowing down in the vicinity of the component, since thermal neutrons in the core have a low probability of diffusing out to far-core components. The methods employed to calculate material activation for in-core components might not be sufficiently accurate to perform activation calculations of reactor decommissioning waste since the calculated neutron spectrum, and hence cross-sections, are not representative of far-core components.

The vast majority of analytical tools employed to neutronically evaluate far-core components have been utilized to calculate material embrittlement due to neutron fluence in reactor pressure vessels. While these code methodologies have been generally oriented towards predicting high energy neutron fluence levels, they also can be used, with some modification, to calculate neutron activation. The LEPRICON methodology ${ }^{7}$ has been used to predict fluence levels in PWRs to within $20 \%$ of measured data provided by experimental dosimetry measurements. The LEPRICON methodology employs transport calculations that are normalized to data obtained from self-powered neutron detectors located in the core. 
Monte Carlo analytical methods have shown the best potential to treat the neutronics problem presented by far-core components. Monte Carlo methods employed to predict high-energy neutron flux levels have shown agreement that is within $15 \%$ of measured data. ${ }^{8}$ The ability to accurately predict high-energy neutron flux levels in the far-core components is important since the high energy neutrons serve as the source for the thermal neutrons. Thermal neutrons, created through the slowing down of the high energy neutrons, are responsible for the bulk of the material activation.

\subsection{Monte Carlo Method Using MCNP}

The characterization technique discussed in this report is based on an activation analysis method that employs MCNP to calculate neutron activation of far-core reactor components. The Monte Carlo technique overcomes many of the calculational limitations experienced by other activation analysis methods. To a large extent, the method used for activation analysis in this study implements the basic methodology outlined in Reference 6.

The Monte Carlo method is an activation analysis tool, similar to other activation analysis methods, except in the choice of the computational tool used to perform the activation calculations. MCNP is used to directly calculate the concentrations of 10 CFR 61 radionuclides in the waste components of interest. The input to the MCNP model consists of geometry data, irradiation history and cooling time, and material composition data.

Monte Carlo methods for treating neutron and photon transport problems saw their genesis during the World War II effort at Los Alamos. Since that time, spurred by the advent of more powerful computers, much effort has been invested at Los Alamos to produce the latest Monte Carlo techniques and supporting data. In contrast to other methods of numerical analysis, Monte Carlo is characterized by the use of random sampling to simulate a problem and construct its solution. An exact solution is not derived or calculated, but individual events, governed by probability distributions, are simulated until enough events are statistically sampled to describe the entire problem. The probability distributions are chosen to mimic the potential for an interaction to occur in nature.

In the case of neutron or photon transport, where the physical process can be modeled without considering transport equations, individual particles are followed throughout their lives from a source until termination. Probability distributions are taken from data (which are represented by crosssections) that dictate the outcome of events during the course of the particle's life. In general, the more individual particles that are followed, the better the simulation of the problem. The statistical sample, therefore, becomes more precise.

MCNP is a general-purpose Monte Carlo code that can be used for neutron, photon, or coupled neutron/photon transport. MCNP has the ability to perform three-dimensional calculations to model an entire reactor using continuous neutron energy data. This capability allows for the elimination of many of the geometric approximations inherent in one- or two-dimensional transport codes.

MCNP is used throughout the world on a variety of projects, by a variety of users, and is a well tested and accepted analytical tool. The user base includes utilities, vendors, and national laboratories. MCNP employs the best state-of-the-art physics, data, and mathematical methods used in a Monte Carlo code. These state of the art attributes rest on a very strong, time-proven 
foundation. ${ }^{2}$ The range of problems that can be addressed by MCNP is quite large, but requires a relatively sophisticated user. A particular strength of MCNP for activation problems is that its crosssection libraries contain explicit representations of capture cross-sections for the parent isotopes of 10 CFR 61 radionuclides. MCNP has been used to analyze a broad range of physics problems and reactor designs, including radiation shields, nuclear instrumentation, material activations, magnetic fusion neutronics, criticality analyses, and health-physics problems. MCNP has demonstrated good accuracy and has shown excellent agreement when benchmarked against measured data such as criticality experiments. ${ }^{9}$ The satisfactory use by these many users lends credibility to the results of calculations obtained using MCNP.

The neutron flux seen by far-core components is orders-of-magnitude less than the flux in the core, and the neutron energy spectrum is considerably different than the core average. Accurate calculation of the neutron spectrum is necessary to properly weight the spectrum-averaged activation cross-section. A thermalized spectrum, for example, will result in considerably more activation than a fast spectrum of the same magnitude. In addition, the neutron flux seen by far-core components can be significantly influenced by fast neutron streaming from the core region. The neutron activation of far-core components can also be strongly influenced by three-dimensional effects. The threedimensional MCNP model provides the ability to treat these neutronics problems associated with the far-core components in a precise manner.

The use of Monte Carlo codes, such as MCNP, to solve certain classes of problems has been limited in the past due to the significant cost of the computer resources that are required. With the availability of fast and relatively inexpensive workstations, MCNP can be expanded to include these additional classes of problems.

\subsection{Advantages/Disadvantages of MCNP Analysis Compared to Other Methods}

The advantages of performing an MCNP characterization of the decommissioning wastes fall in to three basic areas: extrapolation of the current activation state to a future state in an operating reactor, translation of results from one reactor to another, and increased accuracy due to the calculational methodology.

Reactor operating conditions that may impact component characterization include such changes as moving from a high neutron-leakage core loading pattern to a low-leakage core loading pattern, or the implementation of axial blankets in the core. A limitation inherent in the direct assay method is its inability to extrapolate the waste classification of a component from its current state to its status at end of life while accounting for nonlinear changes in irradiation history. A current characterization of a future waste component provides only limited information relative to its characterization at end of life. Unless the reactor operating conditions remain constant throughout the life of the plant, significant uncertainties are introduced in predicting the future waste characterization of reactor internal components. The prediction of the waste classification of a reactor component based on direct assay characterization from a currently shutdown reactor provides valuable information and is sufficiently accurate for near-term disposal. The direct assay method provides a reasonable means of classifying the reactor decommissioning waste from a specific reactor. However, translating the classification results from a specific reactor to another reactor with different geometry, materials of 
construction, or irradiation history introduces uncertainties that may be too large to be used for future planning purposes.

By contrast, code analysis methods, once benchmarked, provide the ability to extrapolate current data on waste components to predict future waste classification based on projections of reactor operating conditions and plant life. The code analysis methods also provide the ability to project the impact of changes in reactor operation on the waste classification of reactor internal components. Code analysis methods provide a more direct means of translating the classification results from one reactor to another based on the relative changes in reactor characteristics. The reactor geometry, materials of construction, and irradiation history are direct input to code analysis methods. If desired, analysis models for individual reactors could be generated, and projections of waste classifications could be made for each reactor based on the individual geometry and operating history.

The specific use of MCNP as the calculational tool provides advantages over other methodologies because of the sophistication of the code. Many of the activation analysis methods do not employ codes with sufficient sophistication to treat the activation of far-core components as accurately as MCNP. MCNP has the ability to perform three-dimensional calculations using continuous neutron energy data. Many codes used previously for activation analysis are capable of only one- or two-dimensional calculations. In addition, one-group activation codes and transport codes may not be sufficiently capable to accurately treat the neutronics environment seen by far-core components. MCNP has the capability to accurately model the geometry and neutronic environment in far-core locations. The tradeoff for this accuracy is the increased skill required to build the MCNP model relative to other code models and the increased computer time required to compute the results. However, MCNP provides the ability to explicitly model a waste component to any desired degree of accuracy in both geometry and material composition.

An additional advantage in using MCNP is in its use of specific isotopic cross-sections for the nickel activation calculations. Many cross-section sets for use in less sophisticated codes have only elemental cross-sections available for nickel. The MCNP library contains isotopic cross-section data for each reaction of interest, specifically for reactions that produce ${ }^{59} \mathrm{Ni}$ and ${ }^{63} \mathrm{Ni}$. The reactions used in MCNP for this analysis are listed in Section 3.2.

The use of MCNP may also have several disadvantages. As mentioned above, the accuracy of the tool is a tradeoff with the amount of skill required to build an acceptable model. More detailed and larger amounts of reactor data (geometry, irradiation history, etc.) are required in order to take advantage of the increased capabilities of the code. Additionally, increased model size and accuracy requires more model engineering time and computer run time to complete the analysis. To the authors' knowledge, there is little, if any, experience in the development of large MCNP models that include accurate representations of far-core components. Complete reactor cores have been modeled (including work performed by the authors), but vessel internal components outside of the core have not been previously modeled with any accuracy.

The development of large MCNP models may stretch the design limits of the code or may require the use of novel modeling techniques during model development. As with any code, applications need to be tested and when possible, first-time applications should be compared to known data sources to ensure that the code and/or code model is performing adequately for that particular application. Without such testing, or validation, of the code model, inaccurate results may be 
obtained. For this reason, it is proposed that the code model developed for this analysis be validated using laboratory sample analysis. As part of this report, a sampling plan has been drafted that should adequately validate the code model.

The MCNP model provides no means of characterizing the surface contamination on a waste component; however, no other code methodologies account for this either. Since surface contamination results from fission products, activated corrosion products, and transuranics that have plated out on the waste component, the only practical way of assessing the contribution of the surface contamination to the waste classification is through direct sampling of the crud on the surface of the component. For components with a relatively large surface-to-volume ratio, the inability to address surface contamination represents a significant shortcoming. However, the surface-to-volume ratio for components like reactor vessel internals is sufficiently small that the contribution of surface contaminants to the overall waste classification is expected to be negligible. The surface contaminants on the large reactor vessel internal components may be neglected because of the volume averaging that is permitted (Reference 1) when calculating the limiting radionuclide concentrations in 10 CFR 61.

\subsection{Objectives of Current Analysis}

\subsubsection{Model Development}

The primary objective of this project is to develop an activation analysis model, using MCNP, that can accurately calculate the activation levels in far-core components of reactor cores. In addition, a means of validating the code model is desired.

To meet the model development objectives, a candidate reactor was chosen as a subject for the analysis. The criteria for making the choice of reactor were as follows:

- Decommissioning status of the reactor facility

- Utility support for project objectives

- Reactor operating history

- Reactor information availability

- Reactor should be representative of other U.S. reactors.

When the candidate reactor facilities were investigated, the focus was two-fold. The chosen facility had to both provide input to the activation model and be a facility from which samples could be taken. These samples could be used in laboratory analysis that would serve to validate the code model.

The two most important criteria were the status of the reactor and the ability of a utility to support the study. Facilities that had been partially decommissioned were considered to be less likely to be able to provide data or material samples to this study. Vessel internals are often removed from a reactor during the period of storage prior to decommissioning. Even if the internals are intact, 
reactors shut down several years ago for later decommissioning are generally put into a storage mode in which the containment is essentially sealed, making it costly and difficult to obtain samples.

Reactors shut down more recently were preferred to reactors shut down several years ago because there is a higher likelihood that the reactor is still accessible for sampling and that there will be utility staff available to support the sampling.

The ability of a utility to support project personnel gathering reactor information and to support sample laboratory analysis of the reactor components was mandatory. It was also mandatory that the utility share reactor design data and operating information. Without utility assistance, a quality analysis program could not be performed.

To a lesser extent, the reactor operating history was a decision criterion. The reactor must have run for a sufficient period of time at high power to produce a quantity of activation products in the reactor vessel internals that would reasonably represent reactors that have operated for their full useful life. In addition, the availability of detailed information on the reactor vessel internals and fuel cycle information for the reactor was a factor. If vessel internals were replaced or if fuel cycle characteristics were changed during the reactor life and information on the early reactor years is not complete, the analysis will be affected. The proposed analysis method depended on the quality of information available for input to the code model.

The reactor chosen should be representative of commercial light-water reactors in the U.S. The more representative the facility is of the U.S. commercial facilities, the easier it will be to extrapolate data from the study to other facilities of interest. The focus is therefore on commercial-size pressurized-water reactors (PWRs), which is the dominant reactor type in the country.

The decision was made to pursue Yankee Rowe as the subject for this study. The reactor is a Westinghouse PWR that has recently discontinued operations and is in the process of being decommissioned. In addition, Yankee Atomic Electric Company (YAEC) was able to provide a significant amount of support to this study, including the timely distribution of design information and support for a sampling plan. These factors were the overriding factors in the decision. In addition, however, Yankee Rowe had operated for more than 22 effective full power years (EFPY) before operations were discontinued, which was sufficient time for large quantities of activation products to build in the far-core components. YAEC also has detailed information available relating to the design and operation of the facility, and was able to make this information available for the study.

While Yankee Rowe meets the first four criteria well, its design differs somewhat from other PWRs in commercial operation. However, the reactor is still representative of general PWR designs. The main difference is the power rating (485-600 MWt) and therefore the physical size, which is somewhat smaller than most PWRs. While the size may be smaller, all of the far-core components typically found in PWRs are found in Yankee Rowe. Additionally, the components of most interest (core baffle, barrel, etc.) are located similar distances from the active core. These similarities in overall design allow for reasonable extrapolations to other reactors without unreasonable difficulties. The extrapolations are aided through the use of parametric studies which investigate the possible effects of some of these design differences. 


\subsubsection{Calculational Objectives}

The calculational objective-was to obtain as accurate an estimate as possible of the volumes of metal LLW that would be activated to levels above Class $C$ limits in the candidate reactor. The achievement of the calculational objective depended on the modeling decisions made. Once adequate data were acquired, model development criteria were established for different reactor regions that allowed for an accurate calculation of activation levels without introducing unnecessary complications to the model. Judgements were made as to which components would be modeled in detail, and which would be lumped or smeared. Those components that are specifically modeled are expected to play an important role in the final result, either as a direct contributor to GTCC LLW or through the propagation of phenomenological effects to other components. All modeling decisions are based on the expected effects on the outcome of the analysis with respect to accuracy, model engineering time, and required computer resources. As with all decisions, trade-offs are required. In this case, most of the trade-offs are between calculational accuracy and either model complexity or computer run time.

When trade-offs are made, it is useful to evaluate the effects of the trade-offs. To evaluate some of the trade-offs made, a limited number of parametric studies were performed and documented in Appendix A. The parametric cases are compared to the base case to determine the effects of different modeling options.

\subsubsection{Validation With Measured Data}

A final objective was to define a component sampling plan that would adequately validate the code calculations. While the actual laboratory analysis is not in the scope of this report, the establishment of a sampling plan in itself is important and is presented in Appendix B to this report. Establishing a sampling plan in conjunction with the code analysis work allows for the choosing of samples that can appropriately validate the analysis model. A sampling plan devised after the analysis work is complete may not allow for full appreciation of the validation effort that is desired. Additionally, by developing a sampling plan in advance of the model development, the MCNP model can be built to reflect where the samples are desired. This is more desirable than the alternative, where the MCNP model structure might drive the sampling plan and require that samples be taken from inaccessible locations.

In the event that samples cannot be taken from Yankee Rowe, the sampling plan is intended to outline the effort believed to be necessary to validate the analysis model. Any future validation efforts should take into consideration those phenomena and effects discussed in the sampling plan. 


\section{MODEL DEVELOPMENT}

\subsection{Data Acquisition}

The types of data required to build the model consist of reactor configuration and operational data. The configurations specifically required are those of the reactor internals. The data requested include vessel internals information, including the dimensions, material compositions, and in-core drawings of the following components:

- Biological shielding (neutron shield tank)

- $\quad$ Pressure vessel (including head)

- Thermal shield

- Core barrel

- Core baffle

- Upper/lower core support plates

- Core hold down ring

- Control rod guide tube/shroud assemblies

- Control rods and followers

- Fuel assembly hardware (instrument tubes, cladding, nozzles, etc.)

- Any wear pads used

- $\quad$ Other internals (supports, etc.).

Reactor operation data mainly encompass fuel cycle information, including

- Axial/radial power profiles [Beginning of Cycle (BOC), End of Cycle (EOC), and/or average for each cycle]

- Control/shim blade positions (if applicable at BOC, EOC, and/or average for each cycle)

- Assembly load patterns (including burnup at BOC, EOC, and/or average for each cycle)

- Fuel assembly types and enrichments (including any variations in cladding materials on a cycle basis)

- Soluble boron concentrations. 
Further information was requested pertaining to any internals change-out programs over the life of the plant or any other information that would directly affect activation levels.

The data received from YAEC on the Yankee Rowe reactor consist largely of information contained on the original blueprints of the reactor vessel and internals. Additionally, fuel cycle information for all cycles was provided.

The blueprints provide an accurate picture of the Yankee internals design. All internals parts and sizes are identified in detail. The total quantity of data available from the blueprints exceeded the modeling requirements, e.g., much of the fine detail on the drawings was not necessary for the activation calculations.

The available fuel-cycle information was also very complete. Fuel load and burnup information on all 21 fuel cycles was received in sufficient detail to construct a sufficiently accurate model of the reactor operating history.

Information that was not available, but which may have an impact on the analysis, is the material data. There is insufficient data on the elemental composition of the materials of construction. Much of this information was not generally measured at the time the reactor was built. Material compositions, in particular the trace elements, are important contributors to error in activation calculations because several of the activation parent elements of interest to GTCC LLW classification are the trace elements in metals. For this study, the best information available from YAEC on metals are used in lieu of actual material composition data. Parametric studies are used to estimate the overall effects of uncertainties in the material compositions on waste classification. A sampling . program would provide critical information in this area.

YAEC was helpful in providing information for this study, and in providing explanations and clarification of the data when requested.

\subsection{Cross-Section Data}

The accuracy of neutron interaction cross-section data is of key importance in minimizing the uncertainty in MCNP calculations. Continuous-energy (or pointwise) cross-section libraries are available for use with MCNP (Reference 2). The physics data for the interactions are contained in these neutron cross-section libraries. For each element or nuclide, there is a set of data detailing through which processes the interactions take place, at which angles scattered neutrons are likely to emerge, and how much energy the scattered neutrons are likely to possess.

The cross-section data depend on incident neutron energy and are tabulated at a number of energy points sufficiently dense that linear-linear interpolation at intermediate energies can represent the desired quantity. The cross-section data in the MCNP libraries have come from many sources, and are considered some of the best available. The specific cross-section set used is the ENDF/B-V nuclear data library. ${ }^{10}$

Most cross-sections available to MCNP are tabulated for only three distinct temperatures: $300 \mathrm{~K}, 600 \mathrm{~K}$, and $3000 \mathrm{~K}$. The water cross-sections and some cross-sections for fissile isotopes are exceptions for which there are several more temperatures available. A small uncertainty will be 
introduced into the Monte Carlo computations because the cross-section data is not tabulated for the exact reactor operating temperatures. This uncertainty is acceptably small because the captured crosssections for the parent isotopes of $10 \mathrm{CFR} 61$ radionuclides vary slowly as a function of temperature.

The specific reactions involved in determining the concentrations of the GTCC isotopes are found in Table 2. This MCNP model, unlike other models, explicitly models all nuclear interactions, including neutron-proton ( $n, p)$ reactions. An effort has been made to model all sources of the GTCC isotopes, even if the contribution of the reaction is relatively minor. In this manner, the most complete estimate of the GTCC isotopes could be made.

\subsection{Model Assumptions and Approximations}

\subsubsection{Reactor Physical Characteristics}

To properly understand the physical system that is being modeled, a brief description of the actual reactor design is instructive. Figures 1 through 8 show pictures of the Yankee Rowe reactor components as they were assembled into the reactor in 1960. A brief examination of the figures will indicate the size of some of the larger components. It is worthwhile to note that the Yankee Rowe reactor is a relatively small Westinghouse PWR, and that components from other reactor facilities can be expected to be considerably larger. As an example, the Yankee Rowe core barrel has a diameter of approximately 94 in., whereas the core barrel for a typical 1,100 MWe Westinghouse PWR has a diameter of about 148 in. ${ }^{11}$ Further discussion of the differences between Yankee Rowe components and components from other representative light-water reactors is given in Section 4.5.

Figure 9 shows a drawing of a radial cross-section of the Yankee Rowe core at the core midplane. The identified components that are important to this study include the reactor core, the core baffle and barrel, the thermal shield, and the pressure vessel. Around the exterior of the pressure vessel is the neutron shield tank (not shown). All of these large components are constructed of stainless steel except for the pressure vessel, which is carbon steel with a stainless steel liner.

Table 2. Parent reactions for GTCC isotopes of interest.

\begin{tabular}{lllllll}
\hline${ }^{14} \mathrm{~N}$ & $\longrightarrow$ & $(\mathrm{n}, \mathrm{p})$ & $\longrightarrow$ & ${ }^{14} \mathrm{C}$ & \\
${ }^{13} \mathrm{C}$ & $\longrightarrow$ & $(\mathrm{n}, \gamma)$ & $\longrightarrow$ & ${ }^{14} \mathrm{C}$ & \\
${ }^{58} \mathrm{Ni}$ & $\longrightarrow$ & $(\mathrm{n}, \gamma)$ & $\longrightarrow$ & ${ }^{59} \mathrm{Ni}$ & & \\
${ }^{93} \mathrm{Nb}$ & $\longrightarrow$ & $(\mathrm{n}, \gamma)$ & $\longrightarrow$ & ${ }^{94} \mathrm{Nb}$ & & \\
${ }^{94} \mathrm{Mo}$ & $\longrightarrow$ & $(\mathrm{n}, \mathrm{p})$ & $\longrightarrow$ & ${ }^{94} \mathrm{Nb}$ & $\beta-$ & $\mathrm{Tc}^{99}$ \\
${ }^{98} \mathrm{Mo}$ & $\longrightarrow$ & $(\mathrm{n}, \gamma)$ & $\longrightarrow$ & ${ }^{99} \mathrm{Mo}$ & \\
${ }^{60} \mathrm{Ni}$ & $\longrightarrow$ & $(\mathrm{n}, \mathrm{p})$ & $\longrightarrow$ & ${ }^{60} \mathrm{Co}$ & & \\
${ }^{62} \mathrm{Ni}$ & $\longrightarrow$ & $(\mathrm{n}, \gamma)$ & $\longrightarrow$ & ${ }^{63} \mathrm{Ni}$ & & \\
${ }^{63} \mathrm{Cu}$ & $\longrightarrow$ & $(\mathrm{n}, \mathrm{p})$ & $\longrightarrow$ & ${ }^{63} \mathrm{Ni}$ & & \\
${ }^{59} \mathrm{Co}$ & $\longrightarrow$ & $(\mathrm{n}, \gamma)$ & $\longrightarrow$ & ${ }^{60} \mathrm{Co}$ & \\
\hline
\end{tabular}


믐

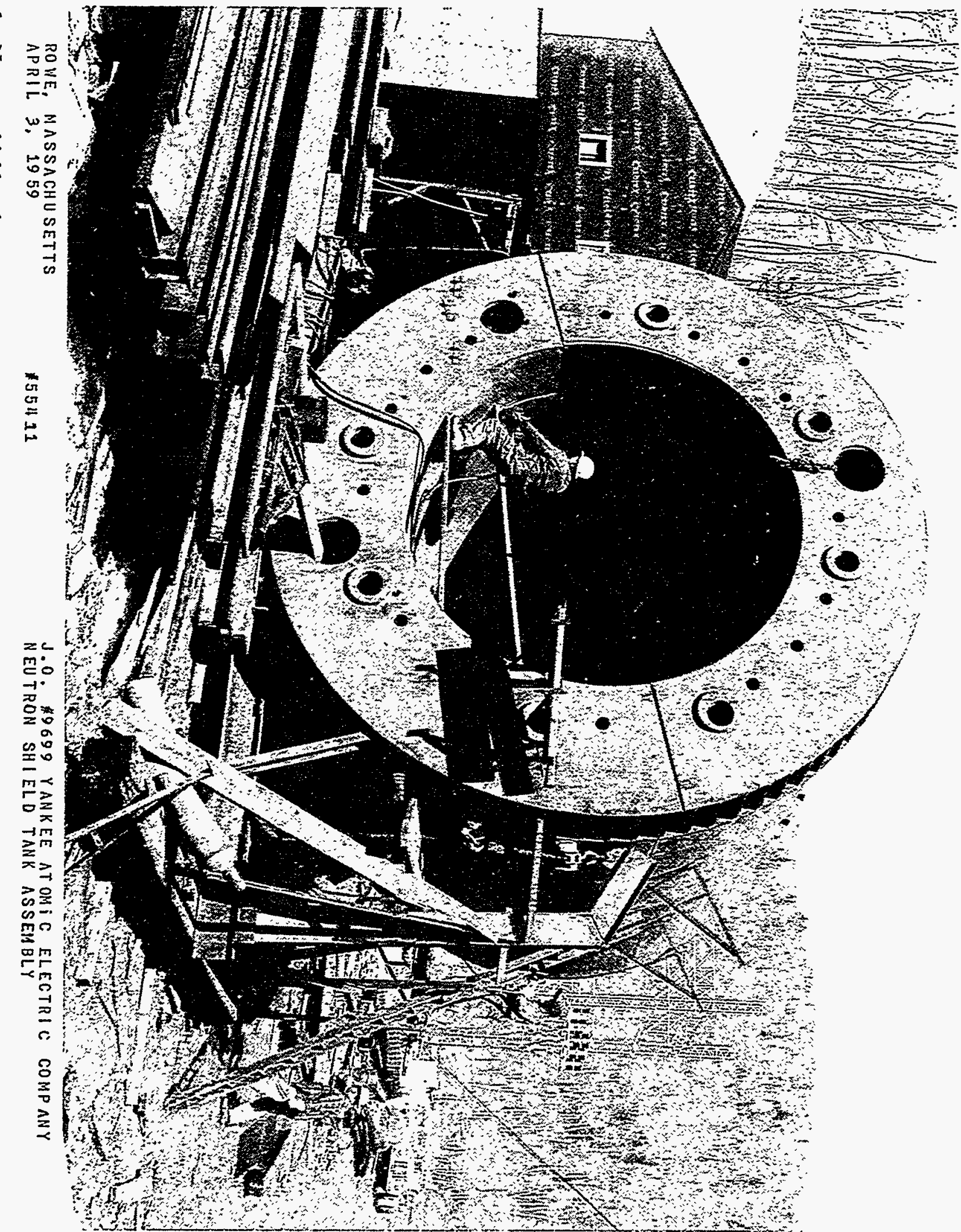




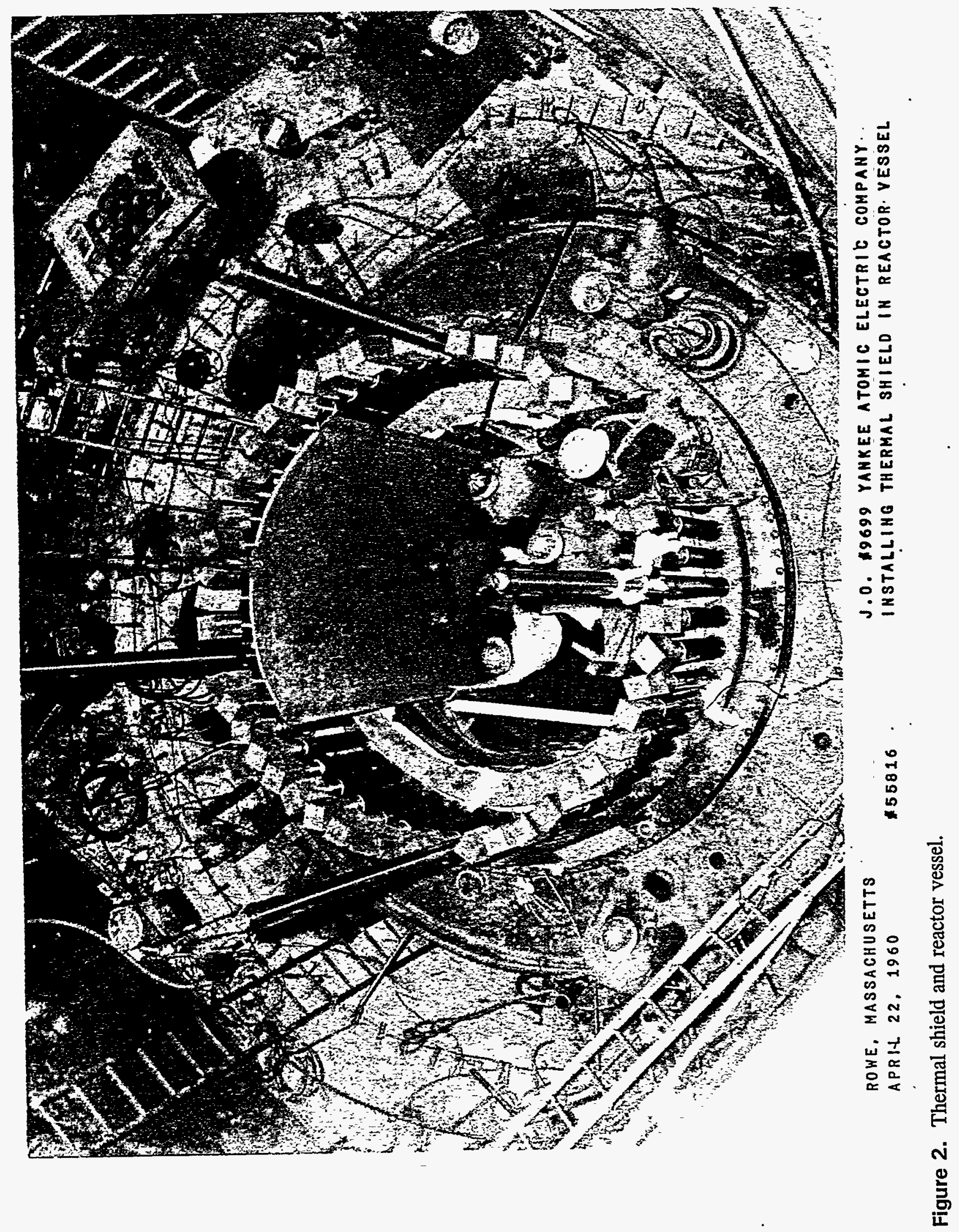




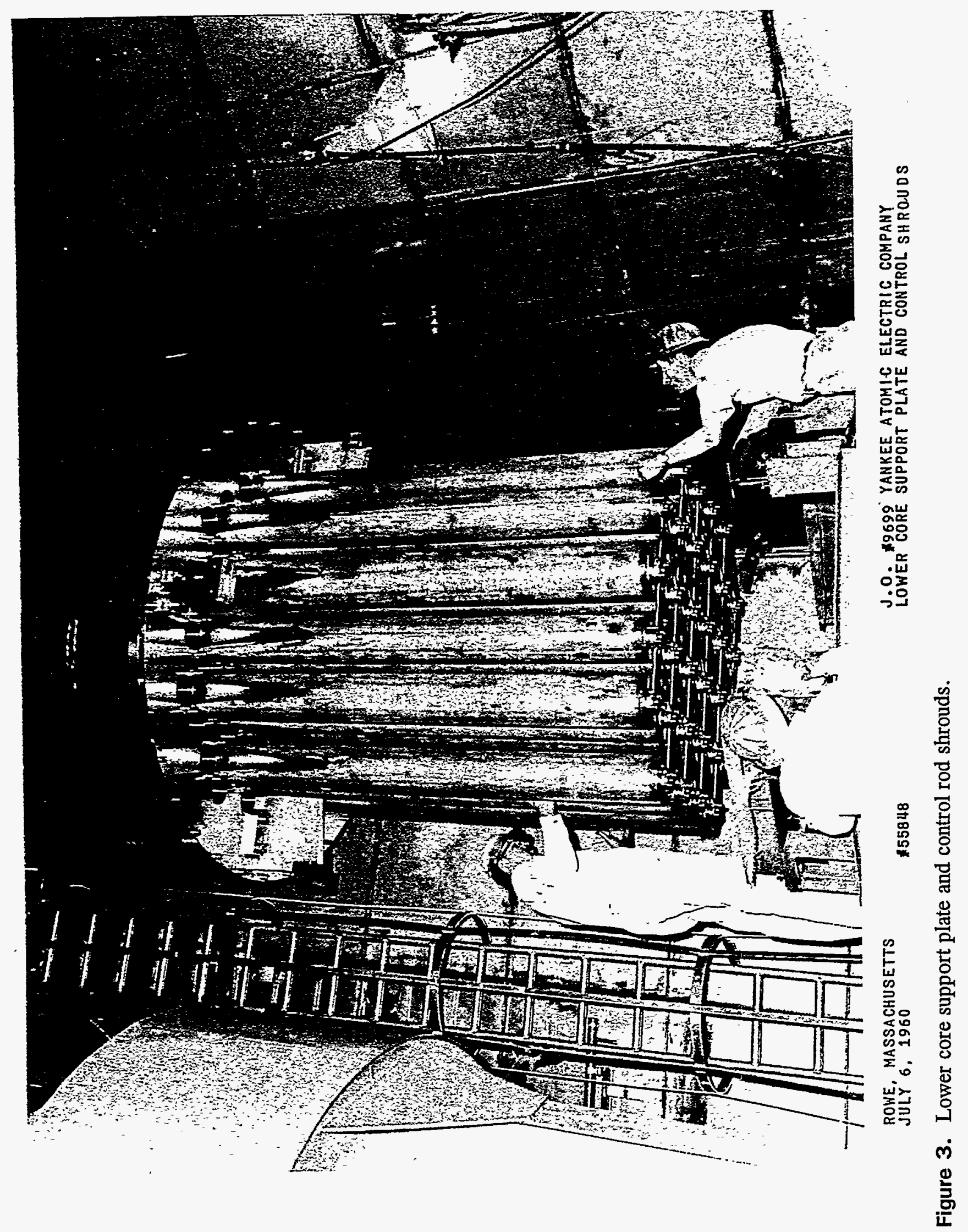




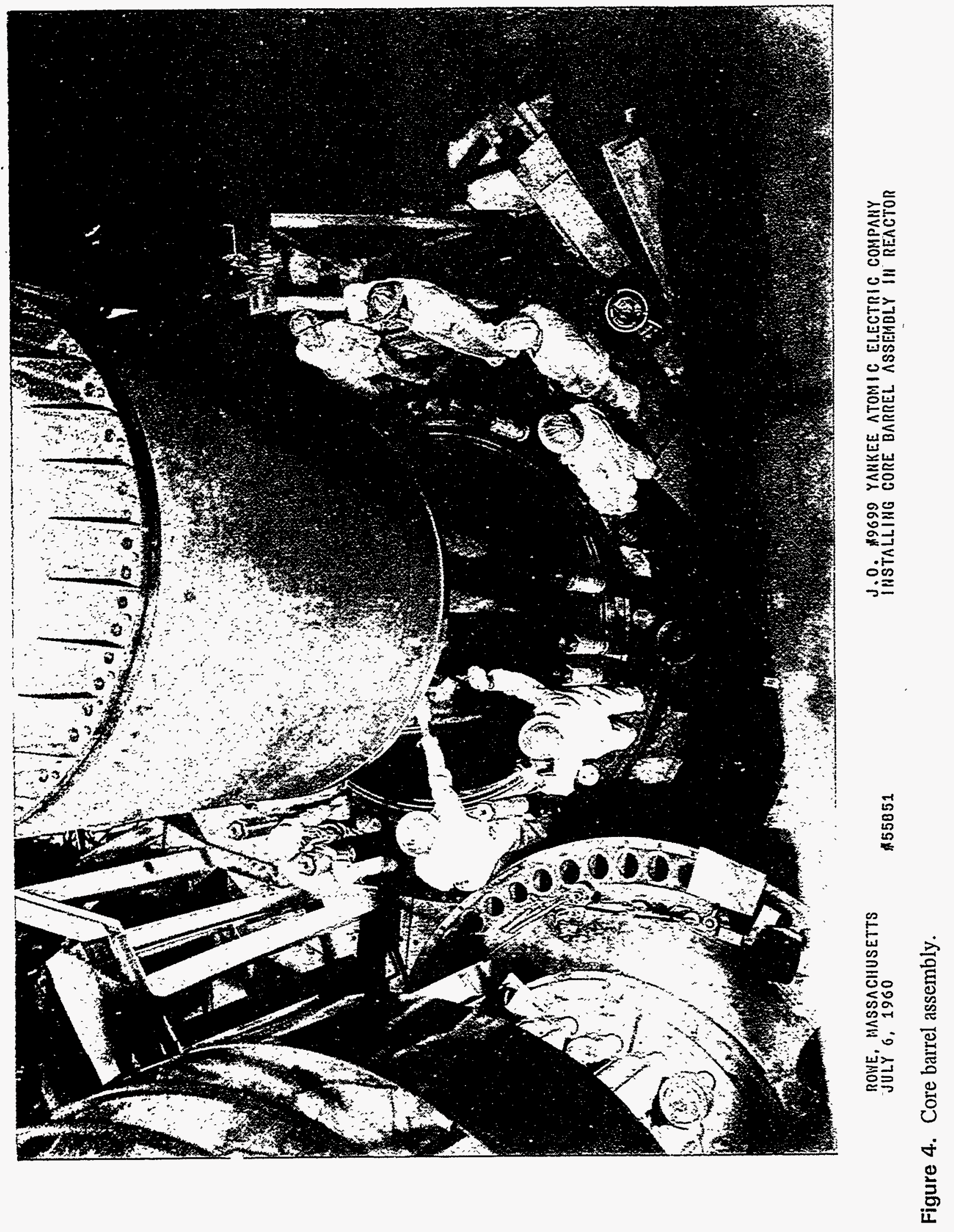




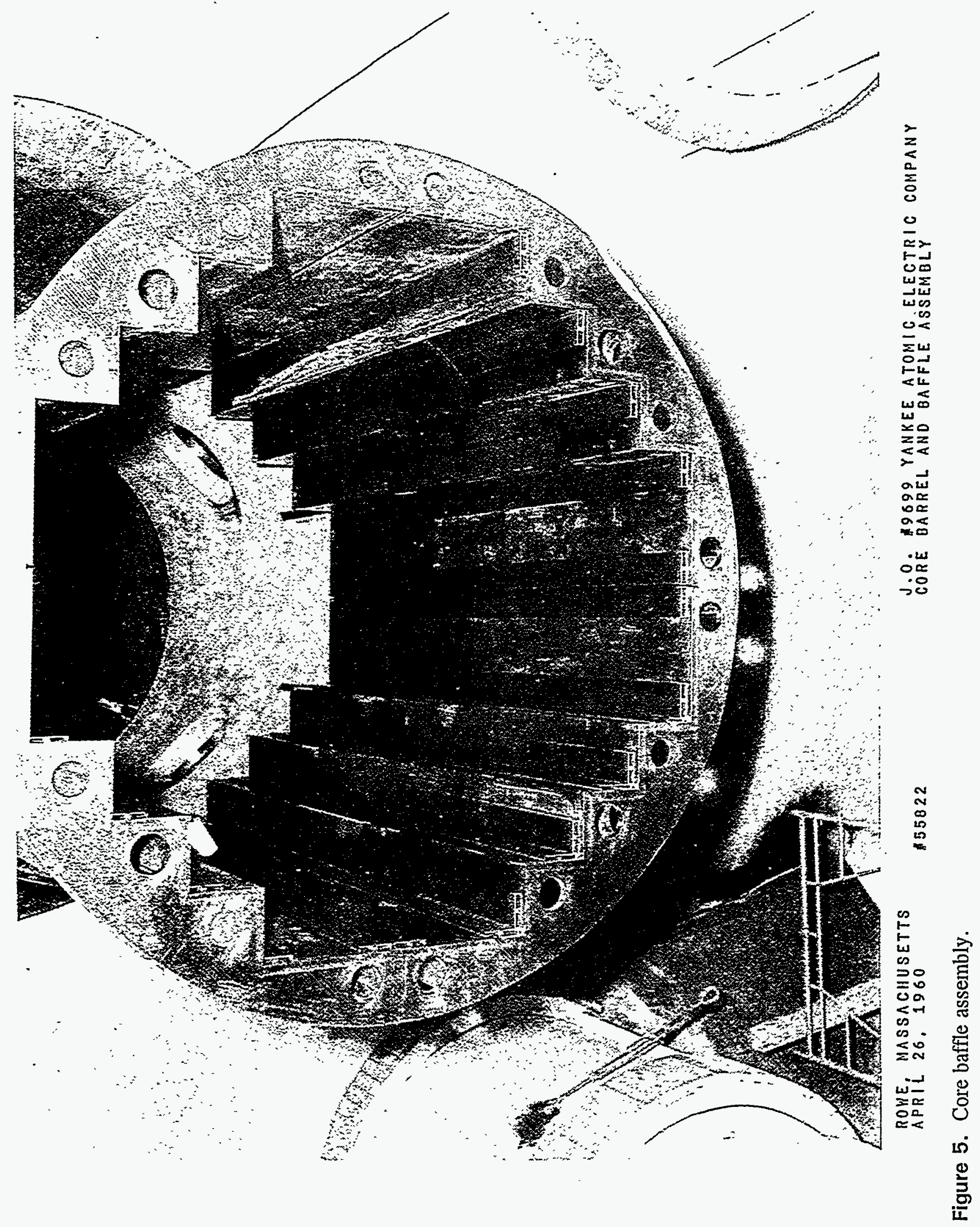




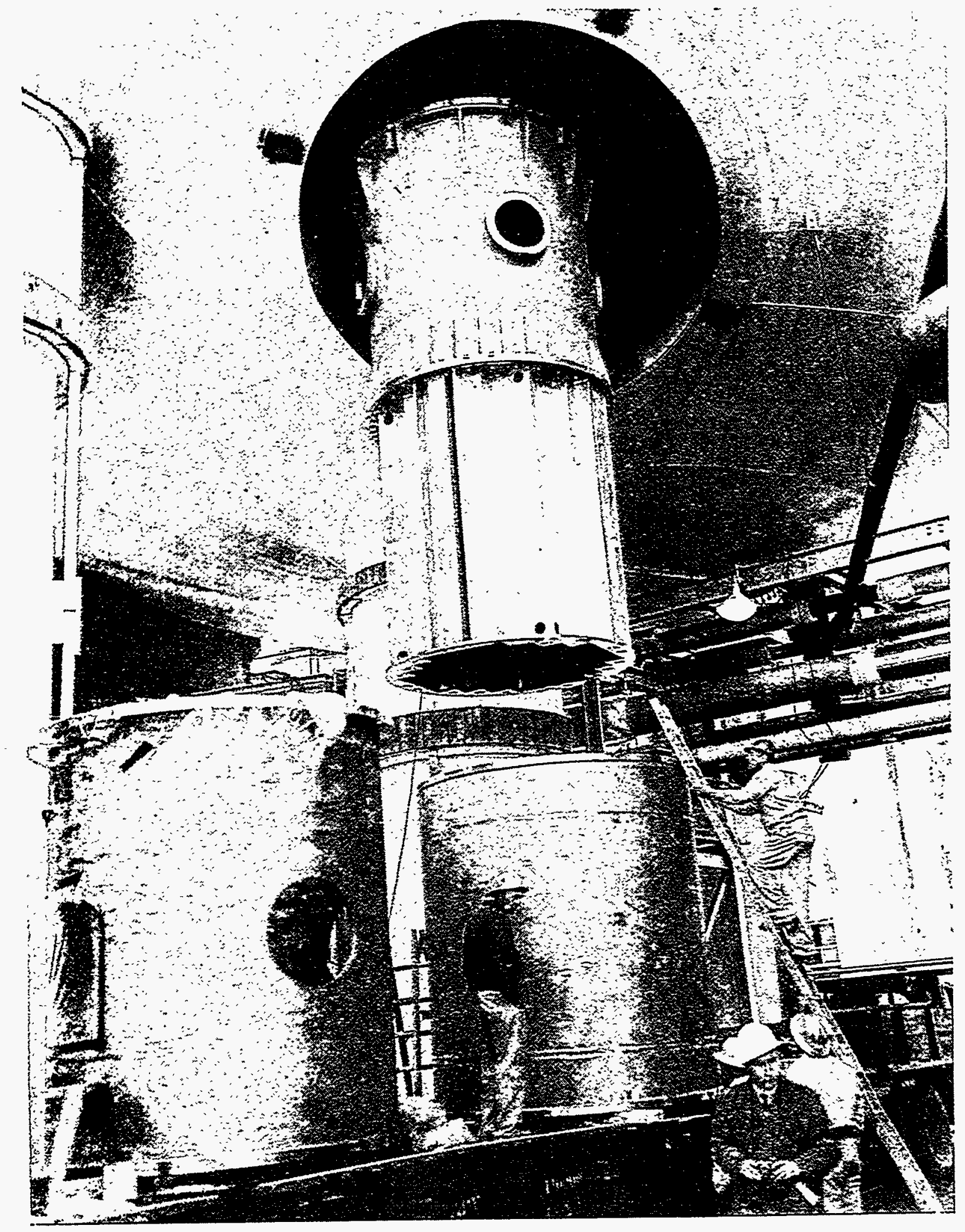

ZOWE. MASSACHUSETTS

IPRIL 26,1960

$\$ 55823$

J.0. \$9699 YANKEE ATOMIC ELECTRIC COMPANY CORE BARREL AND BAFFLE ASSEMBLY

Figure 6. Core baffle and core barrel assembly. 

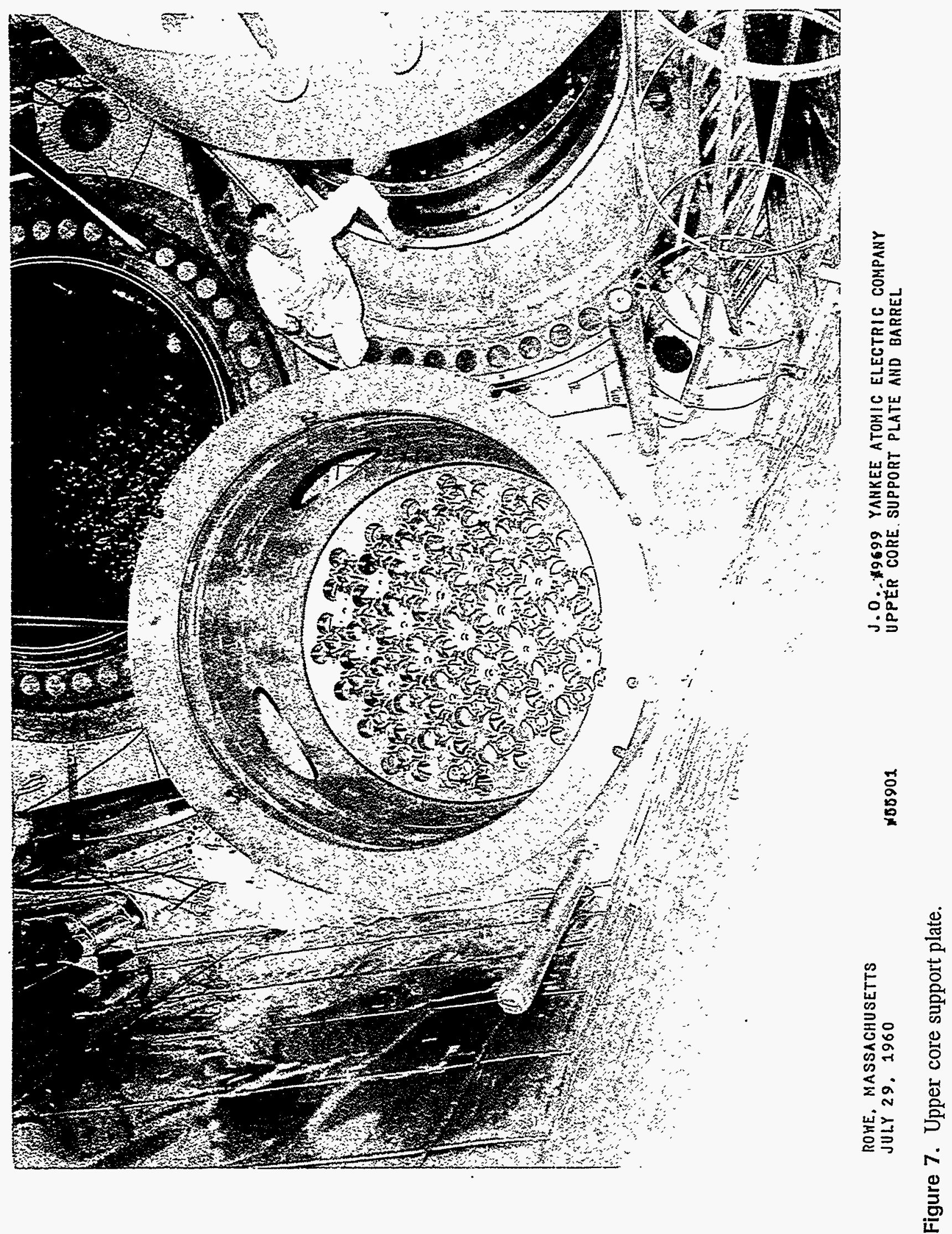


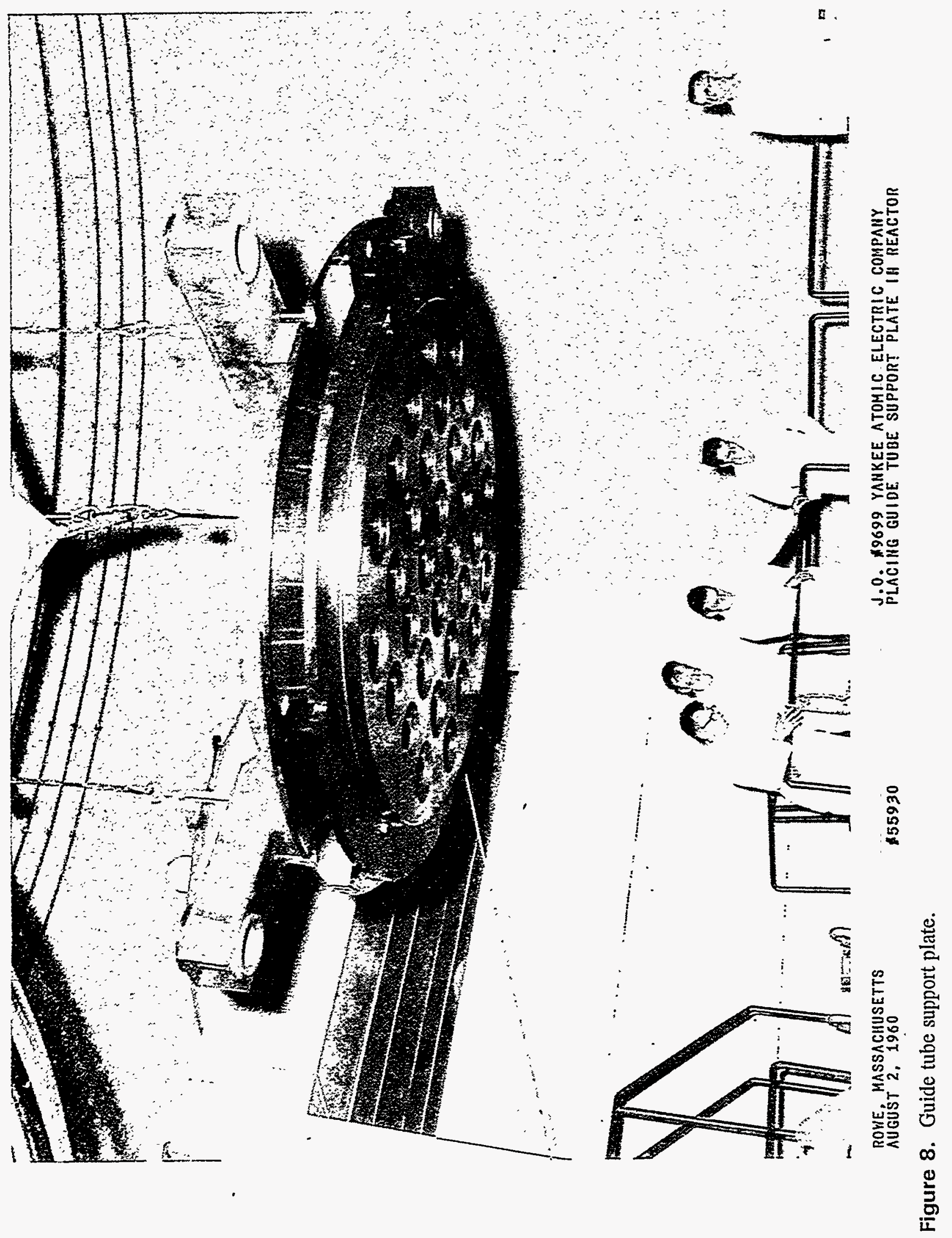




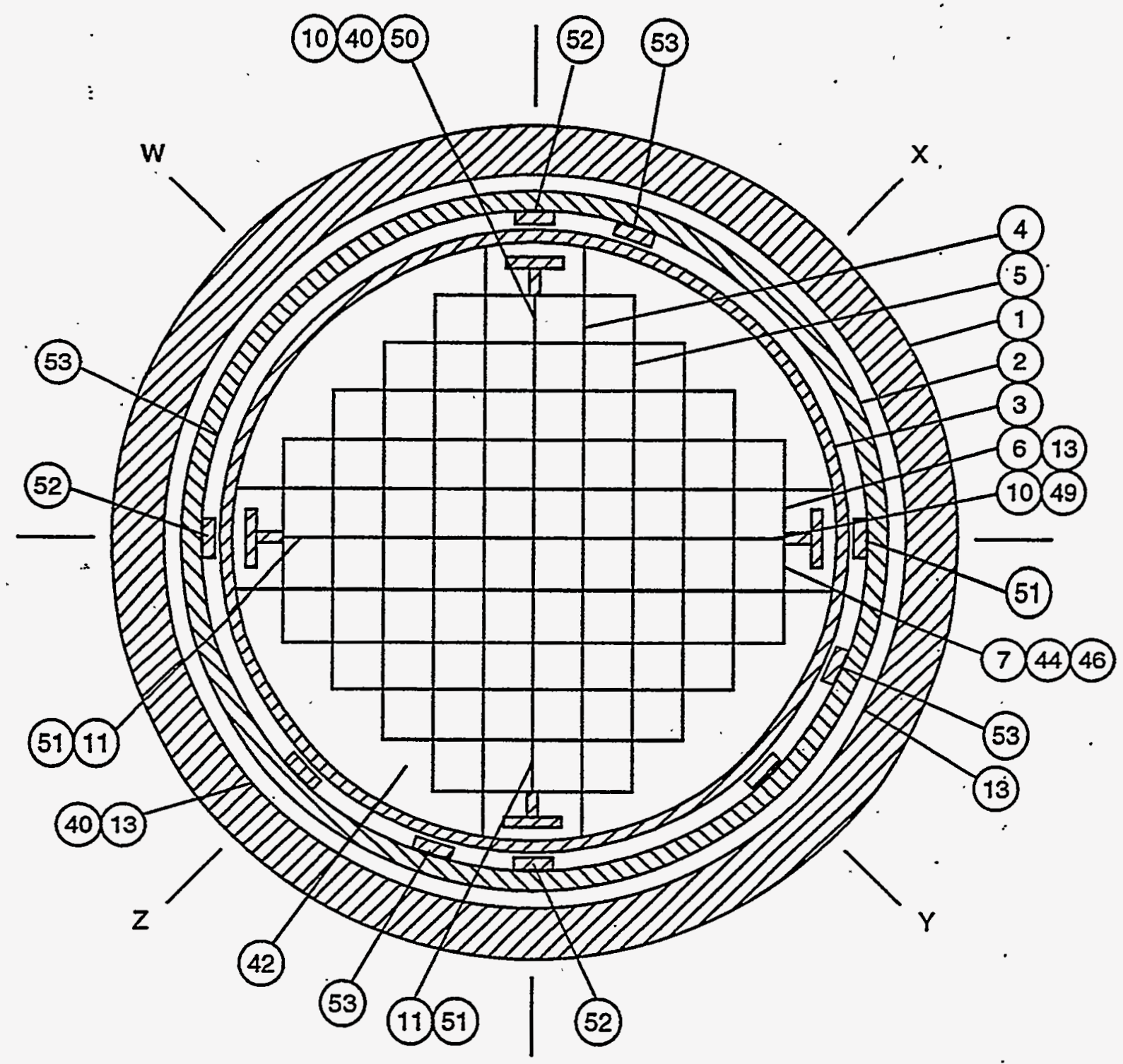

1. Reactor Vessel

2. Thermal Shield

3. Core Barrel

4. Control Rod Assy.

5. Shim Rod Assy.

6. Fuel Assy. (Type A)

: 7. Fuel Assy. (Type B)

8. Core Baffle

10. Baffle Vane Assy.

11. Baffle Vane Assy.

13. Pressure Ves'sel Liner

39. Specimen Tube Assy. (Type B)
40. Guide Sleeve

42. Specimen Tube Assy. (Type A)

43. Fuel Assy. (Type A)

44. Fuel Assy. (Type B)

45. Fuel Assy. (Type -A)

46. Fuel Assy. (Type -B)

48. Secondary Source Vane Assy.

49. Secondary Source Vane Assy.

50. Secondary Source Vane Assy.

51. Secondary Source Vane Assy.

52. Secondary Core Support

53. Thermal Shield Seam Clamp

Figure 9. Yankee Rowe reactor radial section (Reference 12). 
Figure 10 illustrates the layout of the core components in the axial direction. The illustration is a simplification of the axial drawings of the Yankee Rowe reactor. Note that the control rod guide tubes extend throughout the upper and lower vessel regions; however, not all of the tubes are shown so that other features may be illustrated. In addition to the above components, the figure identifies the positions of the upper and lower core support plates, the upper guide tube plate, and the vessel head and nozzles. It can be seen that the height of the components relative to the active core may vary (e.g., the thermal shield is taller than the core barrel), and that the cross-sections of some components, such as the upper support plate, can be complicated.

\subsubsection{Fuel Model}

The Yankee Rowe core loading patterns employed throughout the life of the plant are generally referred to as "high-leakage." With these types of core loads, fresh fuel is generally loaded around the core periphery, and the once- and twice-burned fuel assemblies are shuffled to the interior of the core. The purpose of this type of pattern is to allow for lower radial peaking across the core. However, the higher power in the peripheral assemblies results in a higher neutron flux at the boundary of the core and hence higher activation of far-core components.

Yankee Rowe was operated using what is generally called "two-batch" fuel management. Using this management scheme, approximately half of all the fuel assemblies are replaced after each cycle of operation under equilibrium conditions. The fresh fuel was placed at the periphery of the core, and once-burned fuel was shuffled to the core center. Very few twice-burned assemblies were used during reactor operation; therefore, the presence of these assemblies has been neglected.

Since the loading patterns were relatively uniform throughout the life of the core, the fuel model (which provides the source neutrons for activation) could be considerably simplified. A single fuelloading pattern averaged over all 21 cycles was used as a representation of the active core throughout the reactor life. It is important that a high-leakage core is used for the activation calculations in the correct cycle lengths. This average core is, therefore, expected to be an accurate representation of the operating conditions of the reactor.

The base fresh fuel enrichment used in the model is $4 \%$. This enrichment was obtained by averaging the enrichments of the fresh fuel used throughout the life of the reactor.

Fuel burnup has an effect on the neutron flux in a reactor. To obtain an average core burnup profile, the fuel cycle and power profile data from YAEC were combined to determine the "average" core condition. This average condition is considered to occur at a point midway through an operating cycle.

For purposes of averaging the core burnup, peripheral fuel assemblies were treated independently of the interior fuel assemblies for two reasons. First, the interior assemblies generally were once-burned fuel, thereby having a higher burnup. Second, the peripheral assemblies operated at a lower relative power than interior assemblies, thereby experiencing a lower burnup during their first cycle. Figures 11 and 12 show a typical core reload pattern and radial power profile for the Yankee Rowe reactor. 


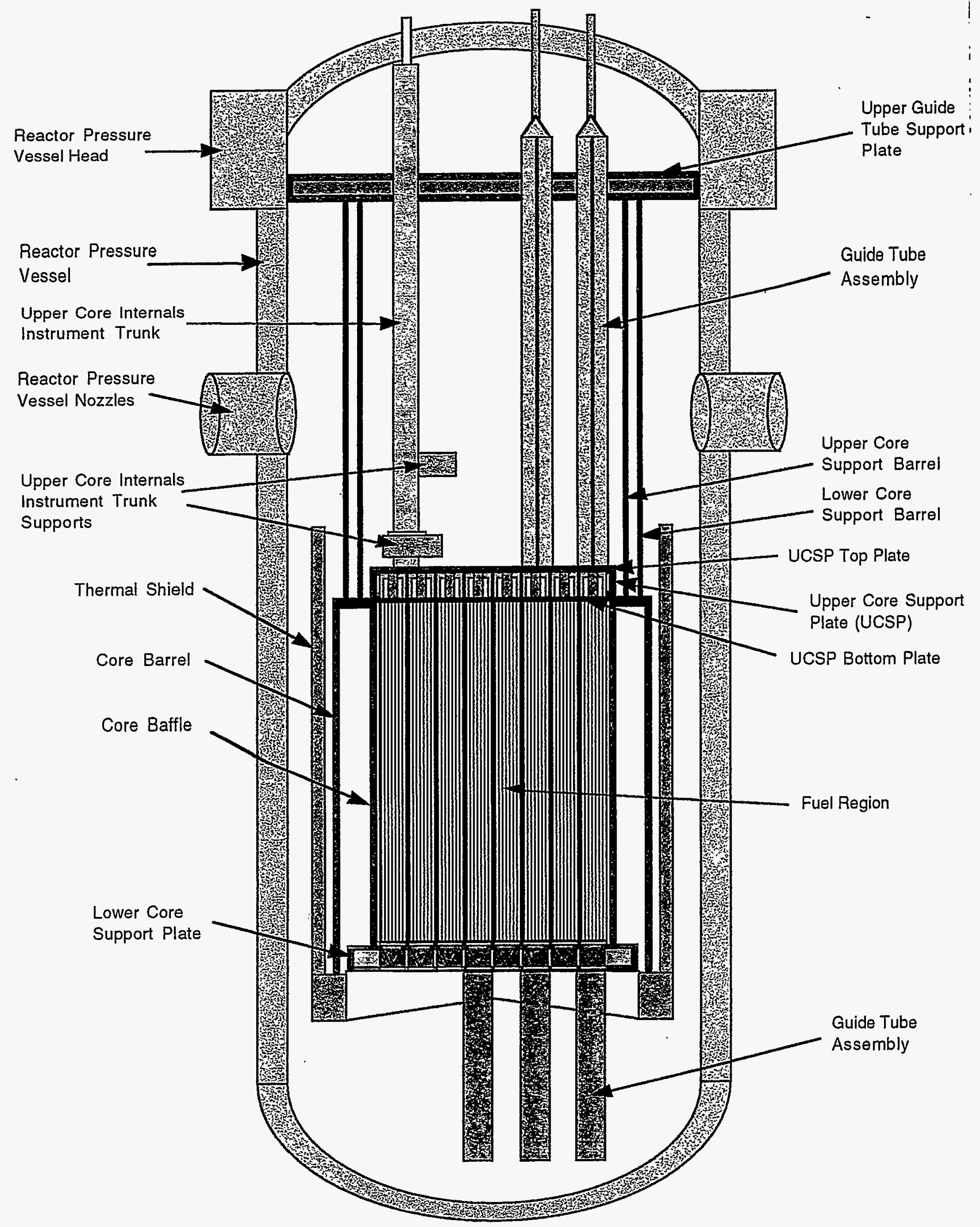

Figure 10. Illustration of Yankee Rowe axial section. 

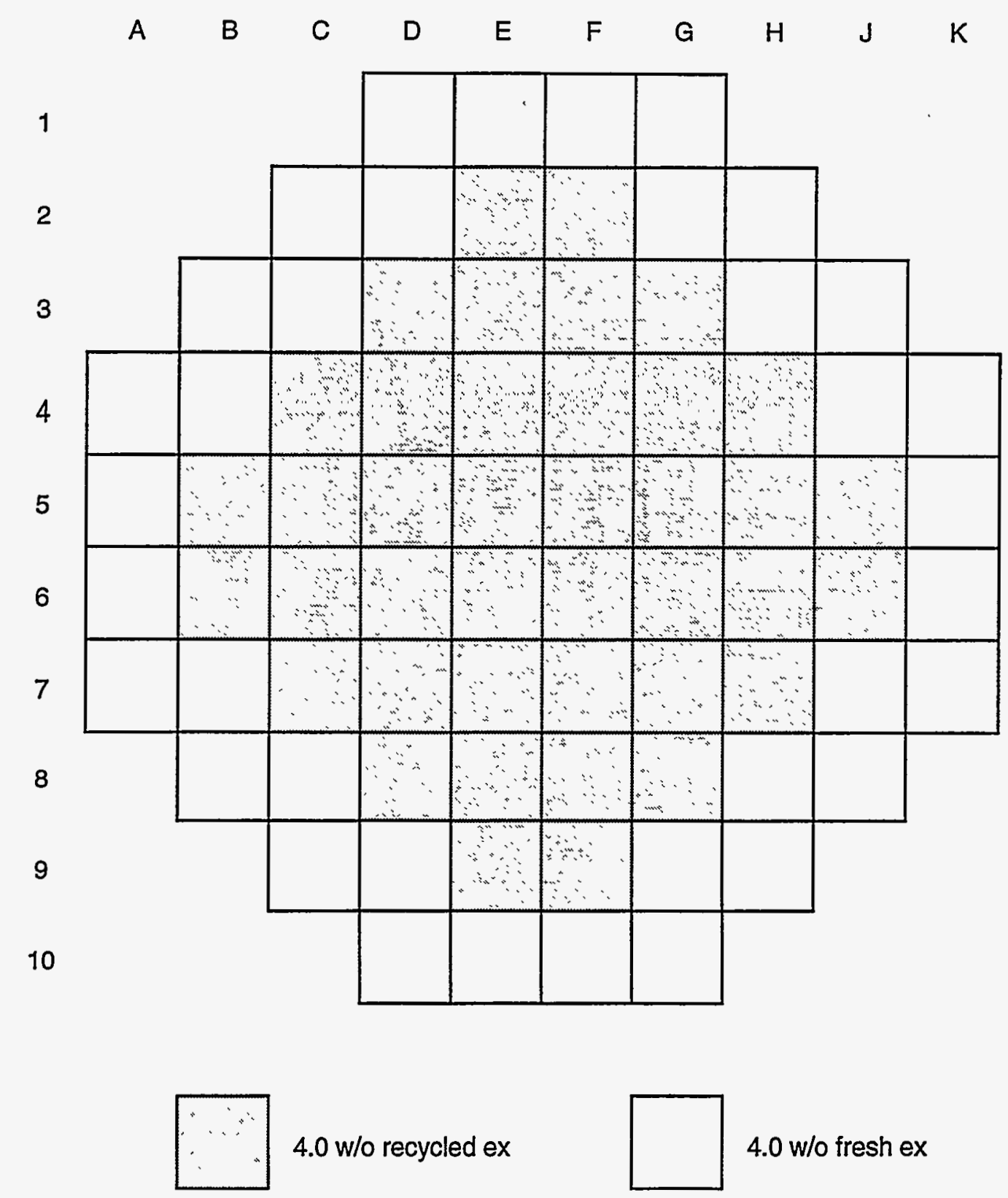

4.0 w/o fresh ex

E95 0065

Figure 11. Typical Yankee Rowe core loading pattern.

The calculation of the appropriate burnup was determined as follows. The peripheral assembly powers were averaged to determine an average value. This value is multiplied by the average assembly burnup for one cycle to determine the burnup per cycle for a representative peripheral assembly. The burnup for the representative peripheral assembly is then divided by 2 to obtain the average burnup during the cycle for use in the calculation (this assumes zero burnup at beginning-ofcycle). 


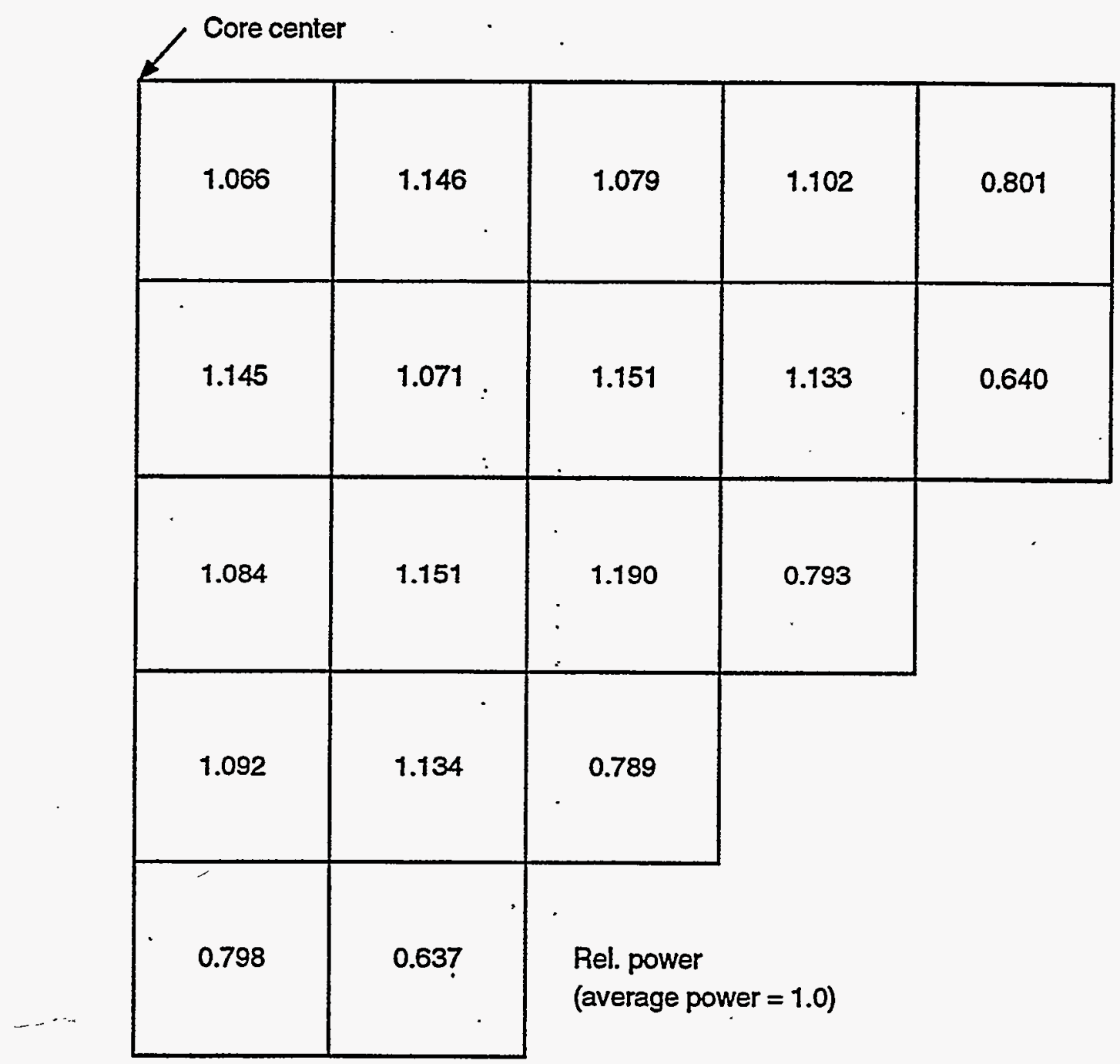

E95 0066

Figure 12. Typical Yankee Rowe radial power profile.

The average burnup for the interior assemblies is determined in a similar fashion. However, since the interior assemblies are generally once-burned, the peripheral assembly burnup is added to the appropriate cycle burnup to account for the initially burned condition.

To account for axial variations in burnup in all assemblies, axial peaking information from YAEC is used to estimate the burnup variations. Fuel of lower burnup was modeled in the top and bottom $1 / 3$ of the core, and fuel with higher burnup is modeled in the central core region. The axial burnup distribution was estimated by using the axial peaking factors provided by Yankee and by assuming a chopped-cosine power profile in the axial direction. The cosine was assumed to be chopped at 0.5 for the calculations.

The calculations result in the use of a fuel burnup of approximately 2,900 megawatt-day/metric ton (MWD/MT) in the top and bottom of the peripheral assemblies, 4,500 MWD/MT in the central portion of the peripheral assemblies, 11,000 MWD/MT in the top and bottom of the interior assemblies, and 18,000 MWD/MT in the central portion of the interior fuel assemblies. These 
burnups were used for the base case Yankee Rowe core model. An illustration of the core loading model can be seen in Figure 13.

Fuel isotopics at various burnups were not readily available. Therefore, the WIMS-E lattice code ${ }^{13}$ has been used to calculate fuel isotopics at burned conditions. To model average core burnup conditions; all WIMS-E isotopic calculations assumed an average water temperature of 553K for water density calculations, with a $1,000 \mathrm{ppm}$ soluble boron concentration. These are average values based on reactor operating data.

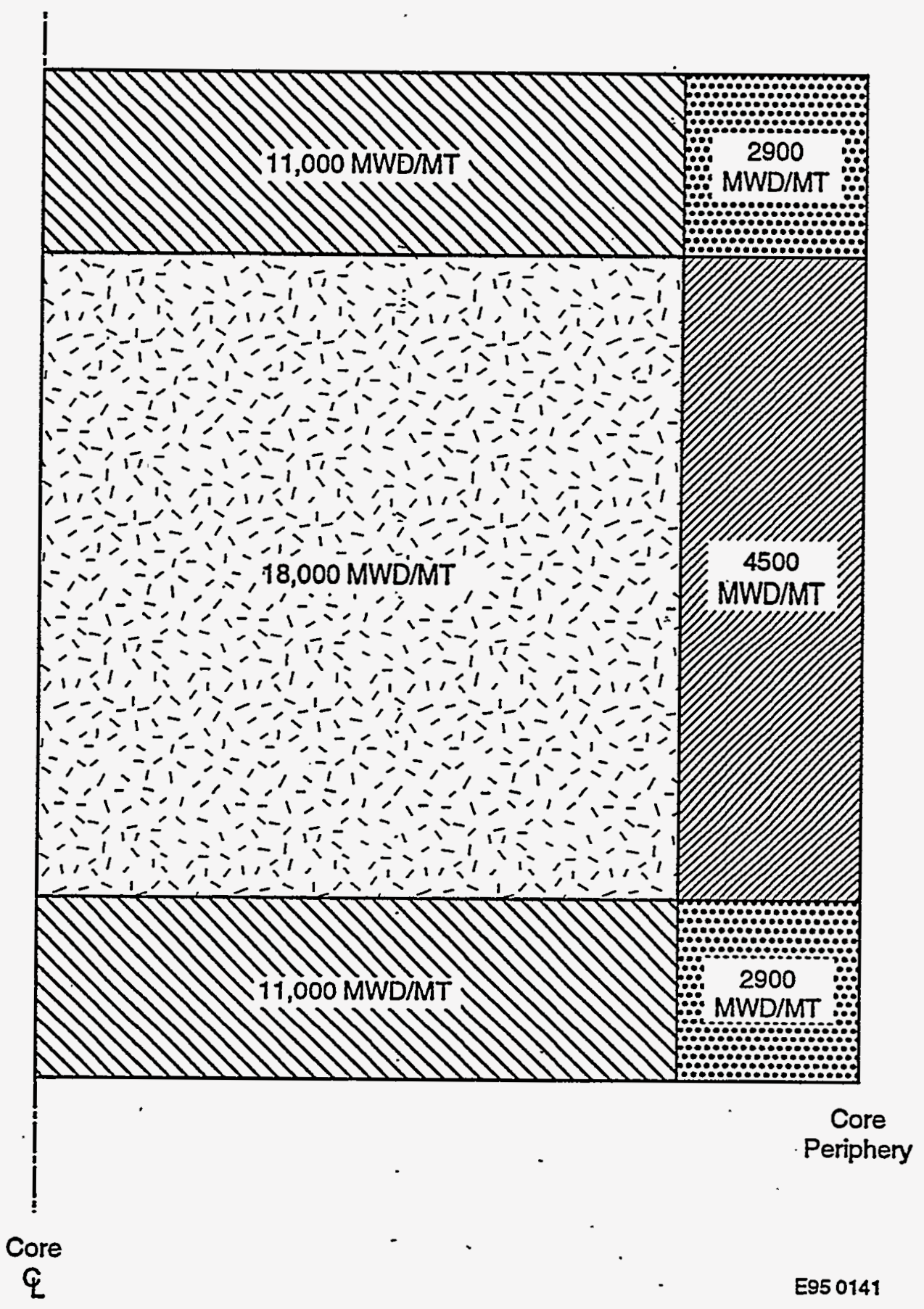

Figure 13. Fuel burnup model. 
Physically, the code model of the fuel is approximated by smearing a fuel "mush" in the center of the reactor core, with fuel pins being explicitly modeled in the outer three rows on the periphery of the core and on the top and bottom 4 in. of the core. An illustration of the fuel model is shown in Figure 14. The explicit rods are modeled at the edge of the core because previous work ${ }^{7}$ has indicated that accurate modeling of rods at the periphery of the core is essential for achieving the correct neutron source spectrum in the far-core regions. Grid spacers and guide bars are ignored as they are expected to have little effect on the neutron source spectrum calculation.

The central fuel "mush" is a smeared model of the fuel, clad, gap, and water regions in the center of the core. This smearing technique is commonly used in reactor physics calculations when fine geometric detail and the neutron source spectrum in the region is not required. The active

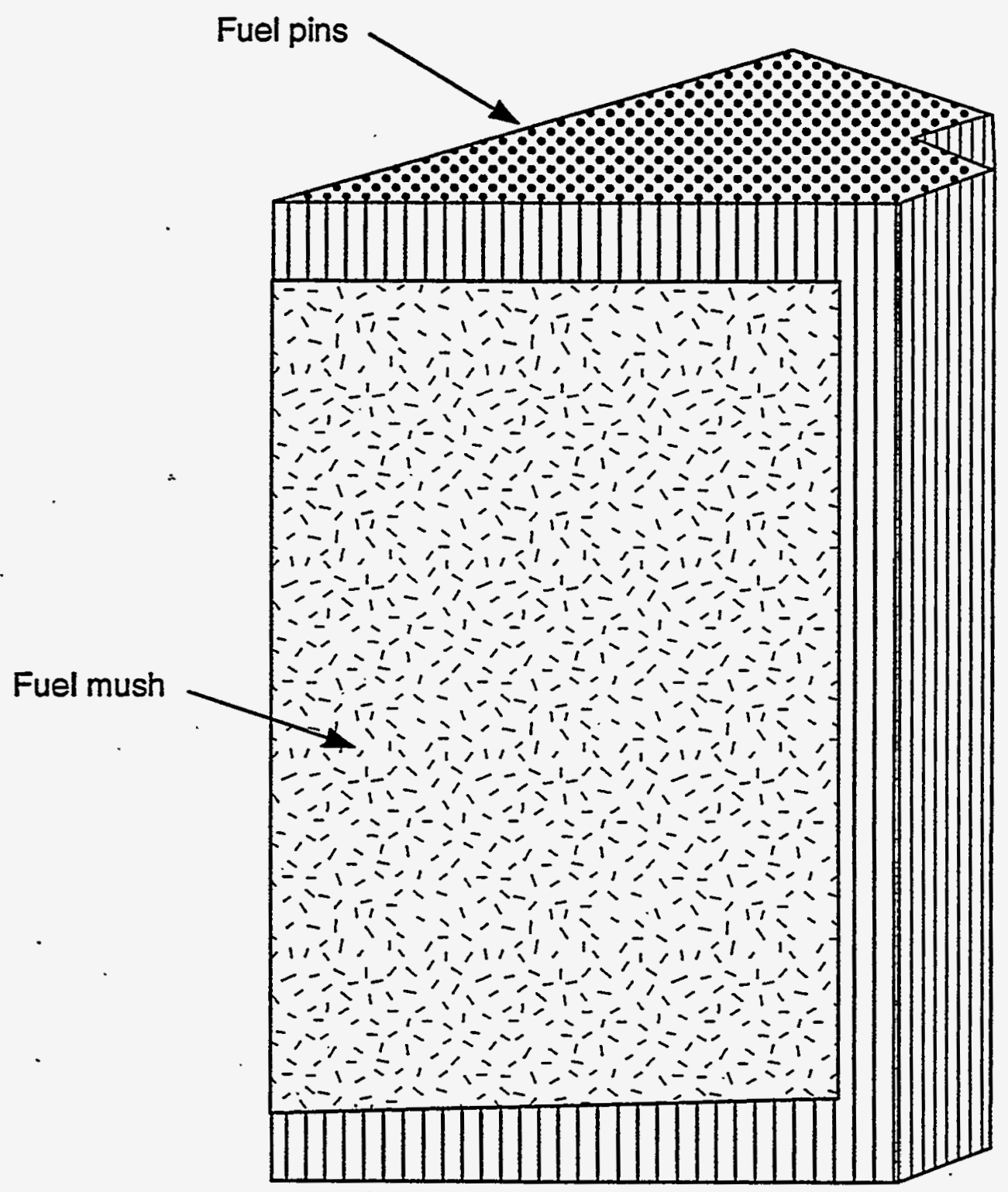

Figure 14. Fuel model. 
regions of the control rods are assumed to be completely withdrawn from the core during full power operation.

During the operating life of the Yankee Rowe reactor, two distinct fuel hardware types were used. The first type, which operated in the reactor for the first 11 cycles, was highly parasitic, using stainless steel fuel cladding and grid spacers. The remaining cycles (with a transition period) were loaded with a low parasitic fuel type, which used zircaloy for the fuel cladding and grid spacers. Only the zircaloy fuel is modeled in this study. It is recognized that the high parasitic fuel type causes lower neutron fluxes in the core region due to the increased capture rates of the stainless steel versus the zircaloy structure. It is expected however, that the material structure in the active core region will have little or no effect on the activation levels of far-core components. This is because the neutrons which reach the far core components are generally born at the periphery of the core, and have little chance of interaction with the fuel assembly structures before escaping the active core. The neutron flux and spectrum outside the active core should not be affected appreciably by the type of fuel used.

In the fuel region, the $900 \mathrm{~K} \mathrm{MCNP}$ cross-section tabulations are used for the materials in this model. The exception to this is the water cross-section tabulation. Water cross-sections at $500 \mathrm{~K}$ were used. Outside the fuel region, all cross-sections at $300 \mathrm{~K}$ were used.

\subsubsection{Component Geometry Model}

The component geometry model is designed with consideration given to several factors. These factors are used to determine the detail that should be used in modeling specific components. The factors are as follows:

1. Component proximity to the active core

2. Component size and weight

3. Effect of the component model on the accuracy of the calculation and on the resources to perform detailed modeling.

1. Component Proximity to the Active Core. The proximity to the active core is a major factor in determining whether a component will be activated to levels above the Class $\mathrm{C}$ limits. To some extent, engineering judgement $c a n$ be used to determine that certain components will not be activated to these high levels. If a component is a large distance away (several feet) from the active core, it is unlikely that sufficient neutrons will reach the component over the life of the reactor to activate the component to levels exceeding the Class $\mathrm{C}$ limits. In these cases, the additional engineering effort required to explicitly model a component is not justified. In the case of the Yankee Rowe reactor, two examples of components judged to be in this category are the vessel head and the upper guide tube support plate. If results had indicated higher-than-expected fluence in this area, the model could have been modified. Engineering judgement provided the starting point.

2. Component Size and Weight. The component size and weight also play a major role in determining the modeling details. Very small components, while a contributor to the waste 
stream, are not specifically modeled because of their size. Nuts and bolts are an example. While there may be a likelihood that some nuts and bolts would be activated to above Class $C$, the effective volume of waste, as compared to the core baffle for example, would be insignificant. The additional engineering effort required to model these parts is not justified; therefore, small components are not modeled. Generally, small components such as nuts and bolts are smeared into the model of the larger components.

\section{Effect of the Component Model on Calculation Accuracy and on Modeling}

Resources. If a component is complex, the decision on whether to model the complex component in detail or in a more approximate fashion may affect the accuracy of the calculation. To determine the effects on the calculational results of making an approximation, some engineering judgement is required.

The degree of complexity of a component, and the degree to which this complexity is modeled, affects the amount of engineering time required to develop the model. The effect on engineering time is a direct relationship: the more complex the component or the component model, the more effort the model will take to develop.

To an extent, calculation accuracy and engineering time are trade-offs. To obtain maximum calculational accuracy, all components could be modeled explicitly with no approximations. This would result, however, in excessive amounts of engineering time to develop the model. Conversely, a very simple model could be used that would require minimal engineering time, but the calculational accuracy would suffer. Engineering judgements were made to balance the engineering time and calculational accuracy of the model.

3.3.3.1 Model Trade-Offs. Many model approximations were made to facilitate reasonable calculational accuracy while still requiring only modest engineering effort and reasonable computer run times. The approximations are described in this section.

To limit the model run time, while only minimally effecting the calculational results, the model was made as dimensionally small as possible. Due to certain calculational effects, computer run time can vary exponentially with the physical size of the model. In the case of the Yankee Rowe reactor, the reactor core length in the axial direction is very large in comparison to the size of the active core. Components and materials that lie above the vessel nozzles (including the vessel head) are judged to (a) be unlikely to be GTCC LLW in themselves and (b) to have little effect on the activation levels of other components. These judgements are expected to be true because in these regions, the neutron flux levels are very small. Therefore, in the axial direction, the detailed model specification is discontinued at the reactor vessel nozzles.

Additionally, in order to minimize computer memory requirements and further shorten computer run time, the core model is divided in half in the axial direction. The reactor model is divided at the active core mid-plane, and a reflective boundary condition is applied at that plane. Dividing the problem in half significantly reduces the computer resources required to run the model without significant loss of calculational accuracy. 
There are certain tradeoffs involved in breaking the model at core mid-plane. In-core axial flux asymmetries could not be modeled. Typically in a PWR, there is a slight flux offset to the lower half of the reactor core due to the slightly cooler water in that region. Physically, this can result in slightly higher activation levels at the lower regions of the core. Since the effect of flux offset on activation has more to do with where activation occurs (e.g., higher or lower on a radial component) than the amount that occurs, it was concluded that the approximation would not significantly affect the radial activation results.

The modeling of only the upper plate of the reactor is expected to introduce some error into the extrapolation of the activation analysis results to other axial components. Since the upper plate is explicitly modeled, little error will be introduced for that component. The results for the lower plate can generally be extrapolated from the upper plate, however some errors can be expected because the lower plate is slightly closer to active fuel and the water temperature at the bottom of the core is lower than at the top. The lower water temperature at the lower plate could mean slightly increased activation levels due to the flux effects discussed previously. Additionally, the control rods are inserted through the upper plate. The control material will absorb some neutrons that otherwise might be available for absorption in the plate, resulting in further activation decreases relative to the lower plate. The total effects would be expected to be noticeable, but they are not expected to influence the component classification.

Another geometric approximation was made in designing a $1 / 8$-core model. Such approximations (using $1 / 8$ - or $1 / 4$-core models) are common in reactor physics calculations because many reactor cores are symmetrical. This practice provides a significant reduction in computer resource requirements while effecting the results very little.

The symmetry in the Yankee Rowe core is somewhat atypical of reactor cores. Strictly speaking, the core (far core components included) is only half symmetric due to the combination of control rods and other ex-core hardware configurations. The use of a $1 / 8$-core model is justified for the following reasons. First, much of the asymmetry has to do with the positions of the control blade locations in the core. These control blades are atypical of PWRs. The locations of the control blades in the core would not affect activation analysis calculations unless the reactor was run with the peripheral control blades inserted, which was rare. Second, the components outside of the core region that cause asymmetries are generally small in comparison to the size of other components of interest, such as the core baffle. The effects of the asymmetries are therefore judged to be small, and the $1 / 8$-core model was concluded to be acceptable.

For some components, the complexity of the component required that a judgement be made about how the complexity could affect the calculational results. If a complex geometry is modeled in detail, the trade-off between calculational accuracy and engineering time required to establish the model must be assessed. The upper core support plate is an example of a large and complex component for which it was determined that a nearly exact model was required. These plates are relatively thick, but have many holes in them. Located close to the core, it provides streaming paths for neutrons which may be significant to activation calculations of far-core components. These possible effects were judged to be significant enough to invest the engineering time required to model the geometry in detail. 
In the case of the fuel assembly nozzles, the opposite was found to be true. While the nozzles are close to the core and are complex components, the detail was "smeared" into a simply modeled geometry. The nozzles are considered part of spent fuel, and therefore part of high-level waste and are not of particular interest to this study, having been addressed in detail in Reference 14 . The nozzles are large metal objects which affect neutron transport, however, and must be modeled approximately to account for spacial effects. The smearing effectively conserves total volume and mass of the component in a simple-to-model geometry. Since the effects on other components of such smearing is judged to be small and significant savings in engineering time occur, this approximation was used.

3.3.3.2 Resulting Geometric Model. Based on the factors and tradeoffs discussed above, determinations have been made as to whether specific components should be explicitly modeled, whether some geometric approximations should be used, or whether a component should be neglected in the model. The resulting model is described below. Figures 15 to 28 provide pictures of the geometry model as generated by MCNP to give an indication of the model complexity which was used.

In the radial direction, evaluations indicated that explicit models should be made of the core baffle, the core barrel, the thermal shield, and the pressure vessel. These components generally have large but simple geometries that are easy to model, and, in the case of the core baffle and core barrel, may be activated to levels above the Class $\mathrm{C}$ limits.

In the axial direction, explicit models are made of the upper core support plate, the control rod guide tubes, and various pieces of support structure near the upper support plate. All of these components are either likely to be activated to above Class $\mathrm{C}$ limits, or they contribute to other phenomena, like streaming, which may have significant effects on other large components.

In the case of the above components for which explicit modeling is used, it should be noted that "explicit" refers to the component major structures, such as large holes, large metal structure, etc. Small items, such as smaller holes, bolts, metal pads, and other small pieces are not modeled. Their overall contribution to the complexity of the model would be great; however, their effect on the activation analysis would be small. Generally, the smaller items are effectively smeared into the larger components. Where it was not feasible to smear the small components, these small items are neglected due to their minimal significance in terms of total waste volume.

Several larger components have been approximated in the MCNP model. These components include the control blades and the fuel assembly nozzles. In the case of the control blades, a smeared representation of the blades was used while maintaining the cruciform shape. The control blades are not of specific interest to this analysis. However the presence of control material above the core during operation impacts the thermal neutron flux above the core, which affects the activation of the upper components.

The modeling decisions made for this work have all been assessed to be reasonable based on fundamental engineering judgements. Since MCNP models of this size and for this purpose have not been attempted before, there is no objective measure of how good the approximations may be. It could reasonably be expected that some modeling judgements may not be as accurate as expected. For this reason, it is desirable for the modeling to be validated using a qualified component sampling 


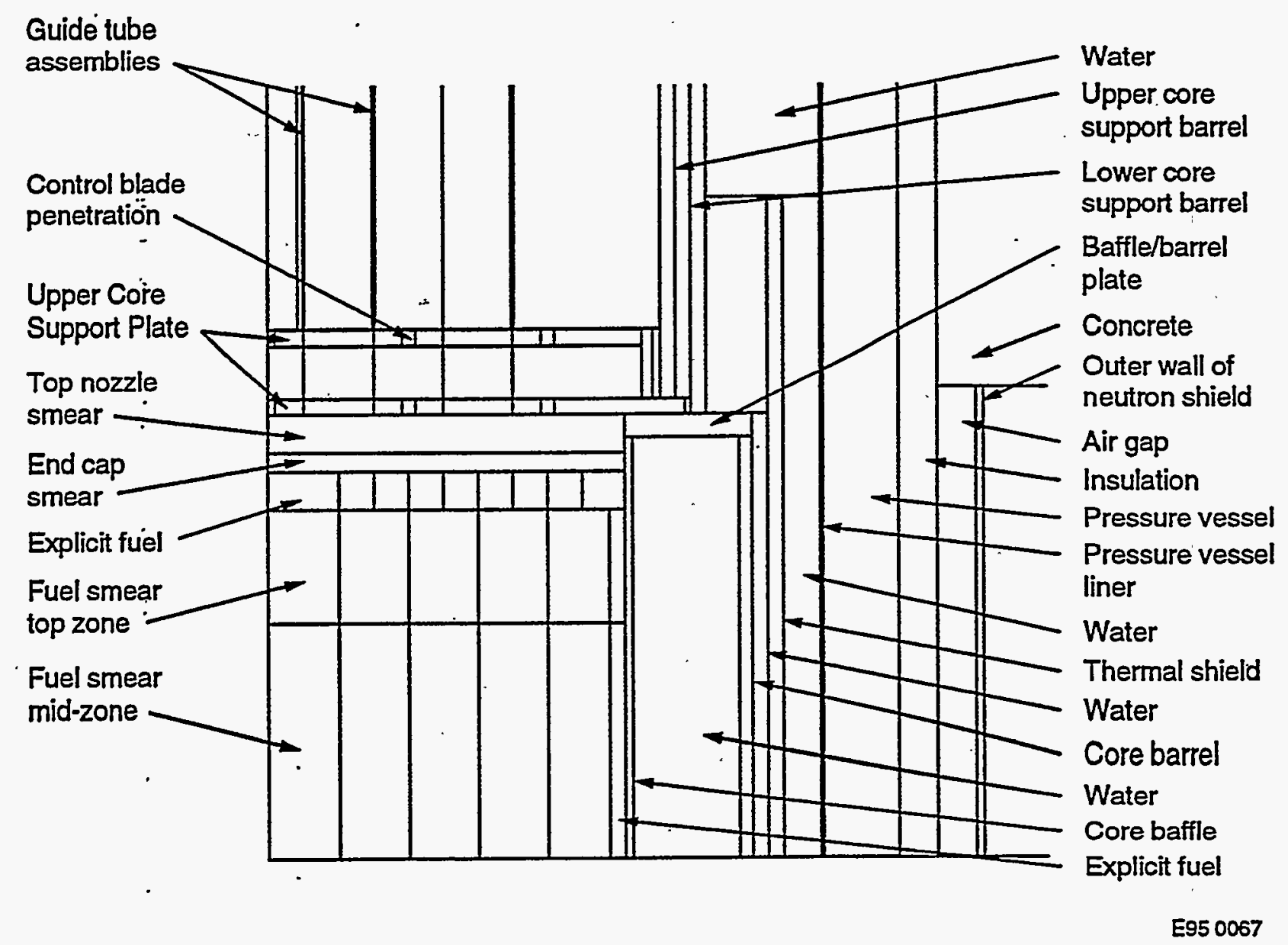

Figure 15. Axial view of Yankee Rowe MCNP model. 


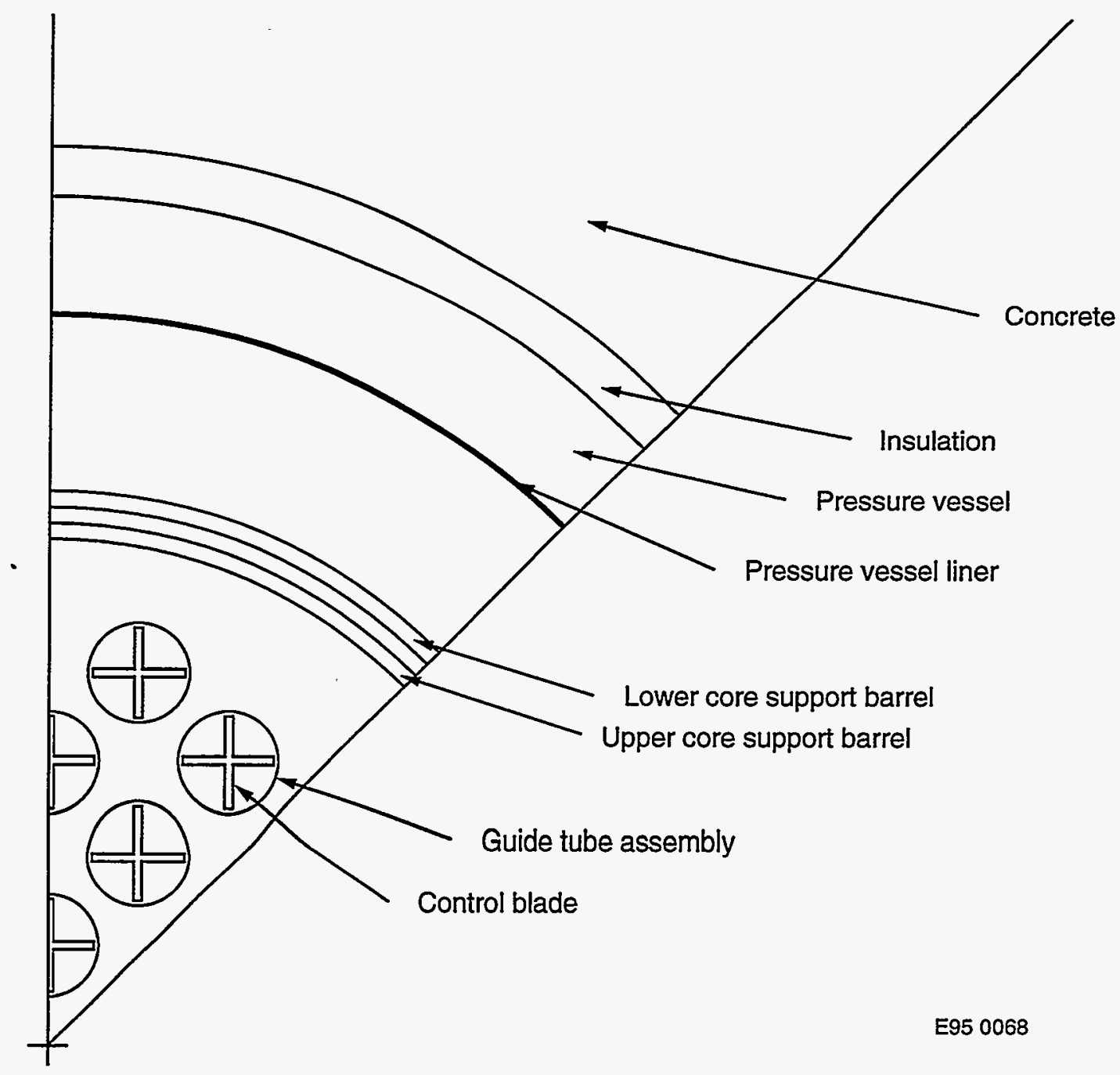

Figure 16. Radial view of Yankee Rowe MCNP model-axial height of $595 \mathrm{~cm}$. 


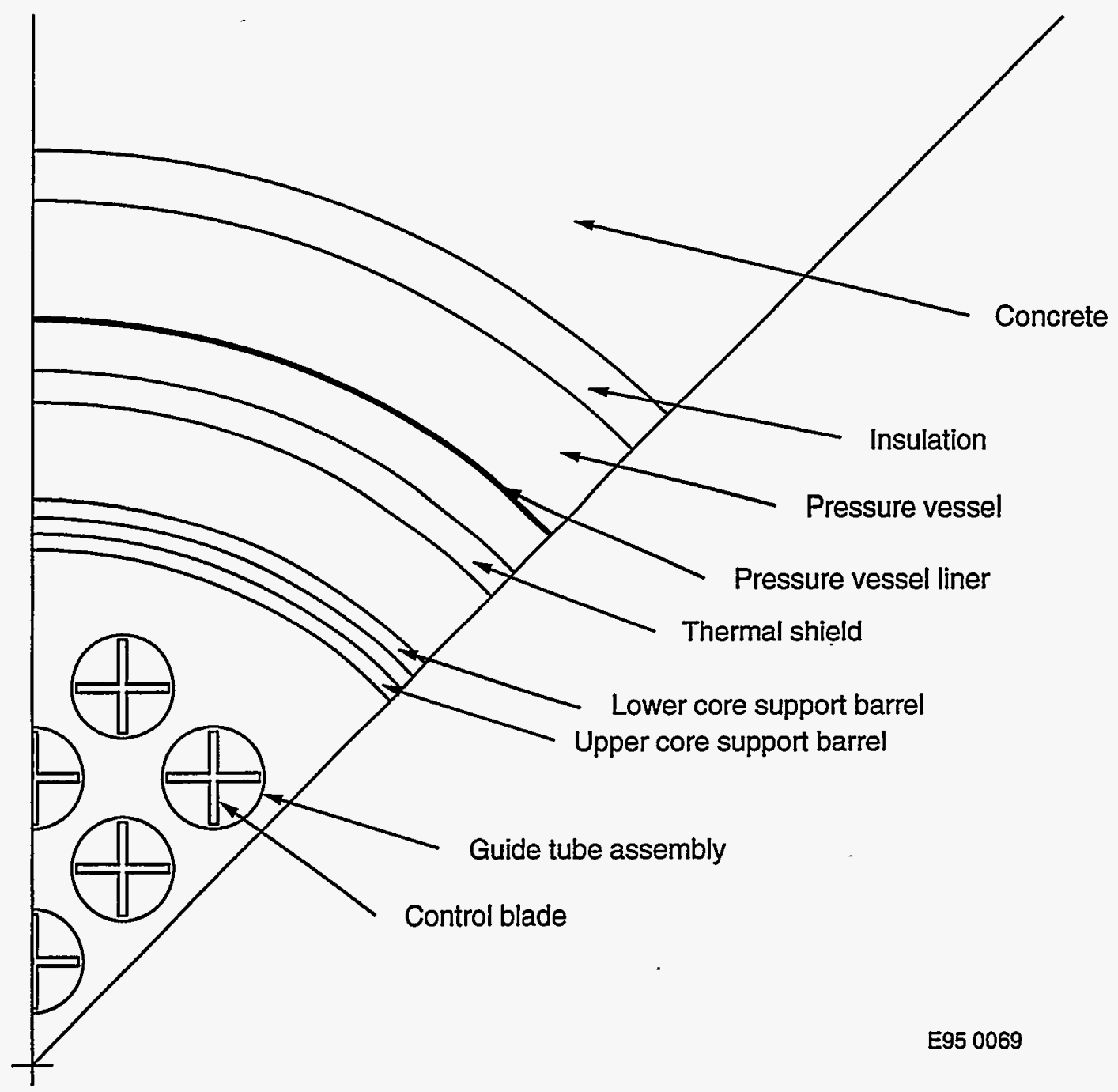

Figure 17. Radial view of Yankee Rowe MCNP model-axial height of $570 \mathrm{~cm}$. 


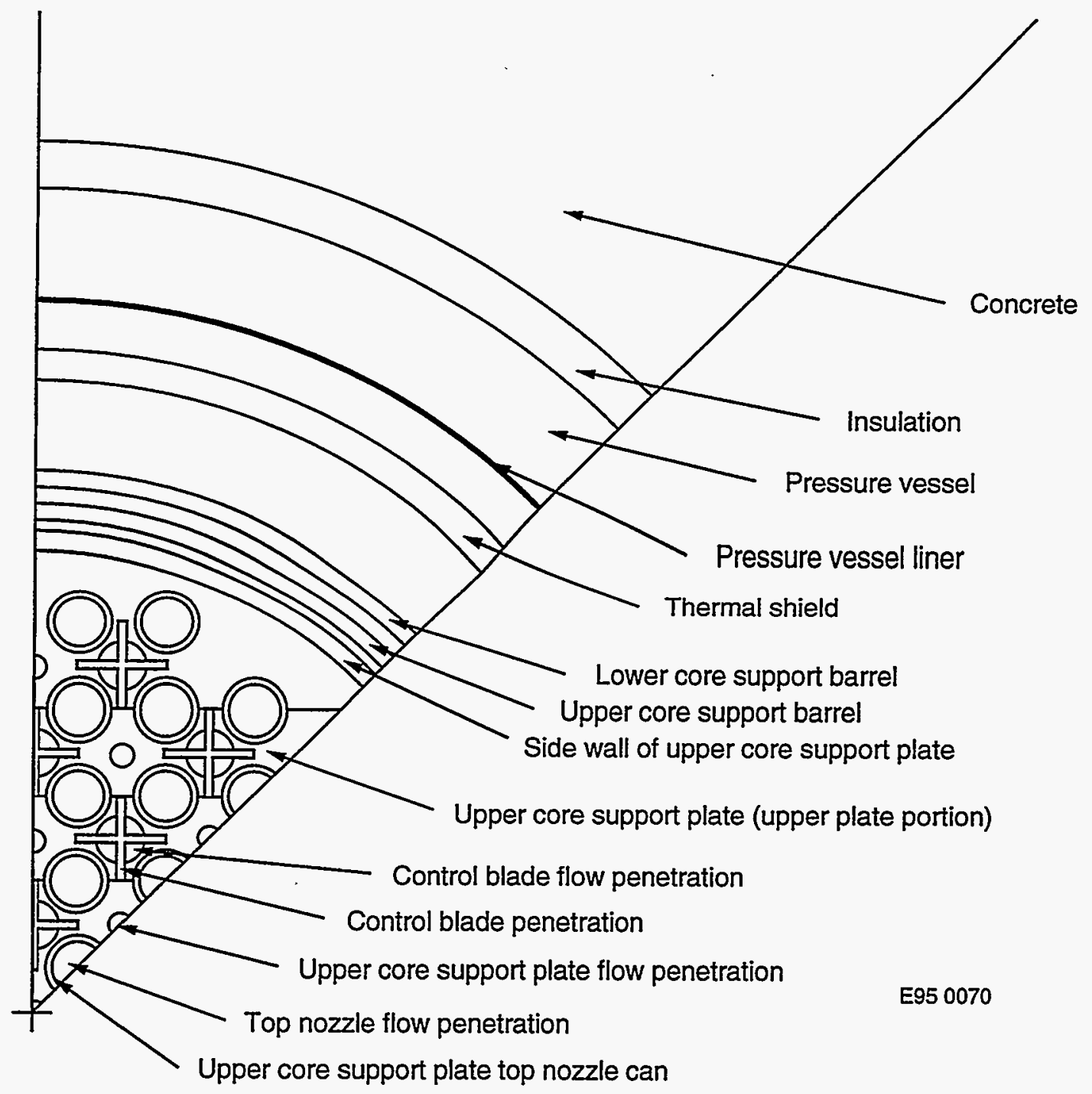

Figure 18. Radial view of Yankee Rowe MCNP model-axial height of $567 \mathrm{~cm}$. 


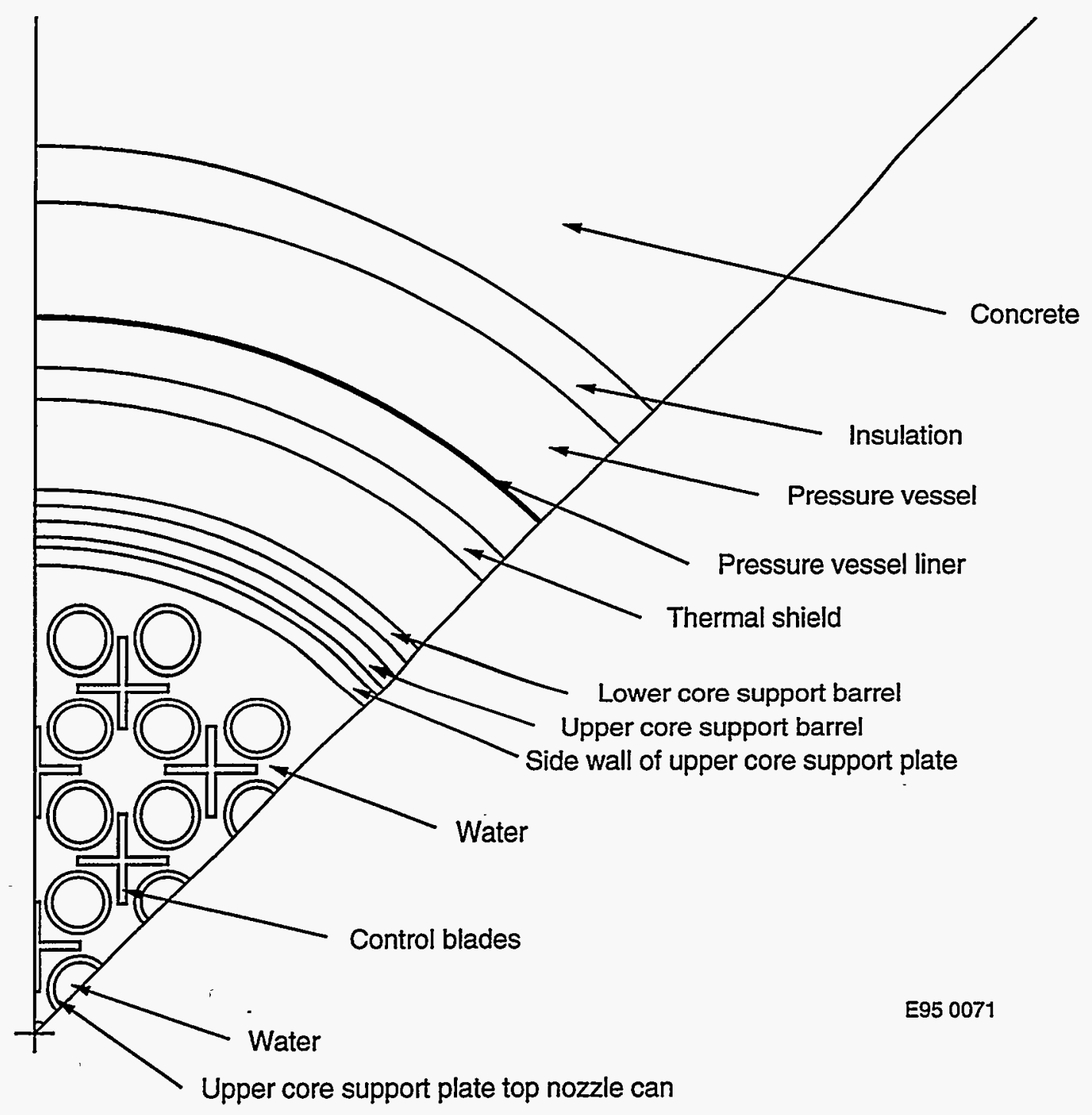

Figure 19. Radial view of Yankee Rowe MCNP model-axial height of $564 \mathrm{~cm}$. 


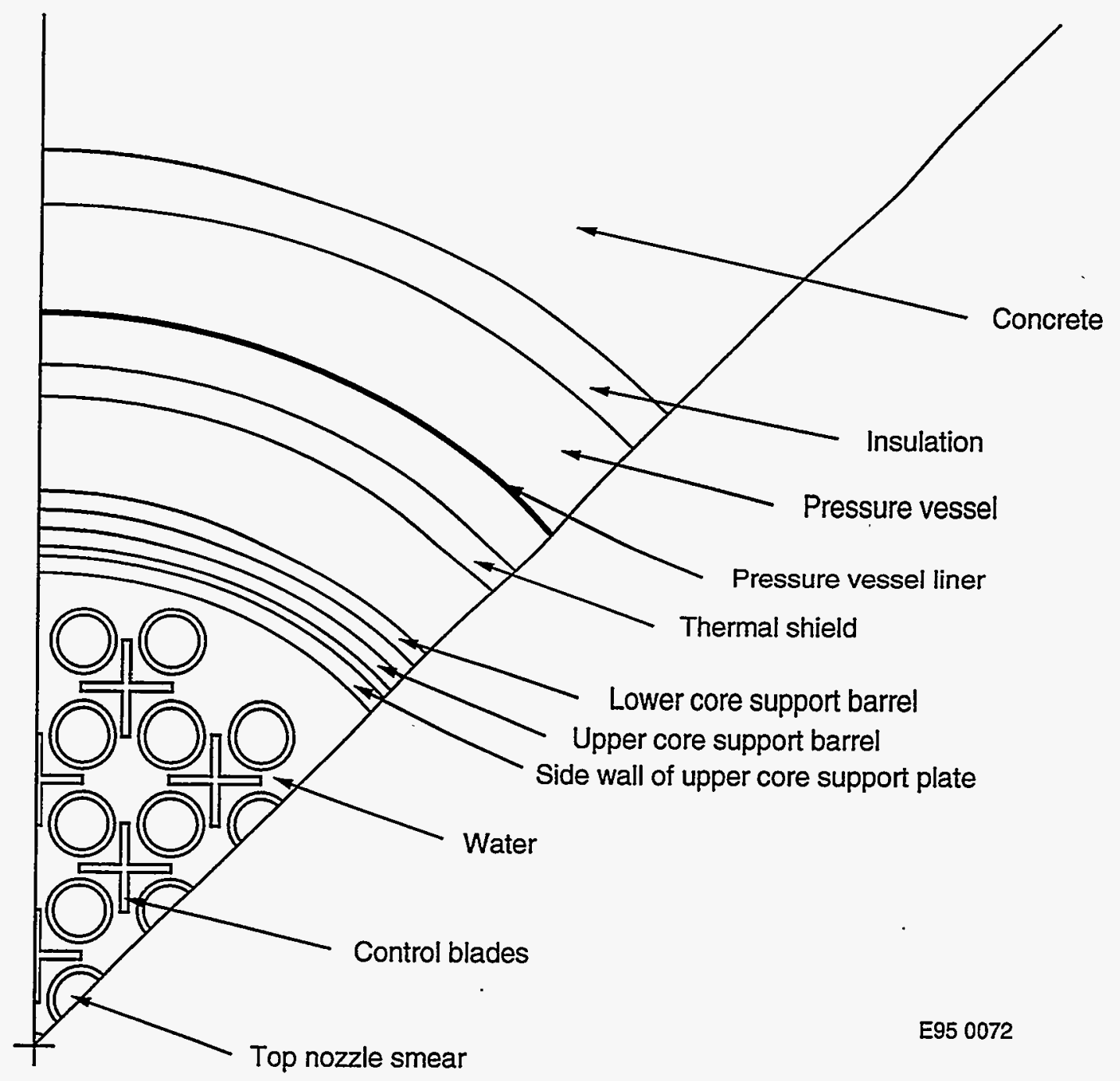

Figure 20. Radial view of Yankee Rowe MCNP model-axial height of $559 \mathrm{~cm}$. 


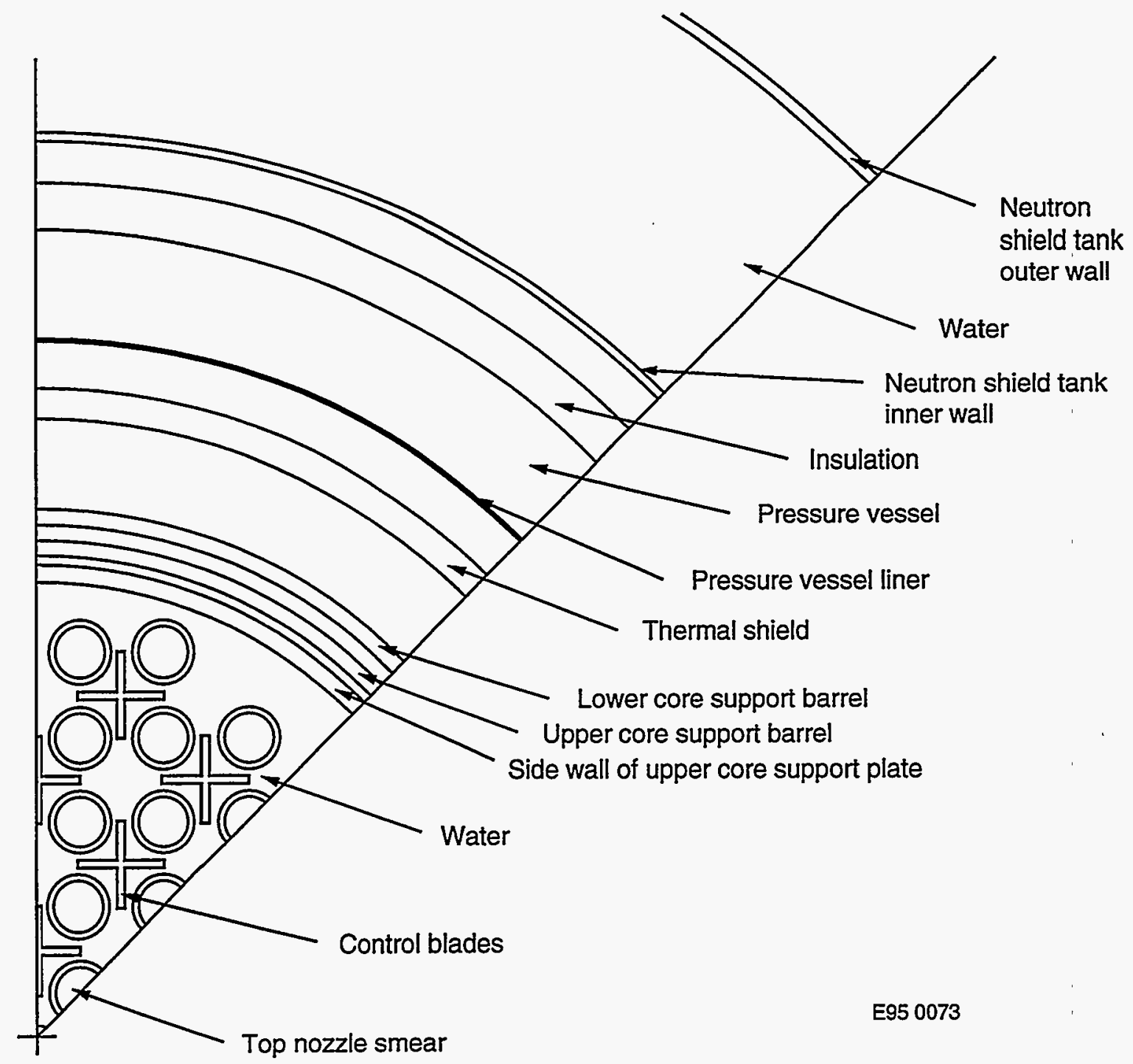

Figure 21. Radial view of Yankee Rowe MCNP model-axial height of $555 \mathrm{~cm}$. 


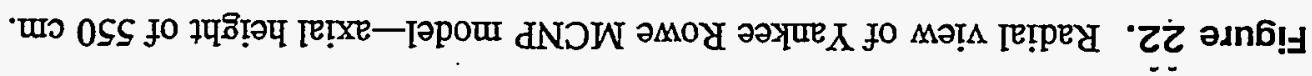

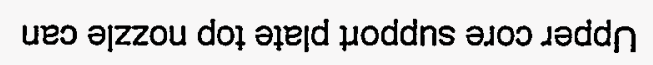

$+\angle 0096 \exists$

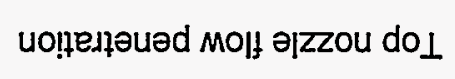

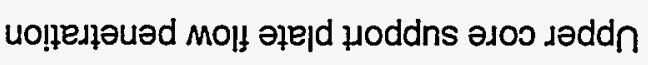
uo!̣enəuad әреiq joגłuo uo!̣edłəuəd Mo|f әре|q 10גұ००

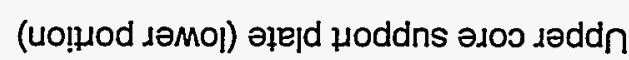
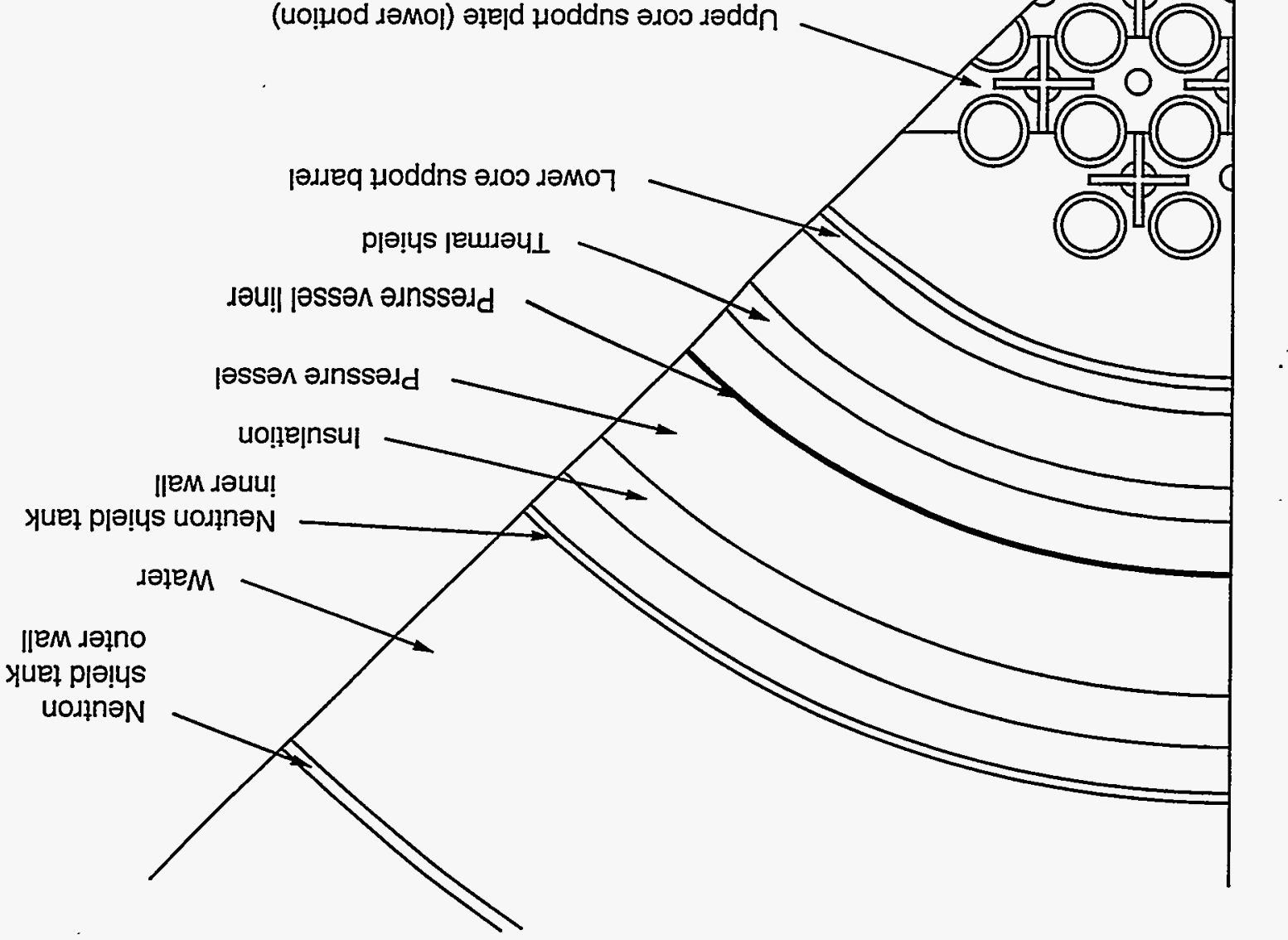


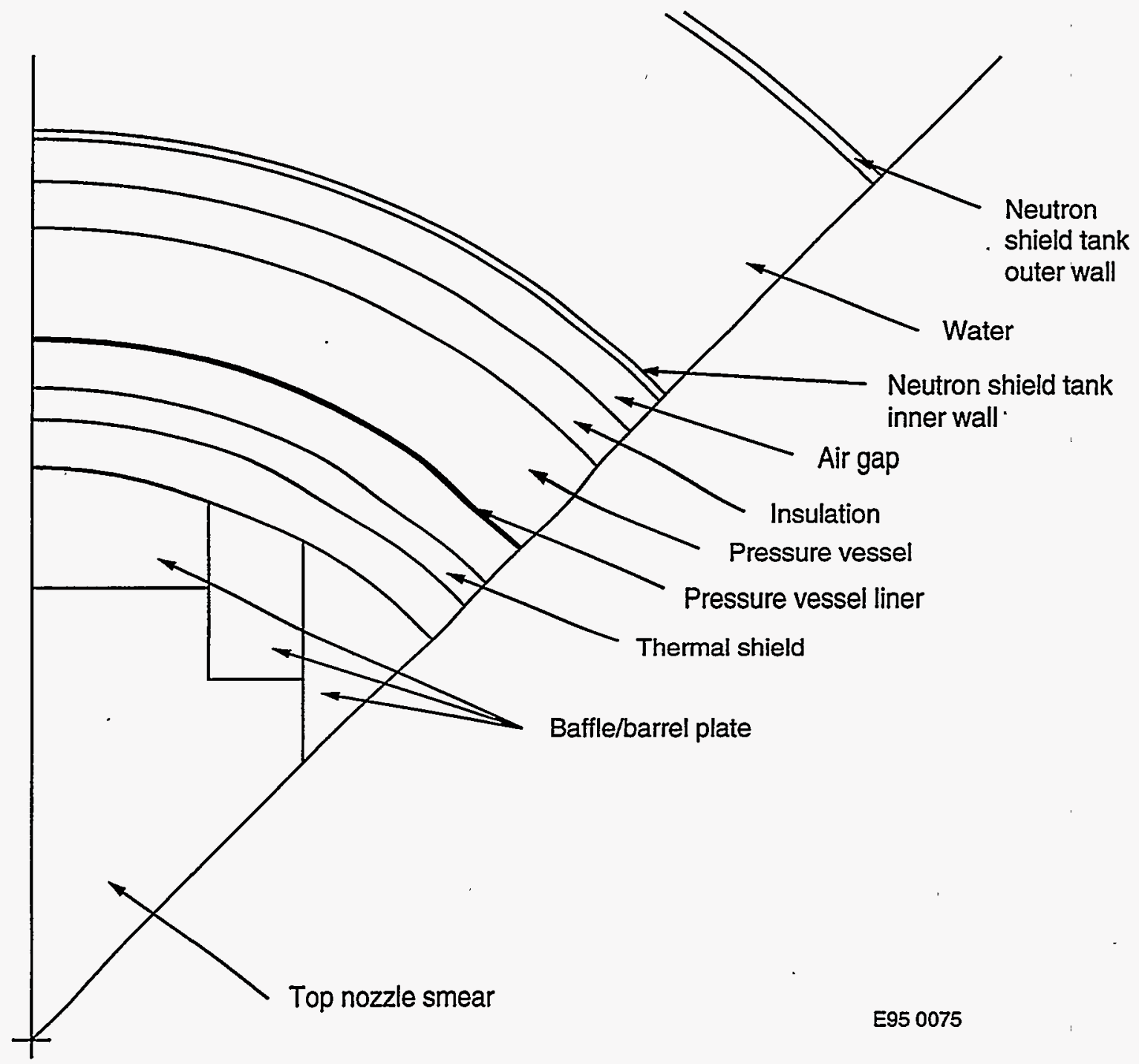

Figure 23. Radial view of Yankee Rowe MCNP model-axial height of $543 \mathrm{~cm}$. 


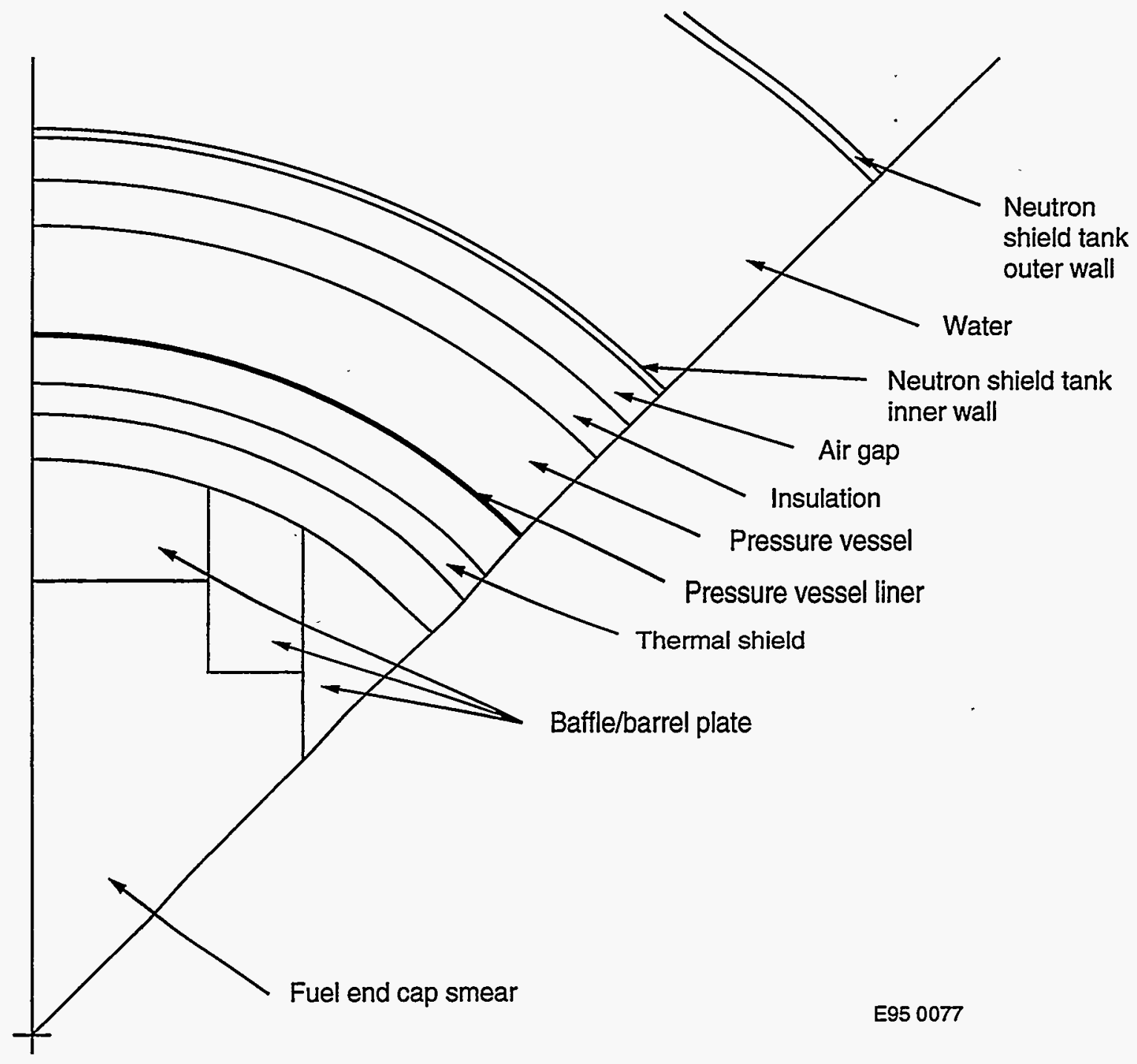

Figure 24. Radial view of Yankee Rowe MCNP model-axial height of $542 \mathrm{~cm}$. 


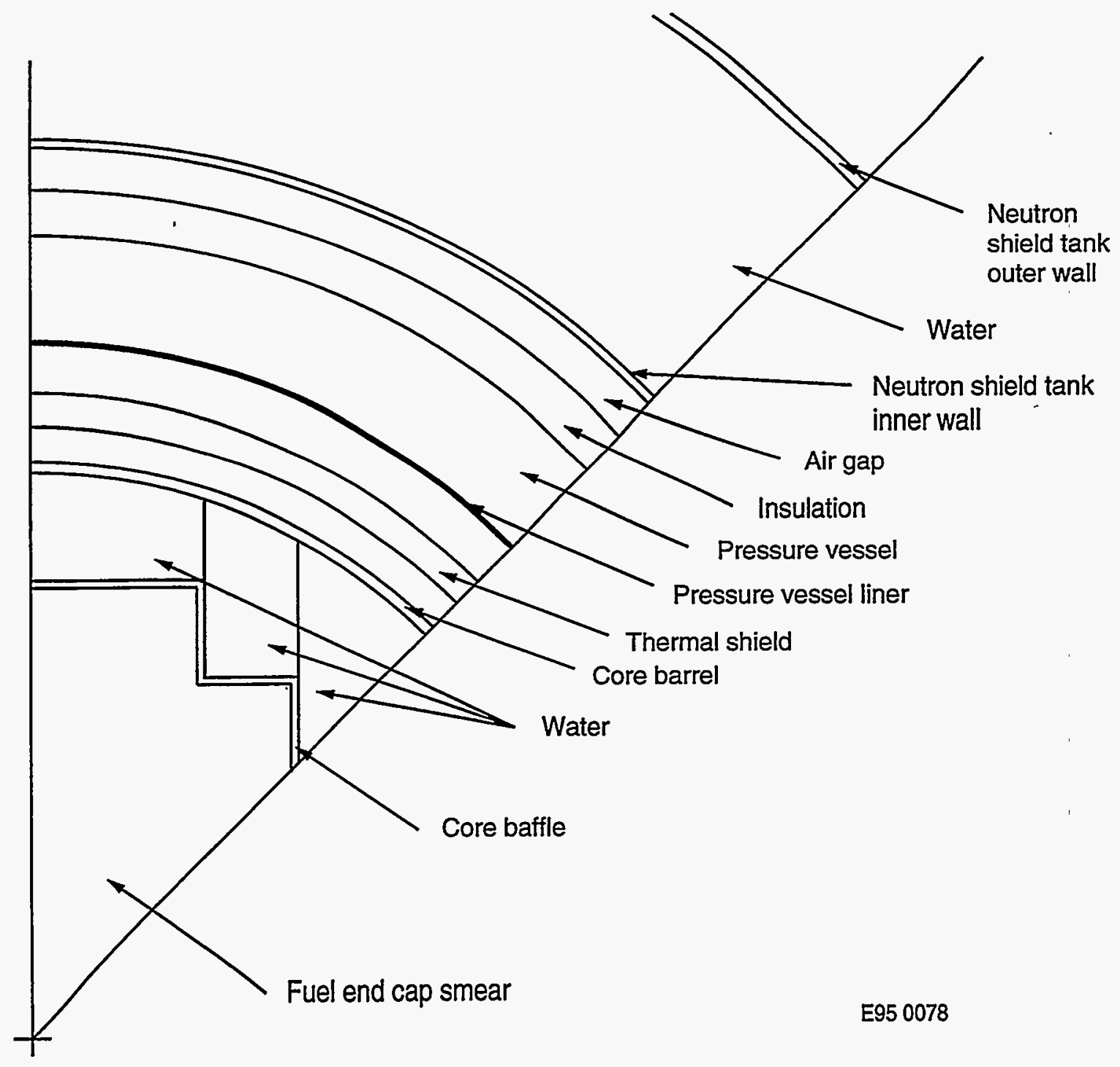

Figure 25. Radial view of Yankee Rowe MCNP model-axial height of $540.5 \mathrm{~cm}$. 


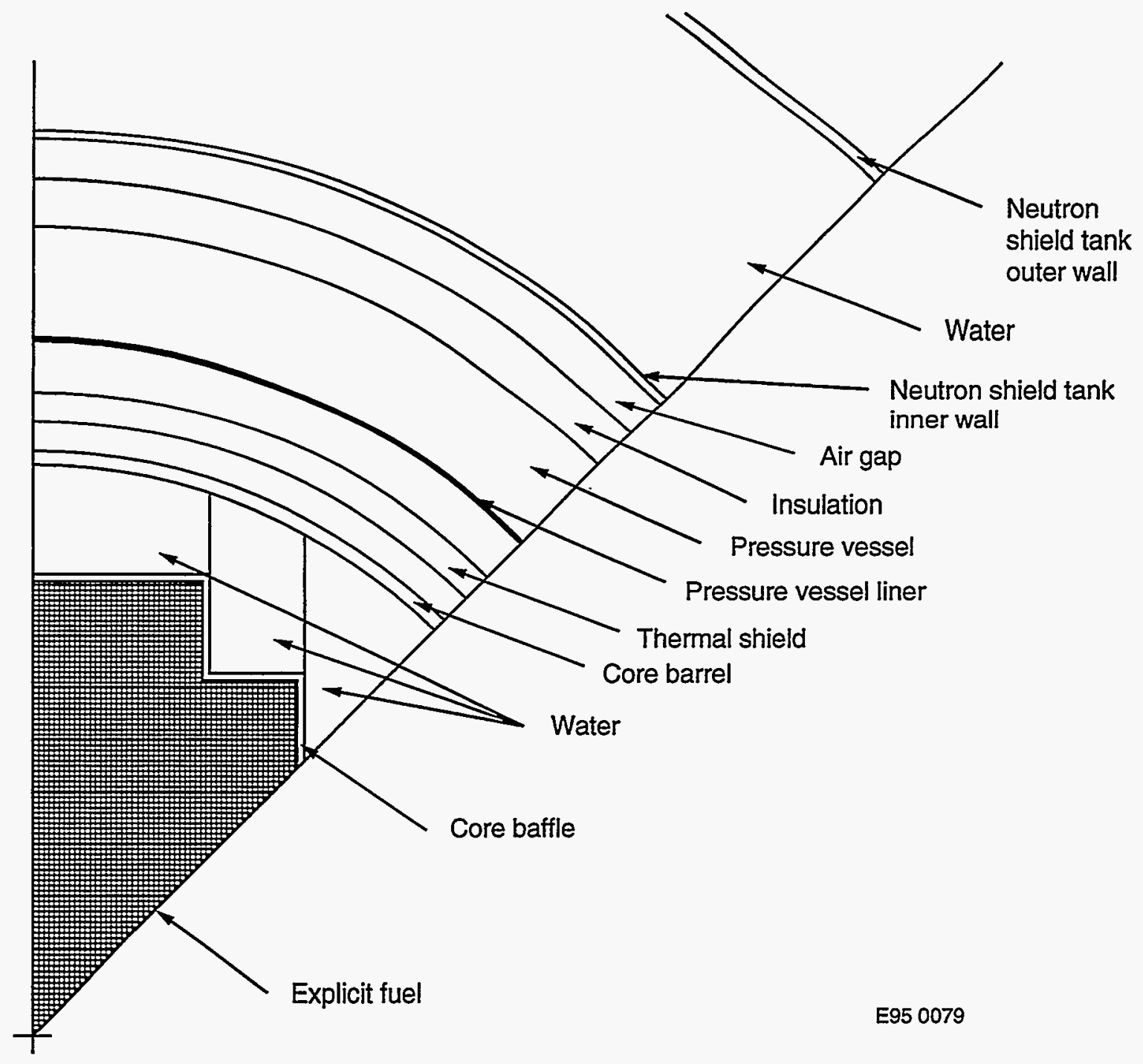

Figure 26. Radial view of Yankee Rowe MCNP model-axial height of $527 \mathrm{~cm}$. 


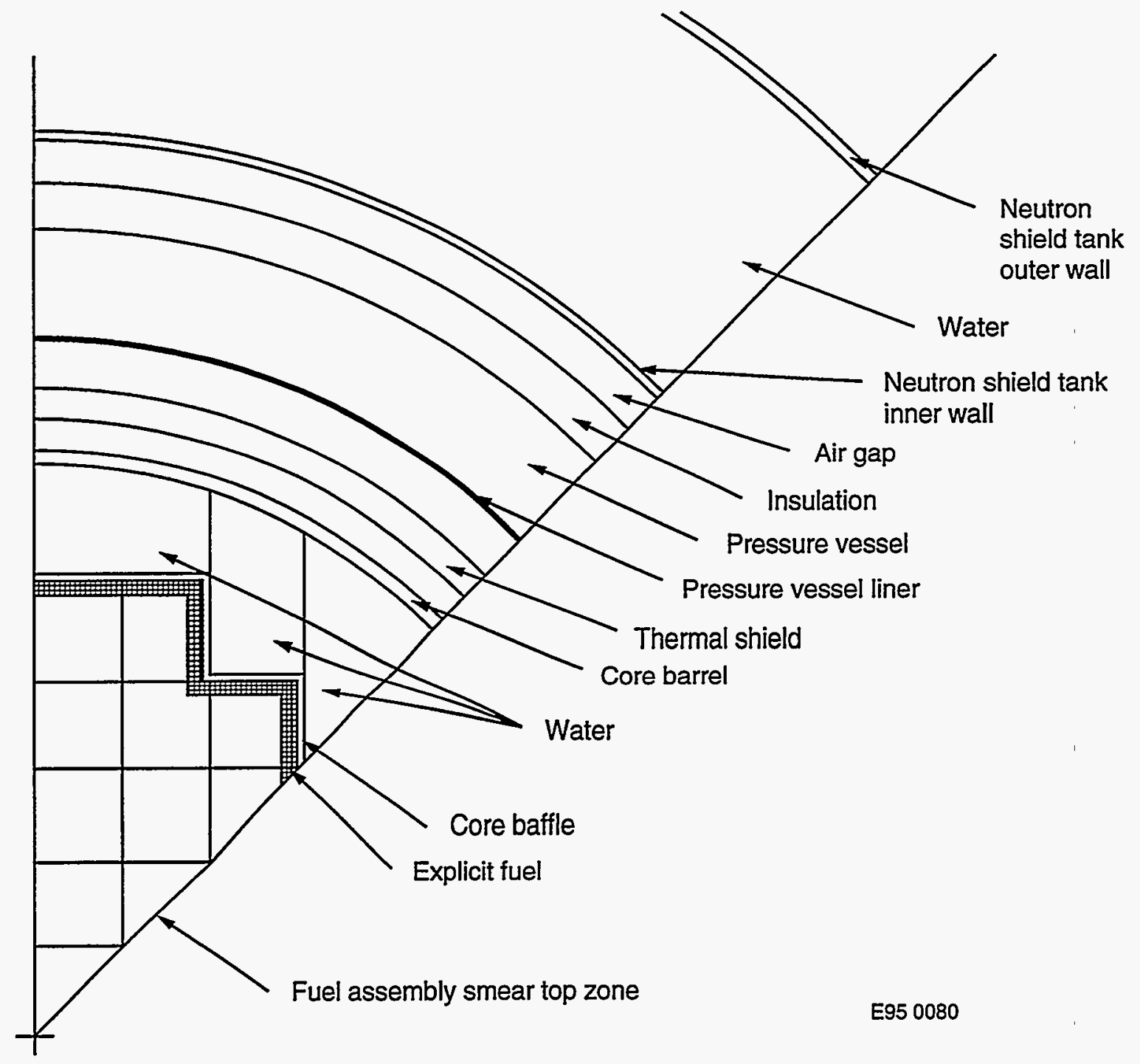

Figure 27. Radial view of Yankee Rowe MCNP model-axial height of $500 \mathrm{~cm}$. 


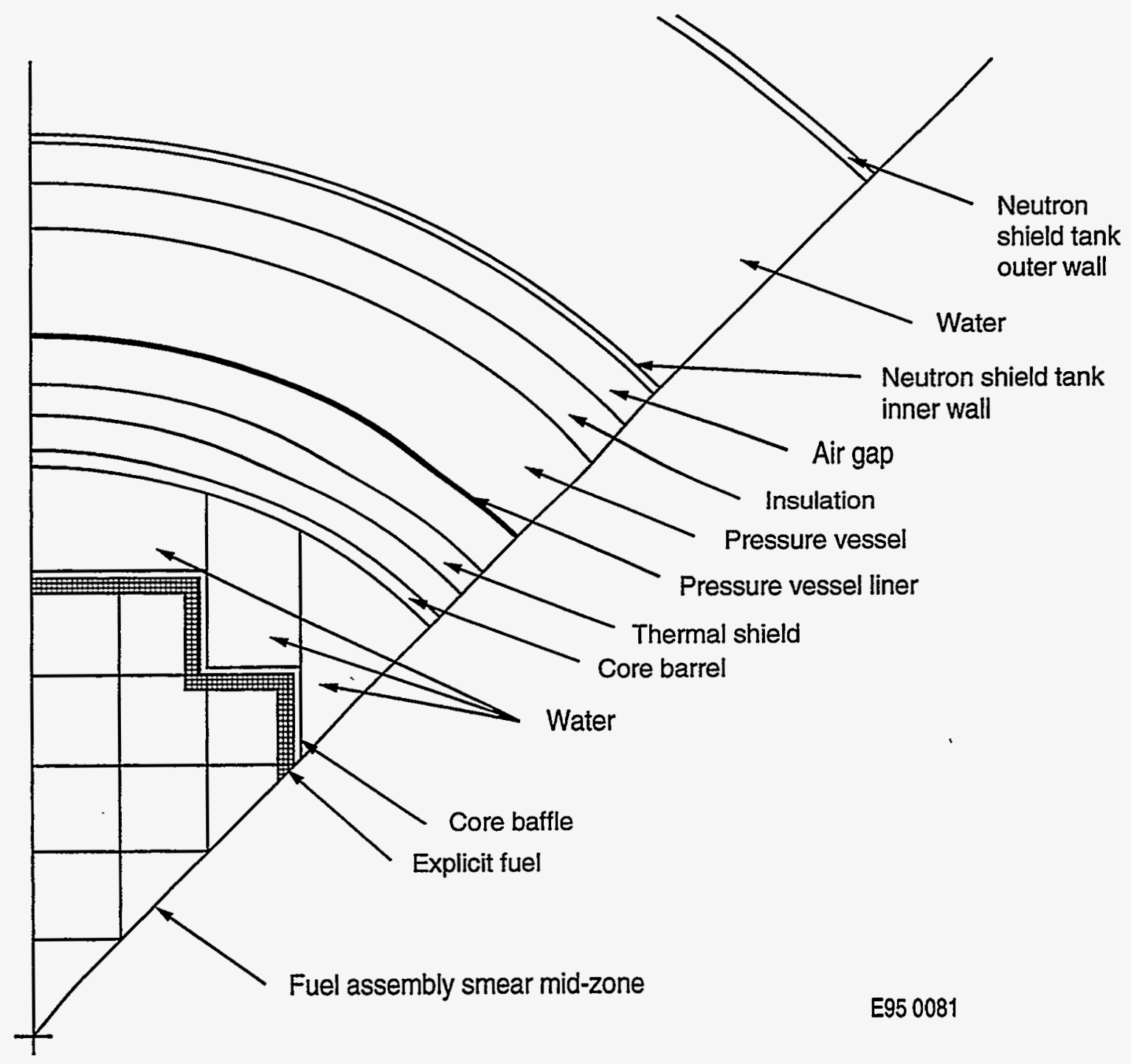

Figure 28. Radial view of Yankee Rowe MCNP model-axial height of $450 \mathrm{~cm}$. 
plan. As part of this report, a sampling plan has been proposed that would serve to verify the model results. Inaccuracies which result from modeling assumptions may be identified and reduced through comparisons to laboratory measurements of component samples. The accuracy can be increased by modifying the portions of the model to be more representative of physical reality. For example, a component geometry that is now approximated may be changed to an explicit model if the approximation has introduced unacceptable error.

\subsubsection{Material Compositions}

Material composition data that include accurate assessments of the trace elements in the base material are difficult to acquire for components manufactured circa the 1950s. Most of the components of interest in Yankee Rowe are stainless steel (SS-304). The YAEC has provided general material composition data for stainless steel which has been used for this analysis. The compositions are listed in Table 3. Where required material compositions were not available from the Yankee data, trace concentrations were assumed.

More accurate material composition data could be obtained by performing component sample analysis in a laboratory. The laboratory analysis could determine the quantities of the parent isotopes

Table 3. Elemental constituents of carbon steel and stainless steel 304 (percent).

\begin{tabular}{llc}
\hline & Carbon steel $^{\mathrm{a}}$ & Stainless steel $^{\mathrm{b}}$ \\
\hline $\mathrm{C}$ & 0.22 & 0.08 \\
$\mathrm{Mn}$ & 1.22 & 2.00 \\
$\mathrm{P}$ & 0.016 & 0.045 \\
$\mathrm{~S}$ & 0.027 & 0.03 \\
$\mathrm{Si}$ & 0.21 & 1.00 \\
$\mathrm{Ni}$ & 0.20 & 9.20 \\
$\mathrm{Cr}$ & 0.07 & 19.00 \\
$\mathrm{Mo}$ & 0.49 & - \\
$\mathrm{Al}$ & 0.02 & - \\
$\mathrm{Cu}$ & 0.19 & - \\
& - & 0.10 \\
$\mathrm{Fe}$ & 97.34 & 68.55 \\
a. Carbon Steel composition is based on the average of Mill Test and Naval Research Laboratory \\
results for upper plate material (SA-302 Grade B). \\
b. Stainless Steel composition is based on Type 304 data from the Metals Handbook (p. 15.2).
\end{tabular}


found in each of the metal samples. The actual composition data could then be input to the model, and more accurate activation levels could be calculated.

While laboratory analytical data are expected to contribute to more accurate calculational results, there are considerable uncertainties in determining material compositions in a large piece of metal. Previous laboratory analytical work has shown that two samples from the same component in different locations can contain differing quantities of trace elements. Variations by an order of magnitude have been measured. ${ }^{14}$ Therefore, to address some of the effects of material composition on the activations levels, the effects of trace element concentrations on activation are investigated in the parametric studies (Appendix A).

In the MCNP model, all cross-sections outside the fuel region were used at an average temperature of $300 \mathrm{~K}$. In general, the isotope cross-sections of interest to this study do not change significantly with temperature.

\subsubsection{Irradiation History and Cooling Time}

The Yankee Rowe reactor power rating remained uniform throughout its operating life. Additionally, the core loading scheme (which allowed high-leakage) also remained the same throughout its operating life. This knowledge allows for significant simplification in the irradiation history model.

As noted in the fuel model description, an average fuel load over the operating history of the reactor was used to approximate the fuel source. The tally output from the MCNP model is measured in units of reactions $/ \mathrm{cm}^{2} /$ source neutron. Using simple unit conversions, this information is converted to $\mathrm{Ci} / \mathrm{m}^{3} /$ source neutron, where the source neutron term indicates the number of neutrons generated in the fuel over the history of the reactor. The reactor experienced 22.374 effective full power years (EFPY). Using average values of $201.7 \mathrm{Mev} /$ fission and 2.58 neutrons/fission at $600 \mathrm{MWt}$, this corresponds to approximately $3.4 \times 10^{28}$ source neutrons for the full core. Since the MCNP model is $1 / 16$ of the Yankee core, $2.1 \times 10^{27}$ neutrons are used for the MCNP calculation.

Table 1 lists the half-lives of the radionuclides of interest in this study. Because the relative operating time of the reactor is short compared to the half-life of the isotopes of interest $\left({ }^{14} \mathrm{C},{ }^{59} \mathrm{Ni}\right.$, ${ }^{94} \mathrm{Nb},{ }^{99} \mathrm{Tc}$, and ${ }^{63} \mathrm{Ni}$ ), the overall contribution of decay to the specific concentration of $10 \mathrm{CFR} 61$ isotopes is relatively small. The effect of isotopic decay was estimated as follows.

As soon as activation products are produced, decays begin to take place based on the half-life of that particular isotope. This decay of the isotopes is continuous. Activation is essentially linear with

flux. Radioisotopic decay during the operational life of the reactor was estimated using the following equation for each isotope of interest:

$N(t)=\frac{Q}{\lambda}\left(1-e^{-\lambda}\right)+N_{0} e^{-\lambda t}$

where

$N(t)=$ number of atoms as a function of time $t$ 


$$
\begin{aligned}
& \mathrm{Q}=\text { average isotopic production rate (atoms/sec) } \\
& \lambda=\text { isotope decay constant } \\
& \mathrm{t}=\text { time } \\
& \mathrm{N}_{0}=\text { initial number of atoms. }
\end{aligned}
$$

To estimate the total number of decays during the reactor lifetime, this equation is applied to each reactor cycle for each isotope of interest. The value of $Q$ is determined from the MCNP results. The decay calculation is carried out through March 1,1994, and the total quantity of activation products at that date is calculated.

\subsubsection{MCNP Tally Structure}

Three different types of tallies were used in the Yankee Rowe MCNP model. These included volume-averaged $(n, \gamma)$ reaction rates, volume-averaged $(n, p)$ reaction rates, and surface-averaged fluxes.

The volume averaged $(n, \gamma)$ and $(n, p)$ reaction rates were used to compute the concentrations of the radionuclides of interest in waste classification. Table 2 tabulates the reactions calculated by MCNP for this study. Volume-averaged reaction rates are tallied for each individual interaction in each MCNP cell of interest. Since many components comprise a large number of MCNP cells, 315 individual volume-averaged tallies are used for the complete analysis.

The surface-averaged fluxes are extracted and tallied to analyze the relative flux behavior as a function of distance from the edge of the active core out to the neutron shield in the radial direction. A total of 10 surface-average flux tallies were generated to obtain the desired results.

Each of the tallies generated are multiplied by a conversion factor found in tally multiplier cards. The multiplier is used to convert the MCNP tally results, which are in reactions $/ \mathrm{cm}^{3} / \mathrm{source}$ neutron, to units of $\mathrm{Ci} / \mathrm{m}^{3}$. The multiplier is constant for each reaction in each cell. 


\section{CALCULATIONAL RESULtS}

The activation calculations were run using MCNP Version 4a on a Hewlett Packard 755 with 192 megabytes of memory and 5 gigabytes of disk space. The HP-755 uses the HP 9.05 operating system.

MCNP Versions 4.2, 4x, 4xe, and 4a are operating on an HP-755 at PNL. PNL receives code versions and upgrades from Westinghouse Hanford Company (WHC), the Hanford site code custodian. Los Alamos National Laboratory distributes regular upgrades and updates to WHC, which then distributes them to PNL. PNL has increased the default code dimensions on its versions to accommodate larger problems such as the Yankee Rowe core model. Conversion testing of all new versions is performed using standard conversion test cases according to PNL software quality assurance procedures. The results of these test cases are compared to benchmark cases for consistency. There are 25 standard test cases; however, only 18 are run at PNL. The remaining cases perform electron transport calculations that are not specifically of interest to PNL at this time.

\subsection{Predicted Activation Levels}

Table 4 lists the isotopes of interest for GTCC LLW and their associated Class C activity limits as listed in 10 CFR 61 . The limits are given in curies per cubic meter of material $\left(\mathrm{Ci} / \mathrm{m}^{3}\right)$.

The predicted activation results for the Yankee Rowe reactor are presented in Tables 5 through 7. The results are presented by component for the components of interest in the reactor, and indicate the results obtained directly from MCNP, which do not include the effects of isotope decay. Also presented are the variances in the MCNP calculations for the specific isotopes. Finally, the last column shows the results with the decay calculations included.

The results are presented in units of $\mathrm{Ci} / \mathrm{m}^{3}$, consistent with the regulatory units put forth in 10 CFR 61. The activity represents the total number of curies averaged over the entire metal volume of a component. Results for specific areas or regions of the larger components were not calculated and are not presented at this time. Such results would be necessary for comparison to component

Table 4. Activated metal isotope activity limits for Class $\mathrm{C}$ waste.

\begin{tabular}{lc}
\multicolumn{1}{c}{ Isotope } & $\begin{array}{c}\text { Activity limit } \\
\left(\mathrm{Ci} / \mathrm{m}^{3}\right)\end{array}$ \\
\hline Long-lived Isotopes & \\
${ }^{14} \mathrm{C}$ & 80 \\
${ }^{59} \mathrm{Ni}$ & 220 \\
${ }^{94} \mathrm{Nb}$ & 0.2 \\
${ }^{99} \mathrm{Tc}$ & 3 \\
Short-lived Isotopes & 7,000 \\
\hline
\end{tabular}


Table 5. MCNP base case activation calculations for long-lived isotopes $\left(\mathrm{Ci} / \mathrm{m}^{3}\right)$.

\begin{tabular}{|c|c|c|c|c|c|c|c|c|c|c|c|c|}
\hline \multirow[b]{2}{*}{ Component } & \multicolumn{3}{|c|}{${ }^{24} \mathrm{Nb}$} & \multicolumn{3}{|c|}{${ }^{39} \mathrm{Ni}$} & \multicolumn{3}{|c|}{${ }^{14} \mathrm{C}$} & \multicolumn{3}{|c|}{${ }^{99} \mathrm{Tc}$} \\
\hline & $\begin{array}{c}\text { Base } \\
\text { calculation }\end{array}$ & $\begin{array}{l}\text { Statistical } \\
\text { error }\end{array}$ & $\begin{array}{c}\text { Base } \\
\text { w/decay }\end{array}$ & $\begin{array}{l}\text { Base } \\
\text { calculation }\end{array}$ & $\begin{array}{l}\text { Statistical } \\
\text { error }\end{array}$ & $\begin{array}{c}\text { Basc } \\
\text { w/decay }\end{array}$ & $\begin{array}{c}\text { Base } \\
\text { calculation }\end{array}$ & $\begin{array}{l}\text { Statistical } \\
\text { error }\end{array}$ & $\begin{array}{l}\text { Base } \\
\text { w/decay }\end{array}$ & $\begin{array}{l}\text { Base } \\
\text { calculation }\end{array}$ & $\begin{array}{l}\text { Statistical } \\
\text { error }\end{array}$ & $\begin{array}{c}\text { Base } \\
\text { w/decay }\end{array}$ \\
\hline $\begin{array}{l}\text { Upper core support } \\
\text { plate }\end{array}$ & $1.981 \mathrm{e}-01$ & $1.81 \%$ & $1.979 \mathrm{e}-01$ & $6.181 e+01$ & $0.71 \%$ & $6.180 e+01$ & $6.174 e-01$ & $0.68 \%$ & $6.161 e-01$ & $2.391 \mathrm{e}-03$ & $5.43 \%$ & $2.390 c-03$ \\
\hline UCSP-Upper plate & $3.311 \mathrm{c}-02$ & $6.38 \%$ & $3.309 \mathrm{e}-02$ & $1.010 c+01$ & $4.74 \%$ & $1.010 \mathrm{e}+01$ & $1.002 \mathrm{e}-01$ & $4.74 \%$ & $9.997 c-02$ & $3.032 \mathrm{e}-04$ & $6.55 \%$ & $3.032 \mathrm{e}-04$ \\
\hline $\begin{array}{l}\text { UCSP-Lower } \\
\text { plate }\end{array}$ & $3.071 \mathrm{e}-01$ & $9.01 \%$ & $3.069 \mathrm{e}-01$ & $9.125 e+01$ & $9.35 \%$ & $9.123 c+01$ & $9.162 \mathrm{e}-01$ & $9.33 \%$ & $9.142 \mathrm{e}-01$ & $4.004 \mathrm{e}-03$ & $10.56 \%$ & $4.004 \mathrm{e}-03$ \\
\hline $\begin{array}{l}\text { Upper core support } \\
\text { barrel }\end{array}$ & $9.641 \mathrm{c}-04$ & $21.93 \%$ & $9.635 c-04$ & $2.427 c-01$ & $9.97 \%$ & $2.426 \mathrm{c}-01$ & $2.461 c-03$ & $9.51 \%$ & $2.456 \mathrm{e}-03$ & $2.300 \mathrm{e}-05$ & $38.90 \%$ & $2.300 \mathrm{e}-05$ \\
\hline $\begin{array}{l}\text { Lower core support } \\
\text { barrel }\end{array}$ & $6.909 e-04$ & $13.00 \%$ & $6.905 \mathrm{e}-04$ & $2.005 e-01$ & $10.91 \%$ & $2.004 c-01$ & $1.995 c-03$ & $10.63 \%$ & $1.991 c-03$ & $7.854 \mathrm{e}-06$ & $34.91 \%$ & $7.854 \mathrm{e}-06$ \\
\hline Core baffle & $1.195 c+00$ & $1.73 \%$ & $1.194 c+00$ & $3.240 e+02$ & $0.62 \%$ & $3.240 c+02$ & $3.237 e+00$ & $0.60 \%$ & $3.230 c+00$ & $1.344 c-02$ & $5.00 \%$ & $1.344 \mathrm{e}-02$ \\
\hline Core barrel & $6.610 \mathrm{e}-02$ & $1.74 \%$ & $6.606 \mathrm{e}-02$ & $2.422 e+01$ & $0.60 \%$ & $2.422 c+01$ & $2.411 e-01$ & $0.58 \%$ & $2.406 \mathrm{e}-01$ & $7.670 \mathrm{e}-04$ & $7.86 \%$ & $7.670 \mathrm{e}-04$ \\
\hline Thermal shicld & $1.440 c-02$ & $3.60 \%$ & $1.439 \mathrm{e}-02$ & $3.847 e+00$ & $1.39 \%$ & $3.847 e+00$ & $3.876 \mathrm{e}-02$ & $1.34 \%$ & $3.868 \mathrm{e}-02$ & $1.297 \mathrm{e}-04$ & $7.15 \%$ & $1.297 \mathrm{e}-04$ \\
\hline Pressure vessel liner & $1.666 \mathrm{c}-03$ & $8.71 \%$ & $1.665 \mathrm{e}-03$ & $6.700 c-01$ & $3.36 \%$ & $6.699 \mathrm{e}-01$ & $6.614 e-03$ & $3.29 \%$ & $6.600 \mathrm{e}-03$ & $1.933 \mathrm{e}-05$ & $28.39 \%$ & $1.933 \mathrm{e}-05$ \\
\hline Pressure vessel & $4.171 \mathrm{e}-03$ & $16.47 \%$ & $4.169 c-03$ & $1.045 e-03$ & $3.25 \%$ & $1.045 \mathrm{e}-03$ & $1.166 c-04$ & $3.00 \%$ & $1.164 e-04$ & $4.483 e-04$ & $16.18 \%$ & $4.483 c-04$ \\
\hline
\end{tabular}


Table 6. MCNP base case activation calculations for short-lived isotopes $\left(\mathrm{Ci} / \mathrm{m}^{3}\right)$.

\begin{tabular}{lccc} 
& \multicolumn{3}{c}{${ }^{63} \mathrm{Ni}$} \\
\cline { 2 - 4 } Component & $\begin{array}{c}\text { Base } \\
\text { calculation }\end{array}$ & $\begin{array}{c}\text { Statistical } \\
\text { error }\end{array}$ & $\begin{array}{c}\text { Base } \\
\text { w/decay }\end{array}$ \\
\hline Upper core support plate & $4.895 \mathrm{e}+02$ & $0.94 \%$ & $4.343 \mathrm{e}+02$ \\
UCSP-upper plate & $7.966 \mathrm{e}+01$ & $0.94 \%$ & $7.068 \mathrm{e}+01$ \\
UCSP-lower plate & $7.223 \mathrm{e}+02$ & $9.35 \%$ & $6.408 \mathrm{e}+02$ \\
Upper core support barrel & $1.908 \mathrm{e}+00$ & $10.12 \%$ & $1.693 \mathrm{e}+00$ \\
Lower core support barrel & $1.568 \mathrm{e}+00$ & $11.09 \%$ & $1.391 \mathrm{e}+00$ \\
Core baffle & $2.549 \mathrm{e}+03$ & $0.62 \%$ & $2.262 \mathrm{e}+03$ \\
Core barrel & $1.918 \mathrm{e}+02$ & $0.60 \%$ & $1.701 \mathrm{e}+02$ \\
Thermal shield & $3.035 \mathrm{e}+01$ & $1.40 \%$ & $2.693 \mathrm{e}+01$ \\
Pressure vessel liner & $5.321 \mathrm{e}+00$ & $3.38 \%$ & $4.721 \mathrm{e}+00$ \\
Pressure vessel & $9.205 \mathrm{e}-03$ & $5.60 \%$ & $8.167 \mathrm{e}-03$ \\
\hline
\end{tabular}

Table 7. MCNP base case activation calculations for ${ }^{60} \mathrm{Co}\left(\mathrm{Ci} / \mathrm{m}^{3}\right)$.

\begin{tabular}{llll}
\hline & \multicolumn{3}{c}{${ }^{\circ} \mathrm{C} 0$} \\
\cline { 2 - 4 } Component & $\begin{array}{c}\text { Base } \\
\text { calculation }\end{array}$ & $\begin{array}{c}\text { Statistical } \\
\text { error }\end{array}$ & $\begin{array}{c}\text { Base } \\
\text { w/decay }\end{array}$ \\
\hline Upper core support plate & $2.183 \mathrm{e}+05$ & $1.02 \%$ & $3.994 \mathrm{e}+04$ \\
UCSP-upper plate & $3.733 \mathrm{e}+04$ & $4.23 \%$ & $6.830 \mathrm{e}+03$ \\
UCSP-lower plate & $3.238 \mathrm{e}+05$ & $9.48 \%$ & $5.924 \mathrm{e}+04$ \\
Upper core support barrel & $9.282 \mathrm{e}+02$ & $15.66 \%$ & $1.698 \mathrm{e}+02$ \\
Lower core support barrel & $8.082 \mathrm{e}+02$ & $15.98 \%$ & $1.479 \mathrm{e}+02$ \\
Core baffle & $1.197 \mathrm{e}+06$ & $0.91 \%$ & $2.190 \mathrm{e}+05$ \\
Core barrel & $8.094 \mathrm{e}+04$ & $0.91 \%$ & $1.481 \mathrm{e}+04$ \\
Thermal shield & $1.417 \mathrm{e}+04$ & $2.14 \%$ & $2.594 \mathrm{e}+03$ \\
Pressure vessel liner & $2.287 \mathrm{e}+03$ & $5.04 \%$ & $4.184 \mathrm{e}+02$ \\
Pressure vessel & $4.715 \mathrm{e}+01$ & $6.12 \%$ & $8.627 \mathrm{e}+00$ \\
\hline
\end{tabular}


sample analysis. The tally structure could easily be modified and calculations performed for specific areas if required. However, as samples may not be representative of the full volume distribution. Samples may have higher or lower activities if they are taken from surface metal. This must be considered during the sampling process planning, and later, during the comparison to the calculated estimates.

The final column in the tables indicates the effect of decay on the results. As can be seen, the decay has only a small effect on the activities of interest due to their long half-lives (Table 1). The isotope with the shortest half-life, ${ }^{63} \mathrm{Ni}$, is only reduced by about $12 \%$ by decay. The exception to this is ${ }^{60} \mathrm{Co}$; however, ${ }^{60} \mathrm{Co}$ is not of concern in waste classification and is presented here for information only.

For informational purposes, the two large segments of the upper core support plate (UCSP) are broken out in the table. The UCSP is a complicated structure consisting of two thick flat plates connected by numerous sleeves through which the coolant water flows (Figure 7). The separation between the plates is about 5 in. While for waste purposes it is likely that the component will be segmented and material averaging will be employed, it is instructive to show the difference in the activation levels between the plates. The difference is about an order of magnitude. This difference is likely the result of the increased distance from the core and is due to the decrease in flux that occurs over that distance. It should be noted that the results presented for the entire UCSP include the activation in both of the constituent plates as well as the sleeves.

An approximate relative flux distribution in the radial direction has been plotted using results from the MCNP calculations (Figure 29). The flux distribution shown is at the axial reactor core centerline, and the plot begins radially at the outer edge of the fuel region. The fluxes are normalized such that the flux at the core boundary is unity. It can be seen that the flux levels decrease by three orders of magnitude from the edge of the core baffle to the pressure vessel, a distance of about $62 \mathrm{~cm}$. Flux decreases in the axial direction above and below the core are expected to be similar. Since activation is proportional to the flux, the activation also decreases by similar amounts for similar materials as is shown in the table results.

These flux results serve to justify the model approximations chosen that limit the overall size of the physical model, specifically in the axial direction. The results indicate that insufficient flux levels exist past $100 \mathrm{~cm}$ from the core to create activation levels that are above the Class $\mathrm{C}$ limits. Since the reactor nozzles are approximately $135 \mathrm{~cm}$ above the active core, discontinuing the model past this point is justified.

For additional information, calculations of activation ratios are presented in Table 8. These ratios may be instructive in showing the relative activation levels calculated for the base case, and could be used to estimate activation ratios for other analysis methods. These numbers are similar to the scaling factors used in other methodologies for determining waste classification. Note that the base compositions in Table 3 are used. Variations in material compositions will effect the ratios.

\subsection{Component Waste Classes}

10 CFR 61 sets forth a method for combining activity levels for different isotopes to determine the resultant waste class. The method is called the sum of the fractions rule. For a particular 


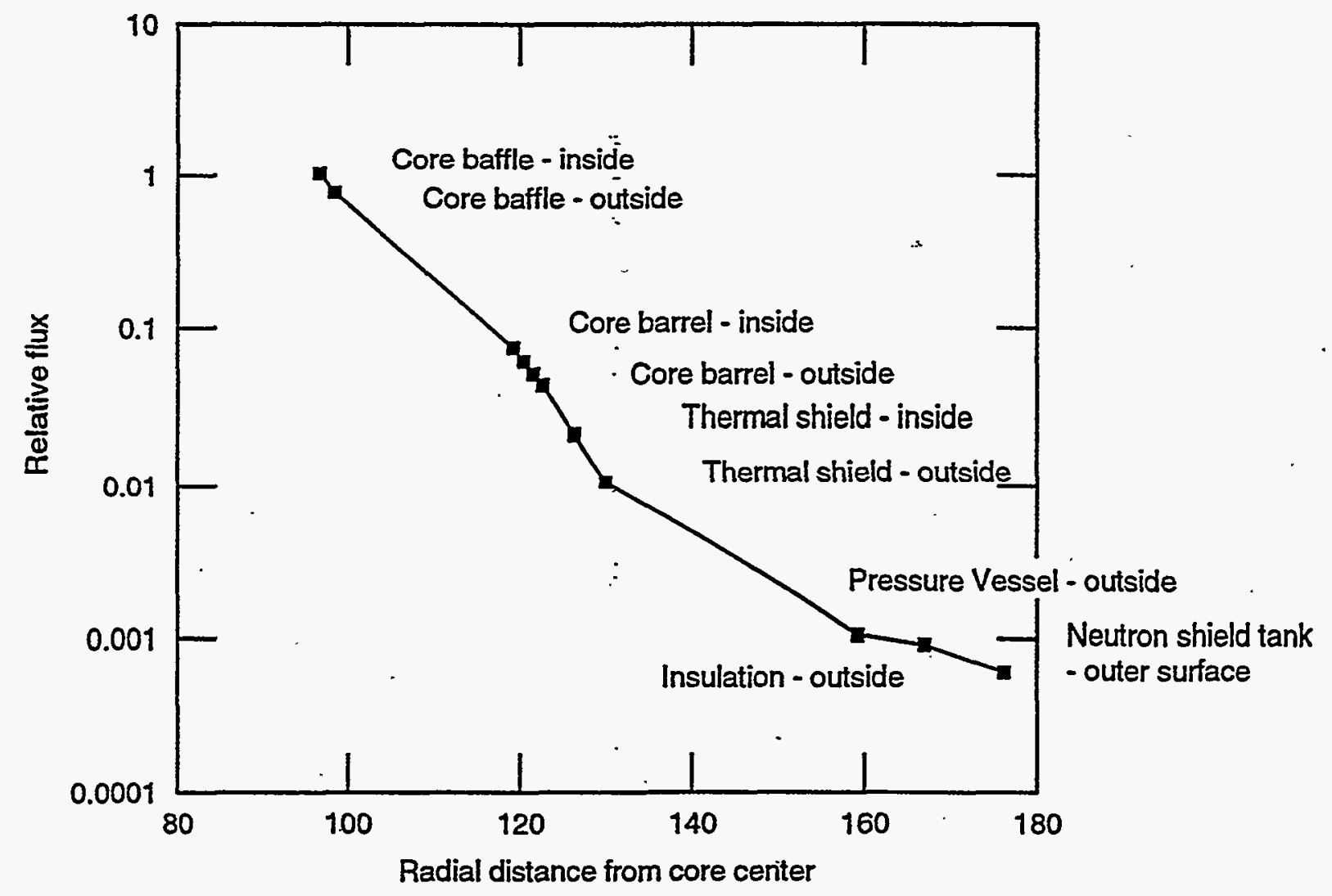

Note: Fluxes are normalized to the flux at the inner surface of the core baffle.

E95 0143

Figure 29. Radial reactor relative flux levels exterior to the active core. 
Table 8. Production rate ratios of activation products.

\begin{tabular}{lccccccc}
\hline Component & ${ }^{60} \mathrm{Co} /{ }^{19} \mathrm{Ni}$ & ${ }^{60} \mathrm{Co} /{ }^{14} \mathrm{C}$ & ${ }^{60} \mathrm{Co} /{ }^{63} \mathrm{Ni}$ & ${ }^{59} \mathrm{Ni} /{ }^{94} \mathrm{Nb}$ & ${ }^{59} \mathrm{Ni} /{ }^{14} \mathrm{C}$ & ${ }^{63} \mathrm{Ni} /{ }^{59} \mathrm{Ni}$ & ${ }^{14} \mathrm{C} /{ }^{94} \mathrm{Nb}$ \\
\hline $\begin{array}{l}\text { Upper core } \\
\text { support plate }\end{array}$ & 646 & 64,829 & 92.0 & 312.2 & 100.3 & 7.03 & 3.11 \\
$\begin{array}{l}\text { Upper core } \\
\text { support barrel }\end{array}$ & 700 & 69,163 & 96.6 & 251.8 & 98.8 & 6.98 & 2.55 \\
$\begin{array}{l}\text { Lower core } \\
\text { support barrel }\end{array}$ & 738 & 74,273 & 92.4 & 290.3 & 100.7 & 6.94 & 2.88 \\
Core baffle & 676 & 67,799 & 100.3 & 271.3 & 100.3 & 6.98 & 2.71 \\
Core barrel & 612 & 61,555 & 106.3 & 366.6 & 100.7 & 7.02 & 3.64 \\
Thermal shield & 674 & 67,054 & 96.8 & 267.3 & 99.4 & 7.00 & 2.69 \\
$\begin{array}{l}\text { Pressure vessel } \\
\text { liner }\end{array}$ & 625 & 63,395 & 87.0 & 402.4 & 101.5 & 7.05 & 3.96 \\
Pressure vessel & 8,255 & 74,135 & 96.3 & 0.3 & 9.0 & 7.82 & 0.03 \\
\hline
\end{tabular}

component, the sum of the fractions of the activity levels is determined by dividing each nuclide's concentration by the appropriate limit for that isotope. That is

$\sum$ of the fractions $\frac{\sum}{I}=\frac{A_{i}}{A_{L i}}$

where

$$
\begin{aligned}
& A_{i}=\text { activity level for isotope } I \text { in } \mathrm{Ci} / \mathrm{m}^{3} \\
& A_{L i}=\text { Class } C \text { limit for isotope } I .
\end{aligned}
$$

The isotope list is shown in Table 1. A separate calculation is performed for long-and short-lived isotopes. If the value calculated for either is greater than 1 , then the component in question is GTCC LLW.

For the purposes of this report, concentration averaging of component radioactivities is not considered. Concentration averaging of radioisotopes may occur at the time the waste is packaged for disposal. Under the rules of concentration averaging, components which individually may have activity levels which are greater than Class $C$ limits can be packaged with components with less activity (with restrictions) such that the final waste container is classified as Class C. Since any concentration averaging would be performed at the time of disposal with prescribed metal pieces, it is not possible to consider the effects of concentration averaging on the results presented in this report. Therefore, only the activation levels of individual components are presented, with the recognition that the classification presented may not be the final disposal classification because of concentration averaging considerations. 
Using this equation (Equation 2) and the calculated activities in Tables 5 and 6, an evaluation is made for each component. Tables 9 and 10 list the components, the calculated sum of the fractions, and whether the component is predicted to be activated above Class $\mathrm{C}$ limits. The calculated sum of the fractions carries through the MCNP variances to show how the calculational uncertainty might affect the waste classification. The calculational uncertainties presented would not affect the waste classification of any of the components listed.

The results of the calculations clearly indicate that the core baffle and the upper core support plate in the Yankee Rowe reactor are predicted to be activated to above Class $\mathrm{C}$ limits. Through the symmetry arguments presented in Section 3, it can also be inferred that the lower core support plate is predicted to be activated to that high level.

A particular item to note from the tables is that the primary contributor to the sum of the fractions in all cases is ${ }^{94} \mathrm{Nb}$. This result is largely due to the low concentration limit relative to the other isotopes of interest, and it indicates that the results will be particularly sensitive to variations in the concentrations of ${ }^{93} \mathrm{Nb}$ and ${ }^{94} \mathrm{Mo}$.

These predictions assume the material compositions for the base metals listed in Table 3. The effects of differing materials compositions are analyzed in the parametric studies in Appendix A.

\subsection{Monte Carlo Statistics}

The relative error has been reported in Tables 5 to 7 with each of the activation levels. This relative error is a measure of the precision of the tally and not a measure of the accuracy of the

Table 9. MCNP base case sum-of-the-fractions calculations for long-lived isotopes.

\begin{tabular}{|c|c|c|c|c|c|c|c|}
\hline \multirow[b]{2}{*}{ Component } & \multirow{2}{*}{$\frac{{ }^{94} \mathrm{Nb}}{\begin{array}{c}\text { Base } \\
\text { w/decay }\end{array}}$} & \multirow{2}{*}{$\frac{{ }^{59} \mathrm{Ni}}{\begin{array}{c}\text { Base } \\
\text { w/decay }\end{array}}$} & \multirow{2}{*}{$\frac{{ }^{14} \mathrm{C}}{\begin{array}{c}\text { Base } \\
\text { w/decay }\end{array}}$} & \multirow{2}{*}{$\frac{{ }^{99} \mathrm{Tc}}{\begin{array}{c}\text { Base } \\
\text { w/decay }\end{array}}$} & \multicolumn{2}{|c|}{ Total } & \multirow{2}{*}{$\begin{array}{c}\text { Above } \\
\text { Class C } \\
\text { limit } \\
(\mathrm{Y} / \mathrm{N})\end{array}$} \\
\hline & & & & & $\begin{array}{c}\text { Base } \\
\text { w/decay }\end{array}$ & $\begin{array}{c}\text { Statistical } \\
\text { error }\end{array}$ & \\
\hline Upper core support plate & 0.990 & 0.281 & 0.008 & 0.001 & 1.279 & $0.70 \%$ & $\mathrm{Y}$ \\
\hline UCSP-upper plate & 0.165 & 0.046 & 0.001 & 0.000 & 0.213 & $4.68 \%$ & $\mathbf{N}$ \\
\hline UCSP-lower plate & 1.535 & 0.415 & 0.011 & 0.001 & 1.962 & $9.23 \%$ & $\mathrm{Y}$ \\
\hline Upper core support barrel & 0.005 & 0.001 & 0.000 & 0.000 & 0.006 & $9.83 \%$ & $\mathbf{N}$ \\
\hline $\begin{array}{l}\text { Lower core support } \\
\text { barrel }\end{array}$ & 0.003 & 0.001 & 0.000 & 0.000 & 0.004 & $10.77 \%$ & $\mathbf{N}$ \\
\hline Core baffle & 5.970 & 1.473 & 0.040 & 0.004 & 7.487 & $0.61 \%$ & $\mathrm{Y}$ \\
\hline Core barrel & 0.330 & 0.110 & 0.003 & 0.000 & 0.444 & $0.59 \%$ & $\mathrm{~N}$ \\
\hline Thermal shield & 0.072 & 0.017 & 0.000 & 0.000 & 0.090 & $1.37 \%$ & $\mathrm{~N}$ \\
\hline Pressure vessel liner & 0.008 & 0.003 & 0.000 & 0.000 & 0.011 & $3.32 \%$ & $\mathrm{~N}$ \\
\hline Pressure vessel & 0.021 & 0.000 & 0.000 & 0.000 & 0.021 & $11.96 \%$ & $\mathrm{~N}$ \\
\hline
\end{tabular}


Table 10. MCNP base case sum-of-the-fractions calculation for short-lived isotopes.

\begin{tabular}{lcc}
\hline \multicolumn{1}{c}{ Component } & $\begin{array}{c}{ }^{63} \mathrm{Ni} \\
\text { Base w/decay }\end{array}$ & $\begin{array}{c}\text { Above Class } \\
\mathrm{C} \text { limit } \\
(\mathrm{Y} / \mathrm{N})\end{array}$ \\
\cline { 2 - 3 } Upper core support plate & 0.062 & $\mathrm{~N}$ \\
UCSP-upper plate & 0.010 & $\mathrm{~N}$ \\
UCSP-lower plate & 0.092 & $\mathrm{~N}$ \\
Upper core support barrel & 0.000 & $\mathrm{~N}$ \\
Lower core support barrel & 0.000 & $\mathrm{~N}$ \\
Core baffle & 0.323 & $\mathrm{~N}$ \\
Core barrel & 0.024 & $\mathrm{~N}$ \\
Thermal shield & 0.004 & $\mathrm{~N}$ \\
Pressure vessel liner & 0.001 & $\mathrm{~N}$ \\
Pressure vessel & 0.000 & $\mathrm{~N}$ \\
\hline
\end{tabular}

result. Specifically, the relative error is a measure of $1 \sigma$ (one standard deviation) from the tally mean. Therefore, though the scatter of the results may be small relative to each other, no determination of the absolute accuracy of the results has been made. To properly validate the analytical results, a component sampling program should be carried out for comparison. The calculational method used in many cases divided components into subregions. These divisions were made for ease of modeling. Since MCNP reports results for each region defined in the input, the subregion results had to be combined to report results for complete components. This process required both the combination of the results and the statistical errors. These combinations were also required to determine the sum of the fractions. In all cases, the results were added appropriately, and the statistical errors $(\sigma)$ were combined using the square root of the sums of the squares method.

Many of the tallies have converged to less than 5\% relative error, which is considered a tight convergence. As a rule of thumb, a relative error greater than $10 \%$ is considered marginal in regions of interest. Several isotopes in some components show considerably larger than $10 \%$ error.

Generally, these isotopes are in components that are a significant distance from the active core or are isotopes for which the initial fraction in the base metal is extraordinarily small. The increased error in the calculations arise because a component far from the active core "sees" a fewer number of neutrons in the calculation, and the smaller statistical sample causes an increased margin of error. For isotopes with extremely small initial fractions, fewer interactions are calculated because of the small number; therefore, the small statistical sample again has an increased error margin. Since the errors in these components or isotopes do not affect the waste classification of the component, achieving smaller errors in these cases is not a particular concern.

In addition to the relative error in the tally distribution, it is important to understand the behavior of the distribution when analyzing the results. The behavior should be normal, smooth, and 
convergent, without large or divergent oscillations. The latter behavior can denote results for which statistical errors may be large, even though the relative error in the tally is small. The MCNP code output provides information on the behavior of the distribution functions that is not explicitly presented in this report, but to which careful consideration has been given when presenting the results.

\subsection{Calculational Difficulties/Problem Areas}

Several calculational problems have been encountered during the development of the MCNP model. Most of these difficulties are associated with (a) the overall size of the problem being modeled, (b) computer code limitations that were encountered due to the problem size, and (c) a modeling approximation that has been identified which may affect the extrapolation of the results to other reactor facilities.

Difficulty was encountered in obtaining sufficiently accurate statistics in far-core components (distances greater than a few inches from the active core) to meet calculational needs. The MCNP tallies degrade significantly, especially at points 1 foot or more from the active core. This degradation is a result of the physical size of the problem. Relative to the in-core regions, the number of neutrons that reach the outer areas of the core can be ten orders of magnitude less. The number of neutron generations required to get enough neutrons into the far-core regions and, therefore, the amount of computer time required, is very large. To obtain the results with the statistics listed in the tables, 15 million particles had to be run.

During the modeling effort, computer code limits were encountered that needed to be adjusted to run the large model. The resulting model of the $1 / 8$, top-half core model required approximately 8,000 regions in MCNP. The model required that MCNP code dimensions be expanded to run with a memory of 15 million words and 300 words per cell description.

One modeling approximation has been identified that is unlikely to significantly affect the results obtained for the Yankee Rowe facility, but which may affect the ability to extrapolate the results to other reactor facilities. The fuel pins were modeled as having fuel pellets to the ends of the fuel rods. Actual fuel pins contain a plenum space above and below the fuel pellets that is filled with gas and spring material. In the fuel pins, this plenum space may cause a streaming effect that would cause an increase in the activation of the support plates above and below the core.

In the case of the Yankee Rowe support plates, the predictions indicate that these components are activated to levels above Class $\mathrm{C}$ limits. Addition of the streaming effect in the fuel pins would therefore not affect the waste classification of the support plates. If the support plates in other reactors were found to be activated to slightly below the Class $C$ limits while neglecting streaming, however, the inclusion of this effect in the model could alter the waste classification.

\subsection{Extrapolation of Results to Other PWRS}

As discussed in Section 2.4.1, the Yankee Rowe reactor is somewhat atypical of U.S. PWRs because of its relative size. There are several considerations that must be taken into account before the results presented here can be extrapolated to other facilities. To assess the degree to which the 
results may be extrapolated, the Yankee Rowe reactor was compared to more typical PWR facility, and the effects of the differences estimated.

The Yankee Rowe reactor is small (600 MWt) compared to most other PWRs, which are generally in the 2,400 to 3,600 MWt range. The increased power output and flux of larger reactors would have a significant effect on activation levels. The larger power reactors also have larger internal components that would also affect the specific activity.

Since component distance from the active core directly affects activity levels, this must also be considered in the extrapolation. Additionally, reactor operating history differences would also influence the extrapolation. Yankee Rowe operated for its entire life with a high-leakage core. Many other reactor facilities have operated for much of their lives with low-leakage cores. Additionally, Yankee Rowe operated for a considerably shorter time that would be expected of other PWRs.

Examination of the activity levels in the Yankee Rowe core baffle indicates that the levels are much higher than the limits for Class $\mathrm{C}$ waste. The core baffles of all PWR cores lie essentially at the core boundary; therefore, it is not expected that the distance from the core would have a great effect on the waste classification. Additionally, most baffles are made of stainless steel, so it would also not be expected that base material differences would affect the classification. The initial trace isotope content may be of concern; however, the parametric studies indicate that if the trace element concentrations are within the accepted ranges for stainless steel, this consideration would not change the waste classification of the component. It could reasonably be assumed, therefore, that the Yankee Rowe results for the core baffle can be extrapolated to other PWR facilities, and that all core baffles will be activated to levels above the Class $C$ limits.

The parametric studies in Appendix A indicate that the relative distance of the reactor component to the active core can have a large impact on activation levels. For the Yankee Rowe reactor, comparison of the results in Tables A-10 to A-12 to those of Tables 5 to 7 show that increasing the internal radius of the core barrel by only $1 / 2$ in. can lead to a $12-20 \%$ change in activity levels.

The core barrel of the Yankee Rowe reactor is approximately 7 in. from the active core. For a more typical PWR, this value is about 8 in. from the active core. This differing distance would clearly have an effect on activation levels in the barrel, and, if the parametric results were extrapolated directly, could lead to a $40 \%$ reduction in the activation levels due to the distance alone.

When considering the core barrel, it is also important to consider the operating history. A lowleakage core would cause a decrease in activation levels, whereas the effects of a high leakage scheme could be better extrapolated from the Yankee Rowe results. Many reactors have used low-leakage fuel loading schemes to reduce the fast neutron flux to the pressure vessel. Additionally, some consideration of the difference in operating times (EFPY) must be made to obtain a valid extrapolation. Extrapolating the Yankee Rowe results to 30 EFPY of operation would result in about a $30 \%$ increase in activation levels.

While the results show that the reactor core barrel is relatively far from the Class $\mathrm{C}$ limit (more than a factor of 2), a general extrapolation to other reactors without specific consideration for reactorspecific characteristics cannot be made. Even considering the factors mentioned above, it would be 
possible for the ${ }^{94} \mathrm{Nb}$ concentration variations alone (Appendix A) to alter the classification of the barrel.

An argument similar to that of the core barrel can be used for extrapolation of the upper core support plate classification. The Yankee Rowe support plates are about 5 to 11 in. above/below the active core. This span compares to a range of 5 to $10 \mathrm{in}$. in a more typical size PWR. The similarity in distances in this case would indicate that similar activation levels could result. With the support plates, the fuel management scheme used is not as important a factor since control of axial leakage was generally not as high a priority as control of radial leakage.

Since the core support plates in Yankee Rowe and larger PWRs are approximately the same distance from the core and the Yankee Rowe plates are predicted to be activated to levels above Class C limits, it is likely that all upper and lower core support plates in other PWR reactors will be activated to such a high level. PWRs which have longer operating times than Yankee Rowe will have even higher activities than Yankee Rowe. Specific material compositions found in individual reactor materials will affect the degree to which the components exceed the Class $\mathrm{C}$ limit; however, it is considered unlikely that niobium levels in the material will be low enough to alter the classification.

The activation of thermal shields and the pressure vessel are not likely to be a problem for most PWRs. The Yankee Rowe thermal shield and pressure vessel are predicted to have activity levels well below the Class $C$ limit. Some reactors do not have a thermal shield, or the shield has been removed or replaced during the operating life. The shield and pressure vessels in larger reactors are also farther from the active core than the Yankee components and may, therefore, be expected to have even lower activations in the case of the higher leakage cores.

\subsection{Validation With Measured Data}

The accuracy of the model and the calculations can only be assured if the model is validated with experimental data from component sampling. A component sampling plan that would serve to validate this model of the Yankee Rowe reactor is found in Appendix B. 


\section{CONCLUSIONS}

\subsection{Analysis Conclusions for Yankee Rowe}

The base MCNP analysis of the Yankee Rowe reactor predicts that the core baffle and the upper and lower core support plates will clearly be activated to levels above Class $C$ limits. It is clear from the parametric studies, however, that the uncertainty in the variations of the base metal material compositions is the predominant uncertainty in the conclusion results. If the lower limit of the material composition ranges were assumed, none of the components would be activated to above Class $C$ except for the core baffle. It is, however, considered unlikely that this would be the case and, therefore, it is considered highly likely that the upper and lower support plates also exceed Class C limits.

The reactor core barrel is predicted to be Class $C$ waste; however the uncertainty in material composition serves to make any prediction suspect without accurate knowledge of the concentrations of ${ }^{93} \mathrm{Nb}$ and ${ }^{94} \mathrm{Mo}$ in the base metal. The possible margin of error in this case indicates that the core barrel may be activated to above Class $C$ limits and, therefore, the results of this analysis are inconclusive.

All other large Yankee Rowe reactor components that were examined should be Class $C$ waste or lower. It appears unlikely that variations in material compositions or other input parameters would have any effect on the classifications for the thermal shield. All other components are predicted to have substantially less activation than the thermal shield, so this would likewise be true of these other components.

\subsection{Extrapolation of Results to Other PWRS}

Extrapolation of the analysis results to other PWR facilities would indicate that all core baffles and core support plates should be activated to levels above Class $C$ limits. Material and operating variations are not likely to affect the waste classification of these components unless the parent nuclides of Class $\mathrm{C}$ isotopes are found to be at the extreme low end of the composition ranges.

The waste classification of core barrels from other PWRs cannot be easily determined from the results of this study. Specific reactor material composition of the components in question would govern the classification of these components in other reactor facilities. The results of this study can be of aid in determining classifications if these specific items are accounted for.

Extrapolation of the results of this study, including the parametric calculations, to thermal shields, pressure vessels, and other large components far from the core indicate that they would not be GTCC LLW.

\subsection{Generic Applicability of the Analysis Methodology}

The analysis methodology described herein utilizes MCNP as a tool for predicting activation in far-core components in nuclear reactor cores. MCNP has the flexibility to model most reactor geometries accurately, and the methodology can be applied to any reactor facility. While most U.S. 
reactors have unique designs, the methodology presented could be adapted for use with any design as long as enough design information exists to build a sufficiently accurate reactor model. However, since many reactors fall into categorical reactor types, these types can be grouped (Westinghouse 1000 MWe PWRs, BWRs, etc.) and general models for the type can be developed to analyze waste streams.

Since parametric studies can be performed for each reactor type, the effect of differing operating conditions can be investigated and conclusions drawn as to the effect on waste classification. Within each type, therefore, sufficient analytical information can be generated to estimate the waste streams from any given reactor.

Like all analysis methodologies, however, the results can only be as accurate as the input to the model. The uncertainties in material composition data affect all analysis methodologies in a similar fashion, and is the most unknown factor in the determination of component waste classifications. 


\section{REFERENCES}

1. 10 CFR 61. U.S. Nuclear Regulatory Commission, "Licensing Requirements for Land Disposal of Radioactive Waste." 1992.

2. Los Alamos National Laboratory. MCNP4-Monte Carlo Neutron and Photon Transport Code System Users Manual. Los Alamos, New Mexico. 1990.

3. Idaho National Engineering Laboratory. Greater-Than-Class C Low-Level Radioactive Waste Characterization: Estimated Volumes, Radionuclide Activities, and Other Characteristics. DOE/LLW-114 Rev. 1. Idaho Falls, Idaho. 1994.

4. Nuclear Regulatory Commission. Evaluations of Uncertainties in Irradiated Hardware Characterization. NUREG/CR-4968. 1987.

5. J. E. Cline \& Associates, Inc. Characterization Of Decommissioned Reactor Internals: DirectAssay Method Assessment. DOE/LLW-161, Rockville, Maryland. 1993.

6. Reid, B. D., E. F. Love, and A. T. Luksic. Characterization of Decommissioned Reactor Internals: Monte Carlo Analysis Technique. DOE/LLW-171, Prepared for Idaho National Engineering Laboratory by Battelle, Pacific Northwest Laboratory, Richland, Washington. 1993.

7. Oak Ridge National Laboratory. Application of the LEPRICON Methodology to the Arkansas Nuclear One, Unit 1 Reactor. EPRI NP-4469. 1986.

8. Butler, J. et al. The PCA Replica Experiment Part 1. AEEW-R 1796, Winfrith, United Kingdom. 1984.

9. Sitaraman, S. "Benchmarking Study of the MCNP Code Against Cold Critical Experiments." In proceedings of 1991 Annual Meeting of the American Nuclear Society in Orlando, Florida, June 2-6, 1991. 1991.

10. Garger, D. ed. "ENDF/B-V," BNL-17541 (ENDF-201), National Nuclear Data Center. Brookhaven National Laboratory, Upton, New York. 1975.

11. Georgia Power Company. Vogtle Nuclear Generating Station Unit 1 and 2 Final Safety Analysis Report. Revision 2. 1992.

12. Westinghouse Electric Corporation. "Large Pressurized Water Nuclear Power Plant Reactor General Assembly." Drawing Number 646J692. 1960.

13. Gubbins, M. E. et al. "A General Introduction To The Use Of The WIMS-E Modular Program." AEEW-R 1329, Winfrith, Dorset, United Kingdom. 1982. 
14. Luksic, A. T. Spent Fuel Assembly Hardware: Characterization and 10 CFR 61 Classification for Waste Disposal. PNL-6906, Richland, Washington. 1989. 
Appendix A

Parametric Studies

A-1 


\section{Appendix A}

\section{Parametric Studies}

As with any set of data and any computer model, some uncertainties may be present.

Uncertainties in material compositions, as-built reactor dimensions, and operational parameters could affect the results of activation calculations. The purpose of parametric studies is to estimate the range of activation uncertainty that may result from data uncertainties and how this may impact the waste classification of the internal components.

In addition to the data uncertainties, it is desirable to extrapolate the results of the activation analysis of Yankee Rowe to other PWRs. One of the criteria in selecting the Yankee Rowe reactor for this study was that it is representative enough of other PWRs in the U.S. to allow extrapolation of the Yankee Rowe results. However, the Yankee Rowe reactor is atypical in that it is smaller than most reactors, and hence the spacing of the internal components is not representative of most reactors. The reactor is likely to have had a different type of operating history than other reactors. Performing parametric studies on a key set of parameters can provide valuable insight into the possible effects that design and operational differences may have on the activation of components in other PWRs.

\section{A-1. PARAMETER SELECTION}

To better provide for the evaluation of data uncertainties and for the extension of the predictive capability of the MCNP model to other reactor types, a set of parametric calculations was performed for the Yankee Rowe reactor. The parameters chosen for the study were designed to address known areas of uncertainty, and known differences between the Yankee Rowe reactor and other reactors.

A considerable number of parameters could be addressed for parametric calculations. Specific examples include the effects of homogenization of the inner core, the effects of average core loading, water density, fuel burnup, metal compositions, mechanical effects (expansion, creep, etc.), and irradiation time. For this study, just a few of these parameters were analyzed. The parameters chosen were considered to have some of the most significant uncertainties associated with them. These parameters are identified and described below.

\section{A-1.1 Material Compositions}

The elemental compositions of the various metallic components of stainless steel and carbon steel are known to vary. This variation directly affects the activation calculations of components in Yankee Rowe.

Tables A-1 and A-2 list the material composition variations within stainless and carbon steel. The tables were provided by YAEC from reference sources. To study the effects of the variations in material composition, the high and low ranges specified for the parent elements of interest were evaluated to establish the activation ranges that may occur. Where certain isotopes (e.g., carbon) are 
Table A-1. Isotopic constituents of stainless steel 304 (Reference A1).

\begin{tabular}{|c|c|c|c|c|c|c|}
\hline \multicolumn{2}{|c|}{ Element } & \multirow{2}{*}{$\begin{array}{r}\text { Average } \\
0.13\end{array}$} & \multirow{2}{*}{$\begin{array}{l}\begin{array}{l}\text { S.D. } \\
(\%)\end{array} \\
-\end{array}$} & \multirow{2}{*}{$\begin{array}{c}\text { Range } \\
-\end{array}$} & \multirow{2}{*}{$\begin{array}{c}\begin{array}{l}\text { Range } \\
\text { factor }^{\mathrm{b}}\end{array} \\
-\end{array}$} & \multirow{2}{*}{$\begin{array}{c}\begin{array}{c}\text { Number of } \\
\text { measurements } \\
\text { used }\end{array} \\
1\end{array}$} \\
\hline $\mathrm{Li}$ & $\mathrm{ppm}$ & & & & & \\
\hline $\mathrm{N}$ & $\mathrm{ppm}$ & $452 \pm 64$ & 14 & 402 to 525 & 1.3 & 3 \\
\hline $\mathrm{Na}$ & $\mathrm{ppm}$ & $9.7 \pm 12.2$ & 126 & 3 to 37 & 12.3 & 7 \\
\hline $\mathrm{Al}$ & $\mathrm{ppm}$ & 100 & - & $<50$ to 200 . & - & 6 \\
\hline $\mathrm{Cl}$ & $\mathrm{ppm}$ & 70 & - & $<50$ to 130 & - & 5 \\
\hline $\mathrm{K}$ & $\mathrm{ppm}$ & $<3$ & - & - & - & 3 \\
\hline $\mathrm{Ca}$ & $\mathrm{ppm}$ & 19 & - & - & - & 1 \\
\hline Sc & $\mathrm{ppm}$ & $<0.03$ & - & - & - & 1 \\
\hline $\mathrm{Ti}$ & $\mathrm{ppm}$ & $<600$ & - & - & - & 10 \\
\hline V & $\mathrm{ppm}$ & $456 \pm 235$ & 52 & 140 to 690 & 4.90 & 9 \\
\hline $\mathrm{Cr}$ & $\%$ & $18.4 \pm 1.1$ & 6 & 16.5 to 20.2 & 0.2 & 13 \\
\hline $\mathrm{Mn}$ & $\%$ & $1.53 \pm 0.27$ & 18 & 1.11 to 1.76 & 1.6 & 13 \\
\hline $\mathrm{Fe}$ & $-\%$ & $70.6 \pm 2.6$ & 4 & 68.0 to 76.7 & 1.1 & 13 \\
\hline $\mathrm{Co}$ & $\mathrm{ppm}$ & $1414 \pm 800$ & 57 & 229 to 2570 & 11.2 & 8 \\
\hline $\mathrm{Ni}$ & $\%$ & $10.0 \pm 0.7$ & 7 & 8.8 to 11.0 & 1.3 & 13 \\
\hline $\mathrm{Cu}$ & ppm & $3080 \pm 2270$ & 74 & 300 to 8150 & 27.2 & 13 \\
\hline $\mathrm{Zn}$ & ppm & $457 \pm 717$ & 157 & $<15$ to 2230 & $>1.3$ & 12 \\
\hline $\mathrm{Ga}$ & $\mathrm{ppm}$ & $129 \pm 143$ & 90 & $<40$ to 450 & $>11.3$ & 13 \\
\hline As & ppm & $194 \pm 259$ & 168 & $<57$ to 1010 & $>17.7$ & 13 \\
\hline $\mathrm{Se}$ & ppm & $\approx 35$ & - & $<2$ to 70 & $>35$ & 13 \\
\hline $\mathrm{Be}$ & ppm & $\sim 2$ & - & $<0.9$ to 8.0 & 78.9 & 8 \\
\hline R. & ppm & $<10$ & - & - & - & 9 \\
\hline $\mathrm{Sr}$ & ppm & 0.2 & - & - & - & 1 \\
\hline $\mathrm{Y}$ & $\mathrm{ppm}$ & $<5$ & - & - & - & 12 \\
\hline $\mathrm{Z}$ & $\mathrm{ppm}$ & $\approx 10$ & - & $<4$ to 20 & - & 13 \\
\hline $\mathrm{Nb}$ & ppm & $89 \pm 90$ & 101 & $<5$ to 300 & $>60$ & 13 \\
\hline Mo & ppm & $02.600 \pm 1500$ & 58 & 80 to 5500 & 68.8 & 13 \\
\hline $\mathrm{Ag}$ & $\mathrm{ppm}$ & $<2$ & - & - & - & 8 \\
\hline $\mathrm{Sb}$ & $\mathrm{ppm}$ & $12-3 \pm 3.8$ & 31 & 6.9 to 17.0 & -2.5 & 8 \\
\hline Cs & ppm & $<0.3$ & - & - & - & 5 \\
\hline $\mathrm{Ba}$ & ppm & $<500$ & - & - & - & 8 \\
\hline $\mathrm{La}$ & ppm & $\approx 0.2$ & - & $<0.05$ to 2.1 & $>42.00$ & 8 \\
\hline $\mathrm{Ce}$ & ppm & $371 \pm 212$ & 57 & $<2$ to 550 & $>275.0$ & 8 \\
\hline $\mathrm{Sm}$ & $\mathrm{ppm}$ & $\approx 0.1$ & - & $<0.05$ to 0.15 & $>3$ & 7 \\
\hline $\mathrm{Eu}$ & ppm & $\approx 0.02$ & - & - & - & Inferred \\
\hline
\end{tabular}


Table A-1. (continued).

Number of

S.D. ${ }^{2}$

\begin{tabular}{llcc}
\multicolumn{2}{c}{ Element } & Average & $(\%)$ \\
\hline Tb & ppm & $0.47 \pm 0.25$ & 53 \\
$\mathrm{Dy}$ & $\mathrm{ppm}$ & $<1$ & - \\
$\mathrm{Ho}$ & $\mathrm{ppm}$ & $<1$ & - \\
$\mathrm{Yb}$ & $\mathrm{ppm}$ & $<2$ & - \\
$\mathrm{Lu}$ & $\mathrm{ppm}$ & $<0.8$ & - \\
$\mathrm{Hf}$ & $\mathrm{ppm}$ & $<2$ & - \\
$\mathrm{W}$ & $\mathrm{ppm}$ & $186 \pm 149$ & 80 \\
$\mathrm{~Pb}$ & $\mathrm{ppm}$ & $67 \pm 50$ & 75 \\
Th & $\mathrm{ppm}$ & $<1$ & - \\
$\mathrm{U}$ & $\mathrm{ppm}$ & $<2$ & - \\
\hline
\end{tabular}

(\%)

53
-
-
-
-
80
75
-
-

Range

factor $^{b}$ measurements

used

a. Relative standard deviation expressed as a percentage of the average value.

b. Range factor shown is the ratio of the highest to the lowest value measured.

Table A-2. Isotopic constituents of carbon steel (Reference A1).

\begin{tabular}{|c|c|c|c|c|c|}
\hline Element & Average & $\begin{array}{l}\text { S.D. } \\
(\%)\end{array}$ & Range & $\begin{array}{l}\text { Range } \\
\text { factor }^{\mathrm{b}}\end{array}$ & $\begin{array}{c}\text { Number of } \\
\text { measurements } \\
\text { used }\end{array}$ \\
\hline $\mathrm{Li}^{-} \mathrm{ppm}$ & 0.30 & - & - & - & 1 \\
\hline $\mathrm{N} \quad \mathrm{ppm}$ & 84 & - & - & - & 1 \\
\hline $\mathrm{Na}$ ppm & $23 \pm 24$ & 102 & 6.6 to 40 & 6.1 & 2 \\
\hline Al ppm & $0.330 \pm 400$ & 102 & $<50$ to 613 & 712 & 2 \\
\hline $\mathrm{ppm}$ & 40 & - & - & - & 1 \\
\hline $\mathrm{K} \quad \mathrm{ppm}$ & $12 \pm 12$ & 100 & $<3$ to 20 & - & 2 \\
\hline $\mathrm{Ca}$ ppm & 14 & - & - & - & 1 \\
\hline Sc ppm & 0.26 & - & - & - & 1 \\
\hline $\mathrm{ppm}$ & $<2$ & - & - & - & 1 \\
\hline $\mathrm{V} \quad \mathrm{ppm}$ & $<80$ & - & $<30$ to 90 & - & 10 \\
\hline $\mathrm{Cr} \%$ & $0.17 \pm 0.13$ & - & 0.06 to 0.36 & - & 10 \\
\hline Mn \% & $1.02 \pm 0.41$ & - & 0.2 to 1.49 & - & 10 \\
\hline $\mathrm{Fe} \%$ & 98 & - & - & - & 10 \\
\hline Co $\mathrm{ppm}$ & $122 \pm 41$ & 34 & 93 to 151 & - & 2 \\
\hline $\mathrm{Ni} \%$ & $0.66 \pm 0.13$ & 20 & $<0.3$ to 0.76 & - & 10 \\
\hline
\end{tabular}


Table A-2. (continued).

\begin{tabular}{|c|c|c|c|c|c|}
\hline Element & Average & $\begin{array}{c}\text { S.D. } \\
(\%)\end{array}$ & Range & $\begin{array}{l}\text { Range } \\
\text { factor }^{b}\end{array}$ & $\begin{array}{c}\text { Number of } \\
\text { measurements } \\
\text { used }\end{array}$ \\
\hline $\mathrm{Cu}$ ppm & $1274 \pm 400$ & 31 & 675 to 1900 & - & 10 \\
\hline $\mathrm{Zn}$ ppm & $\approx 100$ & - & $<4$ to 210 & 753 & 10 \\
\hline $\mathrm{Ga}$ ppm & $\approx 80$ & - & $<20$ to 300 & - & 10 \\
\hline As ppm & $532 \pm 1085$ & 204 & 50 to 3600 & 72.0 & 10 \\
\hline Se ppm & 0.7 & - & - & - & 1 \\
\hline $\mathrm{Br} \quad \mathrm{ppm}$ & 0.85 & - & - & - & 1 \\
\hline $\mathrm{Rb}$ ppm & $48 \pm 35$ & - & 23 to 72 & - & 2 \\
\hline Sr ppm & 0.15 & - & - & - & 1 \\
\hline $\mathrm{Y} \quad \mathrm{ppm}$ & $<20$ & - & - & - & 10 \\
\hline $\mathrm{Zr} \quad \mathrm{ppm}$ & $<10$ & - & - & - & 10 \\
\hline $\mathrm{Nb}$ ppm & $18.8 \pm 12.2$ & 65 & $<8$ to 40 & - & 10 \\
\hline Mo ppm & $0.56 \pm 0.05$ & 10 & 0.45 to 0.63 & - & 10 \\
\hline Ag ppm & $<2$ & - & - & - & 1 \\
\hline $\mathrm{Sb} \quad \mathrm{ppm}$ & $11 \pm 7$ & 64 & 6.1 to 16 & - & 2 \\
\hline Cs ppm & $<0.2$ & - & - & - & 1 \\
\hline La ppm & 0.10 & - & - & - & 1 \\
\hline $\mathrm{Ba} \quad \mathrm{ppm}$ & 273 & - & - & - & 1 \\
\hline $\mathrm{Ce}$ ppm & $<1$ & - & - & - & 1 \\
\hline Sm ppm & 0.017 & - & - & - & 1 \\
\hline $\mathrm{Eu}$ ppm & 0.031 & - & - & - & 1 \\
\hline $\mathrm{Tb} \mathrm{ppm}$ & 0.45 & - & - & - & 1 \\
\hline Dy ppm & - & - & - & - & - \\
\hline Ho ppm & $<0.8$ & - & - & - & 2 \\
\hline $\mathrm{Yb} \mathrm{ppm}$ & $<1$ & - & - & - & 2 \\
\hline Lu ppm & $<0.2$ & - & - & - & 2 \\
\hline Hf $\mathrm{ppm}$ & 0.21 & - & - & - & 1 \\
\hline Ta ppm & 0.13 & - & - & - & 1 \\
\hline W ppm & $5.5 \pm 0.6$ & - & - & - & 2 \\
\hline $\mathrm{Pb}$ ppm & $820 \pm 2430$ & 一 & - & - & 10 \\
\hline Th ppm & 0.18 & - & - & - & 1 \\
\hline $\mathrm{U} \quad \mathrm{ppm}$ & 0.20 & - & - & - & 1 \\
\hline
\end{tabular}


not listed in these tables, the base values from Table 3 are used with a variation of about $10 \%$ in concentration. The concentration ranges considered are found in Tables $A-3$ and $A-4$. The values in these tables are taken from Tables $3, \mathrm{~A}-1$, and A-2; however, the units were converted to be selfconsistent. The base calculation concentrations are shown in the table for comparison. Note that for some isotopes, the ranges in these tables are not self-consistent with the base numbers. This is because trace quantities of some parent isotopes had to be assumed for the base analysis before further data was received from Yankee.

Table A-3. Concentration ranges of GTCC parent elements in carbon steel (weight fractions).

\begin{tabular}{cccc}
\hline Element & $\begin{array}{c}\text { Base case } \\
\text { concentration }\end{array}$ & $\begin{array}{c}\text { Lower } \\
\text { bound }\end{array}$ & Upper bound \\
\hline $\mathrm{Nb}$ & $1.00 \mathrm{e}-04$ & $8.00 \mathrm{e}-06$ & $4.00 \mathrm{e}-05$ \\
$\mathrm{Co}$ & $1.00 \mathrm{e}-04$ & $9.30 \mathrm{e}-05$ & $1.51 \mathrm{e}-04$ \\
$\mathrm{C}$ & $2.20 \mathrm{e}-03$ & $1.98 \mathrm{e}-03$ & $2.42 \mathrm{e}-03$ \\
$\mathrm{Ni}$ & $7.00 \mathrm{e}-03$ & $3.00 \mathrm{e}-03$ & $7.60 \mathrm{e}-03$ \\
$\mathrm{Mo}$ & $1.00 \mathrm{e}-04$ & $4.50 \mathrm{e}-07$ & $6.30 \mathrm{e}-07$ \\
$\mathrm{Cu}$ & $1.90 \mathrm{e}-03$ & $6.75 \mathrm{e}-04$ & $1.90 \mathrm{e}-03$ \\
$\mathrm{~N}$ & $1.00 \mathrm{e}-04$ & $8.40 \mathrm{e}-05$ & $8.40 \mathrm{e}-05$
\end{tabular}

Note that trace concentrations (1.0e-4) were assumed for $\mathrm{Nb}, \mathrm{Co}, \mathrm{Mo}$, and $\mathrm{N}$ as Yankee did not provide values in Table 3. No concentration range for $\mathrm{N}$ is provided in Table A-2.

Table A-4. Concentration ranges of GTCC parent elements in stainless steel (weight fractions).

\begin{tabular}{cccc}
\hline Element & $\begin{array}{c}\text { Base case } \\
\text { concentration }\end{array}$ & Lower bound & Upper bound \\
\hline $\mathrm{Nb}$ & $1.00 \mathrm{e}-04$ & $5.00 \mathrm{e}-06$ & $3.00 \mathrm{e}-04$ \\
$\mathrm{Co}$ & $1.41 \mathrm{e}-03$ & $2.29 \mathrm{e}-04$ & $2.57 \mathrm{e}-03$ \\
$\mathrm{C}$ & $8.00 \mathrm{e}-04$ & $7.20 \mathrm{e}-04$ & $8.80 \mathrm{e}-04$ \\
$\mathrm{Ni}$ & $9.20 \mathrm{e}-02$ & $8.80 \mathrm{e}-02$ & $1.10 \mathrm{e}-01$ \\
$\mathrm{Mo}$ & $1.00 \mathrm{e}-04$ & $8.00 \mathrm{e}-05$ & $5.50 \mathrm{e}-03$ \\
$\mathrm{Cu}$ & $1.00 \mathrm{e}-04$ & $3.00 \mathrm{e}-04$ & $8.15 \mathrm{e}-03$ \\
$\mathrm{~N}$ & $1.00 \mathrm{e}-03$ & $4.02 \mathrm{e}-04$ & $5.25 \mathrm{e}-04$
\end{tabular}

Note that trace concentrations (1.0e-4) were assumed for $\mathrm{Nb}, \mathrm{Mo}$, and $\mathrm{Cu}$ as Yankee did not provide values in Table 3. 


\section{A-1.2 Component Distance From the Active Core}

Outside of the active core, the neutron flux falls off significantly with distance. As is shown in Figure 29, the reduction in flux can be an order of magnitude over just a few centimeters of water. Since activation is proportional to the flux and spectrum in the region near the component, variations in the distance from the active core can significantly affect the activation calculations.

To estimate the effects of distance on activation, the core barrel radial dimensions were increased by $1.27 \mathrm{~cm}(0.5 \mathrm{in}$.). This effectively moves the barrel farther from the core. MCNP was then used to recalculate the activation in the core barrel, and this calculation is compared to the base case.

This parametric calculation serves to illustrate the possible effects of variations in component sizes in the core. The as-built sizes of the components may not exactly match design drawings. For example, it was found that the core barrel in Yankee Rowe was $1 / 2$ in. thicker than indicated on the design drawings. In addition, thermal cycling and irradiation may affect the size of internal components. Thermal expansion normally occurs in metals during temperature changes. For a large component, such as the core barrel, the radius can change by a centimeter or more during heat up to plant operating temperature. Additionally, thermal cycling and irradiation damage can induce stresses in the metal that slightly deform the component over time. Again, the deformations may be on the order of a centimeter. It is useful to assess the sensitivity of the activation calculations to such changes in size.

Other PWRs may have core barrels or other components that are slightly farther or closer to the core than the Yankee Rowe components. The results of this parametric calculation can also aid in the extrapolation of the Yankee Rowe results to those of other reactor facilities.

\section{A-1.3 Irradiation Time}

Reactor operating times have an effect on the total activation of the components. The Yankee Rowe facility had a somewhat shorter operating life than is expected of most U.S. reactors because it prematurely discontinued operations. The effects of increased operating life (increased number of source neutrons) were investigated.

\section{A-2. PARAMETRIC RESULTS}

\section{A-2.1 Material Composition}

The impact of variations in material compositions are shown in Tables A-5 to A-9. The results are listed for each isotope in each component of interest. Tables A-3 and A-4 indicate the base, lower, and upper bound concentrations of the parent isotopes. The concentrations are presented consistently as weight fractions for convenience of comparison. These concentrations are derived from the base concentrations shown in Table 3 and from the ranges of concentrations indicated in Tables A-1 and A-2. 
Table A-5. Concentration parametric calculations for long-lived isotopes $\left(\mathrm{Ci} / \mathrm{m}^{3}\right)$.

\begin{tabular}{|c|c|c|c|c|c|c|c|c|c|c|c|c|}
\hline \multirow[b]{2}{*}{ Component } & \multicolumn{3}{|c|}{${ }^{94} \mathrm{Nb}$} & \multicolumn{3}{|c|}{${ }^{39} \mathrm{Ni}$} & \multicolumn{3}{|c|}{${ }^{14} \mathrm{C}$} & \multicolumn{3}{|c|}{${ }^{99} \mathrm{Tc}$} \\
\hline & $\begin{array}{c}\text { Base } \\
\text { calculation }\end{array}$ & $\begin{array}{l}\text { Lower } \\
\text { bound }\end{array}$ & $\begin{array}{l}\text { Upper } \\
\text { bound }\end{array}$ & $\begin{array}{l}\text { Base } \\
\text { calculation }\end{array}$ & $\begin{array}{l}\text { Lower } \\
\text { bound }\end{array}$ & $\begin{array}{l}\text { Upper } \\
\text { bound }\end{array}$ & $\begin{array}{c}\text { Base } \\
\text { calculation }\end{array}$ & $\begin{array}{l}\text { Lower } \\
\text { bound }\end{array}$ & $\begin{array}{l}\text { Upper } \\
\text { bound }\end{array}$ & $\begin{array}{c}\text { Base } \\
\text { calculation }\end{array}$ & $\begin{array}{l}\text { Lolver } \\
\text { bound }\end{array}$ & $\begin{array}{l}\text { Upper } \\
\text { bound }\end{array}$ \\
\hline $\begin{array}{l}\text { Upper core support } \\
\text { plate }\end{array}$ & 0.19794 & $2.478 c-01$ & $3.236 \mathrm{e}-01$ & $6.180 c+01$ & $5.912 c+01$ & $7.390 c+01$ & $6.161 e-01$ & $2.478 e-01$ & $3.236 \mathrm{e}-01$ & $2.390 \mathrm{e}-03$ & $1.912 \mathrm{c}-03$ & $1.315 \mathrm{e}-01$ \\
\hline $\begin{array}{l}\text { Upper corc support } \\
\text { barrel }\end{array}$ & 0.00096 & $1.489 \mathrm{e}-04$ & $8.961 \mathrm{c} \cdot 03$ & $2.426 \mathrm{c}-01$ & $1.176 e+00$ & $1.470 e+00$ & $2.456 e-03$ & $4.864 \mathrm{c}-03$ & $6.352 e-03$ & $2.300 e-05$ & $1.349 e-05$ & $9.271 \mathrm{c}-04$ \\
\hline $\begin{array}{l}\text { Lower core support } \\
\text { barrel }\end{array}$ & 0.00069 & $1.425 c-04$ & $8.590 e-03$ & $2.004 e-01$ & $1.255 e+00$ & $1.569 c+00$ & $1.991 \mathrm{e}-03$ & $5.216 \mathrm{e}-03$ & $6.812 e-03$ & $7.854 \mathrm{c}-06$ & $1.816 \mathrm{e}-05$ & $1.249 e-03$ \\
\hline Core baffle & 1.19395 & $9.566 \mathrm{e}-02$ & $6.075 e+00$ & $3.240 \mathrm{e}+02$ & $3.099 e+02$ & $3.874 e+02$ & $3.230 c+00$ & $1.299 c+00$ & $1.696 c+00$ & $1.344 \mathrm{e}-02$ & $1.075 \mathrm{c} \cdot 02$ & $7.394 \mathrm{e}-01$ \\
\hline Core barrel & 0.06606 & $7.836 c-03$ & $5.125 \mathrm{e}-01$ & $2.422 c+01$ & $2.317 \mathrm{e}+01$ & $2.896 c+01$ & $2.406 \mathrm{e}-01$ & $9.678 c-02$ & $1.264 \mathrm{e}-01$ & $7.670 \mathrm{c}-04$ & $6.136 c-04$ & $4.218 c-02$ \\
\hline Thermat shicld & 0.01439 & $2.635 c-03$ & $1.725 \mathrm{e}-01$ & $3.847 c+00$ & $8.071 c+00$ & $1.009 e+01$ & $3.868 \mathrm{e}-02$ & $3.333 e-02$ & $4.353 e-02$ & $1.297 \mathrm{c}-04$ & $1.321 \mathrm{c}-04$ & $9.084 e-03$ \\
\hline Pressure vesscl liner & 0.00166 & $4.238 \mathrm{e}-04$ & $2.759 e-02$ & $6.699 \mathrm{c}-01$ & $2.021 c+00$ & $2.526 c+00$ & $6.600 c-03$ & $8.252 e-03$ & $1.078 c-02$ & $1.933 \mathrm{c}-05$ & $1.228 \mathrm{c}-05$ & $8.442 c-04$ \\
\hline Pressure vessel & 0.00417 & $2.095 e-04$ & $8.858 c-04$ & $1.045 \mathrm{c}-03$ & $1.161 \mathrm{c} .03$ & $2.942 c-03$ & $1.164 c-04$ & $3.071 c-04$ & $3.081 \mathrm{c}-04$ & $4.483 c-04$ & $2.733 c .06$ & $3.826 \mathrm{e}-06$ \\
\hline
\end{tabular}


Table A-6. Concentration parametric calculations for short-lived isotopes $\left(\mathrm{Ci} / \mathrm{m}^{3}\right)$.

\begin{tabular}{lccc}
\hline & \multicolumn{3}{c}{${ }^{63} \mathrm{Ni}$} \\
\cline { 2 - 4 } \multicolumn{1}{c}{ Component } & $\begin{array}{c}\text { Base } \\
\text { calculation }\end{array}$ & $\begin{array}{c}\text { Lower } \\
\text { bound }\end{array}$ & $\begin{array}{c}\text { Upper } \\
\text { bound }\end{array}$ \\
\hline Upper core support plate & $4.343 \mathrm{e}+02$ & $4.162 \mathrm{e}+02$ & $5.482 \mathrm{e}+02$ \\
Upper core support barrel & $1.693 \mathrm{e}+00$ & $8.266 \mathrm{e}+00$ & $1.071 \mathrm{e}+01$ \\
Lower core support barrel & $1.391 \mathrm{e}+00$ & $8.832 \mathrm{e}+00$ & $1.137 \mathrm{e}+01$ \\
Core baffle & $2.262 \mathrm{e}+03$ & $2.168 \mathrm{e}+03$ & $2.884 \mathrm{e}+03$ \\
Core barrel & $1.701 \mathrm{e}+02$ & $1.631 \mathrm{e}+02$ & $2.167 \mathrm{e}+02$ \\
Thermal shield & $2.693 \mathrm{e}+01$ & $5.696 \mathrm{e}+01$ & $7.405 \mathrm{e}+01$ \\
Pressure vessel liner & $4.721 \mathrm{e}+00$ & $1.432 \mathrm{e}+01$ & $1.831 \mathrm{e}+01$ \\
Pressure vessel & $8.167 \mathrm{e}-03$ & $8.740 \mathrm{e}-03$ & $2.232 \mathrm{e}-02$ \\
\hline
\end{tabular}

Table A-7. Concentration parametric calculations for ${ }^{60} \mathrm{Co}\left(\mathrm{Ci} / \mathrm{m}^{3}\right)$.

\begin{tabular}{lccc}
\hline & \multicolumn{3}{c}{${ }^{60} \mathrm{Co}$} \\
\cline { 2 - 4 } \multicolumn{1}{c}{ Component } & $\begin{array}{c}\text { Base } \\
\text { calculation }\end{array}$ & $\begin{array}{c}\text { Lower } \\
\text { bound }\end{array}$ & $\begin{array}{c}\text { Upper } \\
\text { bound }\end{array}$ \\
\hline Upper core support plate & $3.994 \mathrm{e}+04$ & $6.468 \mathrm{e}+03$ & $7.259 \mathrm{e}+04$ \\
Upper core support barrel & $1.698 \mathrm{e}+02$ & $1.380 \mathrm{e}+02$ & $1.549 \mathrm{e}+03$ \\
Lower core support barrel & $1.479 \mathrm{e}+02$ & $1.132 \mathrm{e}+02$ & $1.270 \mathrm{e}+03$ \\
Core baffle & $2.190 \mathrm{e}+05$ & $3.546 \mathrm{e}+04$ & $3.980 \mathrm{e}+05$ \\
Core barrel & $1.481 \mathrm{e}+04$ & $2.399 \mathrm{e}+03$ & $2.692 \mathrm{e}+04$ \\
Thermal shield & $2.594 \mathrm{e}+03$ & $7.826 \mathrm{e}+02$ & $8.783 \mathrm{e}+03$ \\
Pressure vessel liner & $4.184 \mathrm{e}+02$ & $1.875 \mathrm{e}+02$ & $2.104 \mathrm{e}+03$ \\
Pressure vessel & $8.627 \mathrm{e}+00$ & $2.053 \mathrm{e}+01$ & $3.333 \mathrm{e}+01$ \\
\hline
\end{tabular}

Careful inspection of the base material composition table (Table 3) and the ranges of isotopics in the material compositions listed in Tables A-1 and A-2 indicates some inconsistencies. As an example, the base concentration for copper in Table 3 is outside of the range of concentrations listed in Table A-1 for stainless steel. These inconsistencies in data are typical of what may be found for the trace isotopes in metals and provide confirmation of the uncertainties in material compositions.

Inspection of the results show that the isotope with the widest variation in activation relative to its Class $\mathrm{C}$ limit is ${ }^{94} \mathrm{Nb}$. This fluctuation occurs because both of its parents, ${ }^{93} \mathrm{Nb}$ and ${ }^{94} \mathrm{Mo}$, are 
Table A-8. Concentration parametric sum-of-the-fractions calculations for long-lived isotopes.

\begin{tabular}{|c|c|c|c|c|c|c|c|c|c|c|c|c|c|c|c|}
\hline \multirow[b]{2}{*}{ Component } & \multicolumn{3}{|c|}{${ }^{24} \mathrm{Nb}$} & \multicolumn{3}{|c|}{${ }^{39} \mathrm{Ni}$} & \multicolumn{3}{|c|}{ "C } & \multicolumn{3}{|c|}{${ }^{99} \mathrm{Tc}$} & \multicolumn{3}{|c|}{ Total } \\
\hline & $\begin{array}{c}\text { Base } \\
\text { calculation }\end{array}$ & $\begin{array}{l}\text { Lower } \\
\text { bound }\end{array}$ & $\begin{array}{l}\text { Upper } \\
\text { bound }\end{array}$ & $\begin{array}{c}\text { Base } \\
\text { calculation }\end{array}$ & $\begin{array}{l}\text { Lower } \\
\text { bound }\end{array}$ & $\begin{array}{l}\text { Upper } \\
\text { bound }\end{array}$ & $\begin{array}{c}\text { Base } \\
\text { calculation }\end{array}$ & $\begin{array}{l}\text { Lower } \\
\text { bound }\end{array}$ & $\begin{array}{l}\text { Upper } \\
\text { bound }\end{array}$ & $\begin{array}{c}\text { Base } \\
\text { calculation }\end{array}$ & $\begin{array}{l}\text { Lower } \\
\text { bound }\end{array}$ & $\begin{array}{l}\text { Upper } \\
\text { bound }\end{array}$ & $\begin{array}{c}\text { Base } \\
\text { calculation }\end{array}$ & $\begin{array}{l}\text { Lower } \\
\text { bound }\end{array}$ & $\begin{array}{l}\text { Upper } \\
\text { bound }\end{array}$ \\
\hline $\begin{array}{l}\text { Upper core support } \\
\text { plate }\end{array}$ & 0.990 & 1.239 & 1.618 & 0.281 & 0.269 & 0.336 & 0.008 & 0.003 & 0.004 & 0.001 & 0.001 & 0.044 & 1.279 & 1.511 & 2.002 \\
\hline $\begin{array}{l}\text { Upper core support } \\
\text { barrel }\end{array}$ & 0.005 & 0.001 & 0.045 & 0.001 & 0.005 & 0.007 & 0.000 & 0.000 & 0.000 & 0.000 & 0.000 & 0.000 & 0.006 & 0.006 & 0.052 \\
\hline $\begin{array}{l}\text { Lowcr core support } \\
\text { barrel }\end{array}$ & 0.003 & 0.001 & 0.043 & 0.001 & 0.006 & 0.007 & 0.000 & 0.000 & 0.000 & 0.000 & 0.000 & 0.000 & 0.004 & 0.006 & 0.051 \\
\hline Core baffle & 5.970 & 0.478 & 30.377 & 1.473 & 1.409 & 1.761 & 0.040 & 0.016 & 0.021 & 0.004 & 0.004 & 0.246 & 7.487 & 1.907 & 32.406 \\
\hline Core barrel & 0.330 & 0.039 & 2.562 & 0.110 & 0.105 & 0.132 & 0.003 & 0.001 & 0.002 & 0.000 & 0.000 & 0.014 & 0.444 & 0.146 & 2.710 \\
\hline Thermal shicld & 0.072 & 0.013 & 0.863 & 0.017 & 0.037 & 0.046 & 0.000 & 0.000 & 0.001 & 0.000 & 0.000 & 0.003 & 0.090 & 0.050 & 0.912 \\
\hline Pressure vessel liner & 0.008 & 0.002 & 0.138 & 0.003 & 0.009 & 0.011 & 0.000 & 0.000 & 0.000 & 0.000 & 0.000 & 0.000 & 0.011 & 0.011 & 0.150 \\
\hline Pressure vesscl & 0.021 & 0.001 & 0.004 & 0.000 & 0.000 & 0.000 & 0.000 & 0.000 & 0.000 & 0.000 & 0.000 & 0.000 & 0.021 & 0.001 & 0.004 \\
\hline
\end{tabular}


Table A-9. Concentration parametric sum-of-the-fractions calculations for short-lived isotopes.

\begin{tabular}{lccc}
\hline & \multicolumn{3}{c}{${ }^{63} \mathrm{Ni}$} \\
\cline { 2 - 4 } \multicolumn{1}{c}{ Component } & $\begin{array}{c}\text { Base } \\
\text { calculation }\end{array}$ & $\begin{array}{c}\text { Lower } \\
\text { bound }\end{array}$ & $\begin{array}{c}\text { Upper } \\
\text { bound }\end{array}$ \\
\hline Upper core support plate & 0.062 & 0.059 & 0.078 \\
Upper core support barrel & 0.000 & 0.001 & 0.002 \\
Lower core support barrel & 0.000 & 0.001 & 0.002 \\
Core baffle & 0.323 & 0.310 & 0.412 \\
Core barrel & 0.024 & 0.023 & 0.031 \\
Thermal shield & 0.004 & 0.008 & 0.011 \\
Pressure vessel liner & 0.001 & 0.002 & 0.003 \\
Pressure vessel & 0.000 & 0.000 & 0.000 \\
\hline
\end{tabular}

shown to have concentration variations that span two orders of magnitude. Because the wide variation of ${ }^{94} \mathrm{Nb}$ concentration envelopes the waste classification limit for ${ }^{94} \mathrm{Nb}$, it becomes a principle discriminator in waste classification. Within the analyzed ranges, ${ }^{94} \mathrm{Nb}$ is also the only GTCC isotope capable of affecting the waste classification of a component by itself (i.e., the upper core support plate). Additionally, because concentration averaging rules limit the variance of ${ }^{94} \mathrm{Nb}$ to a factor of only 1.5 in a waste package, concentration averaging would have limited application in package classification where ${ }^{94} \mathrm{Nb}$ is the discriminating isotope.

The resulting calculations show that if all GTCC parents were found to have the lower bound limits of the specified concentrations, none of the major components of interest would be activated to levels above Class $C$ limits except for the core baffle and core support plates. Even at the upper bounds, if ${ }^{94} \mathrm{Nb}$ were neglected, all components except the baffle would be would be Class $\mathrm{C}$ or below. The particular importance of ${ }^{94} \mathrm{Nb}$ in the classification of the waste is, therefore, a major concern.

Based on the calculations and the material ranges chosen, it can be concluded that for the Yankee Rowe reactor, the only four large components that may be activated to the levels above Class $\mathrm{C}$ limits are the core baffle, upper and lower core support plates, and the core barrel. Whether or not the support plates and barrel are above Class $\mathrm{C}$ limits depends largely on the actual concentration of ${ }^{94} \mathrm{Nb}$ parents in the base metal. Note that the NRC does not specify the material compositions which must be assumed for the analysis.

\section{A-2.2 Component Distance From the Active Core}

The results of this calculation are shown in Tables A-10 to A-14. The tables indicate the results of the calculation using the larger barrel diameter, the statistical error of the calculation, and a comparison between the calculations using the larger barrel and base case barrel size (larger/base). 
Table A-10. Increased core barrel size activation calculations for long-lived isotopes-decayed values (Ci/ $\left.\mathrm{m}^{3}\right)$.

\begin{tabular}{|c|c|c|c|c|c|c|c|c|c|c|c|c|}
\hline \multirow[b]{2}{*}{ Component } & \multicolumn{3}{|c|}{${ }^{94} \mathrm{Nb}$} & \multicolumn{3}{|c|}{${ }^{59} \mathrm{Ni}$} & \multicolumn{3}{|c|}{${ }^{14} \mathrm{C}$} & \multicolumn{3}{|c|}{${ }^{99} \mathrm{Tc}$} \\
\hline & $\begin{array}{l}\text { Larger } \\
\text { barrel }\end{array}$ & $\begin{array}{l}\text { Statistical } \\
\text { error }\end{array}$ & $\begin{array}{c}\text { Larger/ } \\
\text { base }\end{array}$ & $\begin{array}{l}\text { Larger } \\
\text { barrel }\end{array}$ & $\begin{array}{l}\text { Statistical } \\
\text { error }\end{array}$ & $\begin{array}{c}\text { Larger/ } \\
\text { base }\end{array}$ & $\begin{array}{l}\text { Larger } \\
\text { barrel }\end{array}$ & $\begin{array}{c}\text { Statistical } \\
\text { error }\end{array}$ & $\begin{array}{c}\text { Larger/ } \\
\text { base }\end{array}$ & $\begin{array}{l}\text { Larger } \\
\text { barrel }\end{array}$ & $\begin{array}{c}\text { Statistical } \\
\text { error }\end{array}$ & $\begin{array}{c}\text { Larger/ } \\
\text { base }\end{array}$ \\
\hline Core baffle & $1.194 e+00$ & $1.73 \%$ & $100.00 \%$ & $3.240 e+02$ & $0.62 \%$ & $100.00 \%$ & $3.230 \mathrm{e}+00$ & $0.60 \%$ & $100.00 \%$ & $1.344 \mathrm{e}-02$ & $5.00 \%$ & $100.00 \%$ \\
\hline Core barrel & $5.860 \mathrm{e}-02$ & $1.88 \%$ & $88.71 \%$ & $1.927 e+01$ & $0.60 \%$ & $79.55 \%$ & $1.918 \mathrm{e}-01$ & $0.58 \%$ & $79.72 \%$ & $6.260 \mathrm{e}-04$ & $6.99 \%$ & $81.61 \%$ \\
\hline $\begin{array}{l}\text { Thermal } \\
\text { shield }\end{array}$ & $1.440 \mathrm{e}-02$ & $3.47 \%$ & $100.06 \%$ & $3.345 e+00$ & $1.34 \%$ & $86.97 \%$ & $3.390 \mathrm{e}-02$ & $1.28 \%$ & $87.64 \%$ & $1.690 e-04$ & $9.40 \%$ & $130.32 \%$ \\
\hline $\begin{array}{l}\text { Pressure } \\
\text { vessel liner }\end{array}$ & $2.781 \mathrm{e}-03$ & $8.20 \%$ & $167.08 \%$ & $1.085 e+00$ & $3.01 \%$ & $161.94 \%$ & $1.071 \mathrm{e}-02$ & $2.95 \%$ & $162.25 \%$ & $3.636 e-05$ & $3.01 \%$ & $188.14 \%$ \\
\hline $\begin{array}{l}\text { Pressure } \\
\text { vessel }\end{array}$ & $8.941 \mathrm{e}-03$ & $14.56 \%$ & $214.49 \%$ & $1.718 \mathrm{e}-03$ & $2.94 \%$ & $164.48 \%$ & $2.378 \mathrm{e}-04$ & $2.71 \%$ & $204.39 \%$ & $8.559 \mathrm{e}-04$ & $19.97 \%$ & $190.93 \%$ \\
\hline
\end{tabular}


Table A-11. Increased core barrel size activation calculations for short-lived isotopes-decayed values $\left(\mathrm{Ci} / \mathrm{m}^{3}\right)$.

\begin{tabular}{lccc}
\hline & \multicolumn{3}{c}{${ }^{63} \mathrm{Ni}$} \\
\cline { 2 - 4 } \multicolumn{1}{c}{ Component } & $\begin{array}{c}\text { Larger } \\
\text { barrel }\end{array}$ & $\begin{array}{c}\text { Statistical } \\
\text { error }\end{array}$ & Larger/base \\
\hline Core baffle & $2.262 \mathrm{e}+03$ & $0.62 \%$ & $100.00 \%$ \\
Core barrel & $1.353 \mathrm{e}+02$ & $0.60 \%$ & $79.52 \%$ \\
Thermal shield & $2.327 \mathrm{e}+01$ & $1.36 \%$ & $86.44 \%$ \\
Pressure vessel liner & $7.651 \mathrm{e}+00$ & $3.03 \%$ & $162.07 \%$ \\
Pressure vessel & $1.340 \mathrm{e}-02$ & $2.69 \%$ & $164.11 \%$ \\
\hline
\end{tabular}

Table A-12. Increased core barrel size activation calculations for ${ }^{60} \mathrm{Co}-$ decayed values $\left(\mathrm{Ci} / \mathrm{m}^{3}\right)$.

\begin{tabular}{lccc}
\hline & \multicolumn{3}{c}{${ }^{{ }^{60} \mathrm{Co}}$} \\
\cline { 2 - 4 } \multicolumn{1}{c}{ Component } & $\begin{array}{c}\text { Larger } \\
\text { barrel }\end{array}$ & $\begin{array}{c}\text { Statistical } \\
\text { error }\end{array}$ & Larger/base \\
\hline Core baffle & $2.190 \mathrm{e}+05$ & $0.91 \%$ & $100.00 \%$ \\
Core barrel & $1.202 \mathrm{e}+04$ & $0.93 \%$ & $81.13 \%$ \\
Thermal shield & $2.406 \mathrm{e}+03$ & $2.15 \%$ & $92.77 \%$ \\
Pressure vessel liner & $6.964 \mathrm{e}+02$ & $5.08 \%$ & $166.43 \%$ \\
Pressure vessel & $1.415 \mathrm{e}+01$ & $5.37 \%$ & $164.05 \%$ \\
\hline
\end{tabular}

Table A-13. Increased core barrel size sum-of-the-fractions calculations for long-lived isotopes.

\begin{tabular}{|c|c|c|c|c|c|c|}
\hline \multirow[b]{2}{*}{ Component } & \multirow{2}{*}{ 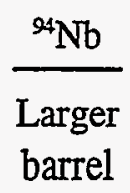 } & \multirow{2}{*}{ 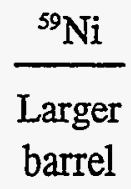 } & \multirow{2}{*}{ 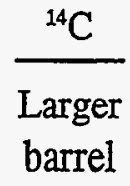 } & \multirow{2}{*}{$\begin{array}{l}{ }^{99} \mathrm{Tc} \\
\text { Larger } \\
\text { barrel }\end{array}$} & \multicolumn{2}{|c|}{ Total } \\
\hline & & & & & $\begin{array}{l}\text { Larger } \\
\text { barrel }\end{array}$ & $\begin{array}{c}\text { Statistical } \\
\text { error }\end{array}$ \\
\hline Core baffle & 5.970 & 1.473 & 0.040 & 0.004 & 7.487 & $0.61 \%$ \\
\hline Core barrel & 0.293 & 0.088 & 0.002 & 0.000 & 0.383 & $0.59 \%$ \\
\hline Thermal shield & 0.072 & 0.015 & 0.000 & 0.000 & 0.088 & $1.32 \%$ \\
\hline Pressure vessel liner & 0.014 & 0.005 & 0.000 & 0.000 & 0.019 & $2: 97 \%$ \\
\hline Pressure vessel & 0.045 & 0.000 & 0.000 & 0.000 & 0.045 & $11.18 \%$ \\
\hline
\end{tabular}


Table A-14. Increased core barrel size sum-of-the-fractions calculations for short-lived isotopes.

\begin{tabular}{|c|c|}
\hline & ${ }^{63} \mathrm{Ni}$ \\
\hline Component & Larger barrel \\
\hline Core baffle & 0.323 \\
\hline Core barrel & 0.019 \\
\hline Thermal shield & 0.003 \\
\hline Pressure vessel liner & 0.001 \\
\hline Pressure vessel & 0.000 \\
\hline
\end{tabular}

When compared to Tables 5 to 7 , the results indicate that movement of the core barrel $1.27 \mathrm{~cm}$ ( 0.5 in.) farther away from the core can cause a reduction of about $12-20 \%$ in the activation of the core barrel. It is expected that this would be due to the decreased flux and spectral changes at that farther distance. Significant reductions in flux and spectral changes can occur over small distances and, therefore, significant changes in activation levels are expected. Movement of the core barrel also has a noticeable impact on the activation levels in the thermal shield. Movement of the core barrel is shown to reduce some activation levels in the thermal shield by about $10-15 \%$. It is likely that the movement of the barrel, and the associated displacement of water between the barrel and the thermal shield, has caused some neutron spectrum effects, which changed the capture rates of the parent isotopes being investigated. While this effect does alter activation rates, it is likely to be of minor concern in waste classification.

Large relative changes in activation levels are noted for the pressure vessel liner and the pressure vessel. Examination of the MCNP output warnings indicate that the values in these regions may have large statistical errors that are not indicated by the standard deviations listed within the code results. It is likely that insufficient neutrons are deposited in these regions to give statistically accurate and well-behaved results (See Section 4.3 for explanation of statistical variations). Since the activation levels are so low that these components are not of concern for Class $\mathrm{C}$ classification, further analysis of these results is not required. The statistical error in these results could likely be reduced by increasing the number of neutron generations in MCNP (with a resulting increase in run time), if desired.

\section{A-2.3 Irradiation Time}

In comparison to what is expected from other PWRs, the Yankee Rowe reactor facility experienced a relatively short operating life. Most reactor facilities have 40-year operating licenses, and if a 75\% capacity factor is assumed, this would mean that a typical reactor could experience about 30 EPPYs of operation by the time its license expires. If a utility chooses to renew its license, a longer lifetime could be achieved.

The base calculations performed for the Yankee Rowe reactor only extend to 22.374 EFPYs of operation. To illustrate the possible effects of longer operating times, the calculational results were 
extrapolated to 30 EFPYs of operation. The results of the extrapolation are found in Tables A-15 to A-19.

The extrapolation was performed for Yankee Rowe by assuming that the reactor was run for an additional 7 cycles using the same fuel management scheme. The cycle lengths and refueling times were estimated to be the average of 19 of the first 20 cycles of operation. The initial cycle was neglected because initial testing served to increase the cycle length while operating at lower powers. Cycle 21 was also neglected because of its premature end. The 30th EFPY therefore ends on January 15,2002 . The isotope decay is also calculated as of this date.

The total number of activated atoms produced is essentially a linear function in the extrapolation. The decay rates of the isotopes, however, cause deviations from a linear extrapolation. The size of the deviation depends on the isotope half-life. The results indicate that if the Yankee Rowe reactor were to have operated for another 8 EFPYs using the same operating schemes (high leakage, similar operating regimes), no component waste classes are predicted to change. All activity concentrations naturally increase, however, and it would become more likely that base metal constituent concentrations could effect the classification of the barrel.

\section{A-3. CONCLUSIONS}

Material compositions of the base metals can have large variations in the amount of trace elements present. These variations in composition can effect the waste classification of the components. A particular problem exists with the variations in the concentrations of the parent isotopes of ${ }^{94} \mathrm{Nb}$, since the variations envelope that Class $C$ limit. Of all factors contributing to the uncertainties in waste classification, material composition uncertainties are the single largest variable. This problem is unique in that the only way to reduce the uncertainty in the material composition numbers may be to take samples from each reactor component in question.

The relative distance of a component from the active core has been shown to significantly affect activation levels. Small deviations can alter activation results by $12-20 \%$ in the core barrel, which can in turn affect the waste classification. This would indicate that any analysis performed could have uncertainties of this magnitude if the difference between design and as-built is not known. Since normal reactor operations could be expected to change component sizes from as-built conditions, this source of uncertainty cannot be ignored. The uncertainty from the geometry, however, is very small in relation to the uncertainty in material compositions.

Component irradiation histories are generally well known, and provide little avenue for the introduction of uncertainty when compared to other factors. The activation levels for the isotopes in question are generally proportional to the time of irradiation and the power. Therefore, the effects of different times of irradiation can be easily evaluated.

\section{A-4. REFERENCES}

A-1. Evans, J. C., et. al. Long-Lived Activation Products in Reactor Materials. NUREG/CR-3474. Prepared for the U.S. Nuclear Regulatory Commission by Battelle, Pacific Northwest Laboratory, Richland, WA. August 1984. 
Table A-15. Reactor exposure parametric for long-lived isotopes-activation at $30 \mathrm{EFPY}\left(\mathrm{Ci} / \mathrm{m}^{3}\right)$.

\begin{tabular}{|c|c|c|c|c|c|c|c|c|c|c|c|c|}
\hline \multirow[b]{2}{*}{ Component } & \multicolumn{3}{|c|}{${ }^{2} \mathrm{Nb}$} & \multicolumn{3}{|c|}{${ }^{39} \mathrm{Ni}$} & \multicolumn{3}{|c|}{${ }^{* 4} \mathrm{C}$} & \multicolumn{3}{|c|}{${ }^{99} \mathrm{Tc}$} \\
\hline & Calculation & $\begin{array}{l}\text { Statistical } \\
\text { error }\end{array}$ & $\begin{array}{l}\text { Calculation } \\
\text { w/decay }\end{array}$ & Calculation & $\begin{array}{l}\text { Statistical } \\
\text { error }\end{array}$ & $\begin{array}{l}\text { Calculation } \\
\text { w/decay }\end{array}$ & Calculation & $\begin{array}{l}\text { Statistical } \\
\text { crror }\end{array}$ & $\begin{array}{l}\text { Calculation } \\
\text { w/dccay }\end{array}$ & Calculation & $\begin{array}{l}\text { Statistical } \\
\text { error }\end{array}$ & $\begin{array}{l}\text { Calculation } \\
\text { w/decay }\end{array}$ \\
\hline $\begin{array}{l}\text { Upper core } \\
\text { support plate }\end{array}$ & $2.659 c-01$ & $1.81 \%$ & $2.657 e-01$ & $8.298 e+01$ & $0.71 \%$ & $8.296 e+01$ & $8.287 e-01$ & $0.68 \%$ & $8.267 e-01$ & $3.209 \mathrm{e}-03$ & $5.43 \%$ & $3.2090-03$ \\
\hline $\begin{array}{l}\text { UCSP-upper } \\
\text { plate }\end{array}$ & $4.445 e-02$ & $6.38 \%$ & $4.441 c-02$ & $1.356 e+01$ & $4.74 \%$ & $1.356 \mathrm{e}+01$ & $1.345 \mathrm{c}-01$ & $4.74 \%$ & $1.342 \mathrm{e}-01$ & $4.070 \mathrm{e}-04$ & $6.55 \%$ & $4.070 c-04$ \\
\hline $\begin{array}{l}\text { UCSP-lower } \\
\text { plate }\end{array}$ & $4.122 e-01$ & $9.01 \%$ & $4.119 c-01$ & $1.225 c+02$ & $9.35 \%$ & $1.225 e+02$ & $1.230 c+00$ & $9.33 \%$ & $1.227 c+00$ & $5.375 c-03$ & $10.56 \%$ & $5.375 \mathrm{a}-03$ \\
\hline $\begin{array}{l}\text { Upper core } \\
\text { support Barrel }\end{array}$ & $1.294 c-03$ & $21.93 \%$ & $1.293 c-03$ & $3.258 \mathrm{c}-01$ & $9.97 \%$ & $3.257 \mathrm{e}-01$ & $3.303 c-03$ & $9.51 \%$ & $3.295 c-03$ & $3.087 \mathrm{e}-05$ & $38.90 \%$ & $3.087 \mathrm{c}-05$ \\
\hline $\begin{array}{l}\text { Lower core } \\
\text { support Barrel }\end{array}$ & $9.275 \mathrm{e}-04$ & $13.00 \%$ & $9.268 \mathrm{e}-04$ & $2.691 \mathrm{e}-01$ & $10.91 \%$ & $2.691 \mathrm{e}-01$ & $2.678 \mathrm{e}-03$ & $10.63 \%$ & $2.672 c-03$ & $1.054 \mathrm{e}-05$ & $34.91 \%$ & $1.054 e-05$ \\
\hline Core baffle & $1.604 e+00$ & $1.73 \%$ & $1.603 c+00$ & $4.350 c+02$ & $0.62 \%$ & $4.349 c+02$ & $4.345 e+00$ & $0.60 \%$ & $4.334 c+00$ & $1.805 c-02$ & $5.00 \%$ & $1.805 \mathrm{e}-02$ \\
\hline Core barrel & $8.873 c-02$ & $1.74 \%$ & $8.867 c-02$ & $3.252 e+01$ & $0.60 \%$ & $3.251 e+01$ & $3.237 \mathrm{e}-01$ & $0.58 \%$ & $3.229 \mathrm{e}-01$ & $1.030 \mathrm{e}-03$ & $7.86 \%$ & $1.030 \mathrm{e}-03$ \\
\hline Thermal shicld & $1.933 c-02$ & $3.60 \%$ & $1.932 \mathrm{c}-02$ & $5.164 e+00$ & $1.39 \%$ & $5.163 e+00$ & $5.203 \mathrm{e}-02$ & $1.34 \%$ & $5.191 \mathrm{c}-02$ & $1.741 \mathrm{c}-04$ & $7.15 \%$ & $1.741 \mathrm{c}-04$ \\
\hline $\begin{array}{l}\text { Pressure vessel } \\
\text { liner }\end{array}$ & $2.236 \mathrm{e}-03$ & $8.71 \%$ & $2.234 \mathrm{c}-03$ & $8.993 \mathrm{e}-01$ & $3.36 \%$ & $8.992 \mathrm{e}-01$ & $8.878 \mathrm{e}-03$ & $3.29 \%$ & $8.856 \mathrm{e}-03$ & $2.595 \mathrm{e}-05$ & $28.39 \%$ & $2.594 c-05$ \\
\hline Pressure vessel & $5.599 \mathrm{c}-03$ & $16.47 \%$ & $5.595 \mathrm{e}-03$ & $1.402 \mathrm{e}-03$ & $3.25 \%$ & $1.402 \mathrm{e}-03$ & $1.565 \mathrm{e}-04$ & $3.00 \%$ & $1.562 c-04$ & $6.018 e-04$ & $16.18 \%$ & $6.017 e-04$ \\
\hline
\end{tabular}


Table A-16. Reactor exposure parametric for short-lived isotopes-activation at $30 \mathrm{EFPY}\left(\mathrm{Ci} / \mathrm{m}^{3}\right)$.

\begin{tabular}{lccc}
\hline & \multicolumn{3}{c}{${ }^{63} \mathrm{Ni}$} \\
\cline { 2 - 4 } Component & Calculation & $\begin{array}{c}\text { Statistical } \\
\text { error }\end{array}$ & $\begin{array}{c}\text { Calculation } \\
\text { w/decay }\end{array}$ \\
\hline Upper core support plate & $6.571 \mathrm{e}+02$ & $0.94 \%$ & $5.731 \mathrm{e}+02$ \\
UCSP-upper plate & $1.069 \mathrm{e}+02$ & $0.94 \%$ & $9.326 \mathrm{e}+01$ \\
UCSP-lower plate & $9.695 \mathrm{e}+02$ & $9.35 \%$ & $8.456 \mathrm{e}+02$ \\
Upper core support barrel & $2.561 \mathrm{e}+00$ & $10.12 \%$ & $2.233 \mathrm{e}+00$ \\
Lower core support barrel & $2.105 \mathrm{e}+00$ & $11.09 \%$ & $1.835 \mathrm{e}+00$ \\
Core baffle & $3.422 \mathrm{e}+03$ & $0.62 \%$ & $2.984 \mathrm{e}+03$ \\
Core barrel & $2.574 \mathrm{e}+02$ & $0.60 \%$ & $2.245 \mathrm{e}+02$ \\
Thermal shield & $4.074 \mathrm{e}+01$ & $1.40 \%$ & $3.553 \mathrm{e}+01$ \\
Pressure vessel liner & $7.142 \mathrm{e}+00$ & $3.38 \%$ & $6.229 \mathrm{e}+00$ \\
Pressure vessel & $1.236 \mathrm{e}-02$ & $5.60 \%$ & $8.960 \mathrm{e}-03$ \\
\hline
\end{tabular}

Table A-17. Reactor exposure parametric for ${ }^{60} \mathrm{Co}$ at $30 \mathrm{EFPY}\left(\mathrm{Ci} / \mathrm{m}^{3}\right)$.

\begin{tabular}{llcl}
\hline & \multicolumn{3}{c}{${ }^{\circ} \mathrm{Co}$} \\
\cline { 2 - 4 } Component & Calculation & $\begin{array}{l}\text { Statistical } \\
\text { error }\end{array}$ & $\begin{array}{l}\text { Calculation } \\
\text { w/decay }\end{array}$ \\
\hline Upper core support plate & $2.930 \mathrm{e}+05$ & $1.02 \%$ & $5.559 \mathrm{e}+04$ \\
UCSP-upper plate & $5.011 \mathrm{e}+04$ & $4.23 \%$ & $9.508 \mathrm{e}+03$ \\
UCSP-lower plate & $4.346 \mathrm{e}+05$ & $9.48 \%$ & $8.247 \mathrm{e}+04$ \\
Upper core support barrel & $1.246 \mathrm{e}+03$ & $15.66 \%$ & $2.364 \mathrm{e}+02$ \\
Lower core support barrel & $1.085 \mathrm{e}+03$ & $15.98 \%$ & $2.059 \mathrm{e}+02$ \\
Core baffle & $1.606 \mathrm{e}+06$ & $0.91 \%$ & $3.048 \mathrm{e}+05$ \\
Core barrel & $1.087 \mathrm{e}+05$ & $0.91 \%$ & $2.062 \mathrm{e}+04$ \\
Thermal shield & $1.903 \mathrm{e}+04$ & $2.14 \%$ & $3.610 \mathrm{e}+03$ \\
Pressure vessel liner & $3.069 \mathrm{e}+03$ & $5.04 \%$ & $5.824 \mathrm{e}+02$ \\
Pressure vessel & $6.329 \mathrm{e}+01$ & $6.12 \%$ & $1.201 \mathrm{e}+01$ \\
\hline
\end{tabular}


Table A-18. Reactor exposure parametric for long-lived isotopes-sum-of-the-fractions at 30 EFPY $\left(\mathrm{Ci} / \mathrm{m}^{3}\right)$.

\begin{tabular}{|c|c|c|c|c|c|c|}
\hline \multirow[b]{2}{*}{ Component } & \multirow{2}{*}{$\frac{{ }^{\mathcal{A}} \mathrm{Nb}}{\begin{array}{c}\text { Calculation } \\
\text { w/decay }\end{array}}$} & \multirow{2}{*}{ 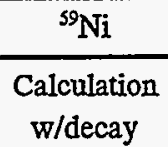 } & \multirow{2}{*}{ 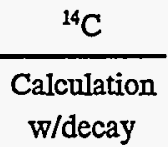 } & \multirow{2}{*}{$\frac{{ }^{99} \mathrm{Tc}}{\begin{array}{c}\text { Caiculation } \\
\text { w/decay }\end{array}}$} & \multicolumn{2}{|c|}{ Total } \\
\hline & & & & & $\begin{array}{l}\text { Calculation } \\
\text { w/decay }\end{array}$ & $\begin{array}{l}\text { Statistical } \\
\text { error }\end{array}$ \\
\hline Upper core support plate & 1.328 & 0.377 & 0.010 & 0.001 & 1.717 & $0.70 \%$ \\
\hline UCSP-upper plate & 0.222 & 0.062 & 0.002 & 0.000 & 0.286 & $4.68 \%$ \\
\hline UCSP-lower plate & 2.060 & 0.557 & 0.015 & 0.002 & 2.633 & $9.23 \%$ \\
\hline Upper core support barrel & 0.006 & 0.001 & 0.000 & 0.000 & 0.008 & $9.83 \%$ \\
\hline Lower core support barrel & 0.005 & 0.001 & 0.000 & 0.000 & 0.006 & $10.77 \%$ \\
\hline Core baffle & 8.013 & 1.977 & 0.054 & 0.006 & 10.050 & $0.61 \%$ \\
\hline Core barrel & 0.443 & 0.148 & 0.004 & 0.000 & 0.595 & $0.59 \%$ \\
\hline Thermal shield & 0.097 & 0.023 & 0.001 & 0.000 & 0.121 & $1.37 \%$ \\
\hline Pressure vessel liner & 0.011 & 0.004 & 0.000 & 0.000 & 0.015 & $3.32 \%$ \\
\hline Pressure vessel & 0.028 & 0.000 & 0.000 & 0.000 & 0.028 & $11.96 \%$ \\
\hline
\end{tabular}

Table A-19. Reactor exposure parametric for short-lived isotopes-sum-of-the-fractions at $30 \mathrm{EFPY}\left(\mathrm{Ci} / \mathrm{m}^{3}\right)$.

\begin{tabular}{lc}
\multicolumn{1}{c}{ Component } & $\begin{array}{c}{ }^{63} \mathrm{Ni} \\
\text { Calculation } \\
\text { w/decay }\end{array}$ \\
Upper core plate & 0.082 \\
Upper plate & 0.013 \\
Lower plate & 0.121 \\
Upper core support barrel & 0.000 \\
Lower core support barrel & 0.000 \\
Core baffle & 0.426 \\
Core barrel & 0.032 \\
Thermal shield & 0.005 \\
Pressure vessel liner & 0.001 \\
Pressure vessel & 0.000 \\
\hline
\end{tabular}


Appendix B

Draft Component Sampling Plan for Yankee Rowe Reactor 


\section{Appendix B}

\section{Draft Component Sampling Plan for Yankee Rowe Reactor}

To assess the MCNP code capability and accuracy in calculating the activation of reactor vessel internals, it is proposed that reactor samples be taken for laboratory analysis. The laboratory analysis results could then be compared to the calculational results in order to validate the code model.

The following is a proposed sampling plan using the Yankee Rowe reactor facility as a model. Twenty sample locations are proposed from various points outside the core. Information is provided on the specific sample sites chosen and the rationale behind the choices. Since it is recognized that the ability to support this sample plan may be limited, the proposed sample locations have been prioritized according to their expected importance to the project.

Figures B-1 to B-4 label the approximate proposed sample locations. Table B-1 locates the samples more specifically, and provides for sample identification. The sample numbers on the figures correspond to the three-digit numbers in the sample ID on the table.

\section{B-1. GENERAL SELECTION INFORMATION}

In general, samples are chosen in the locations with the greatest potential for verifying the MCNP model prediction of activation. Sample locations are proposed primarily to verify the model predictions of core components that are heavy or bulky and are likely to be activated to levels near or exceeding the upper threshold of Class $C$ limits. In general, these components are relatively near the active core. It has also been decided that most of the samples should be from components commonly found in PWRs so that results would be more easily generalized to other plants. Some samples from unique components are proposed, however, to investigate other effects, such as streaming. While these effects may not be of primary importance in the characterization of Yankee Rowe wastes, they may be significant in characterizing wastes at other reactor facilities. If the code results are to be extrapolated to these other facilities, the calculational accuracy in regions where these phenomena occur must be understood.

Samples are also proposed that would facilitate the analysis of axial and radial trends. For example, a series of samples taken vertically up the core barrel would allow investigation of the activation trend along the height of the barrel.

Sample locations are proposed that should be both "easy" and more difficult for the analytical model to predict. An "easy" sample location is one for which it is expected that the code prediction would be very accurate. These areas are in regions where effects such as streaming should have little influence on the activation. The "easy" samples are proposed in order to test the sensitivity of the analysis results to modeling assumptions. Other proposed samples are from core regions that are considered more difficult for the code to predict. Such regions include areas where streaming may be a major factor, or regions sufficiently removed from the core that uncertainties in the flux calculations could become significant. It is expected that code calculations may be less accurate in these areas. 

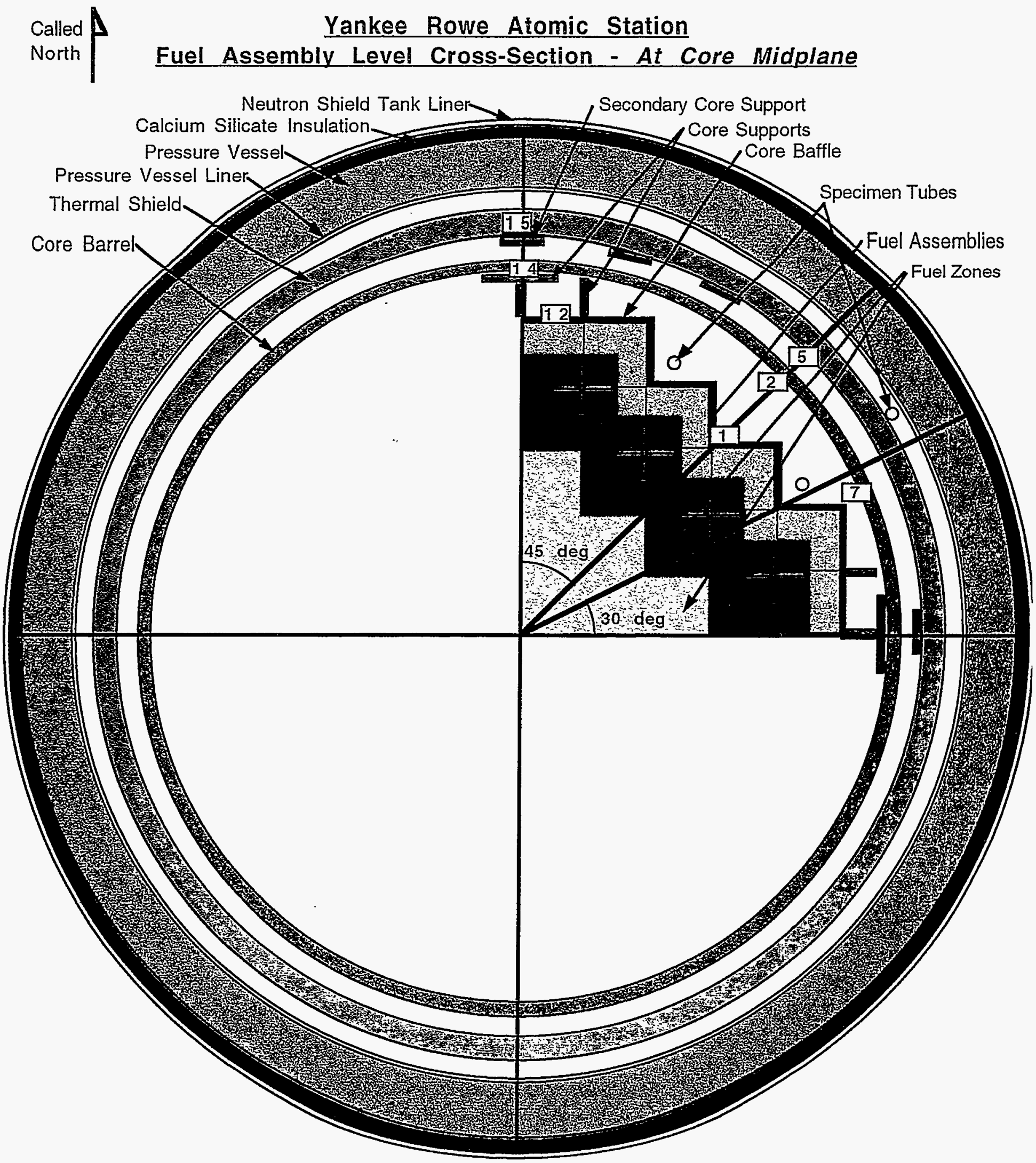

Figure B-1. Yankee Rowe radial view-active core mid-plane. 


\section{Called
North \\ Yankee Rowe Atomic Station}

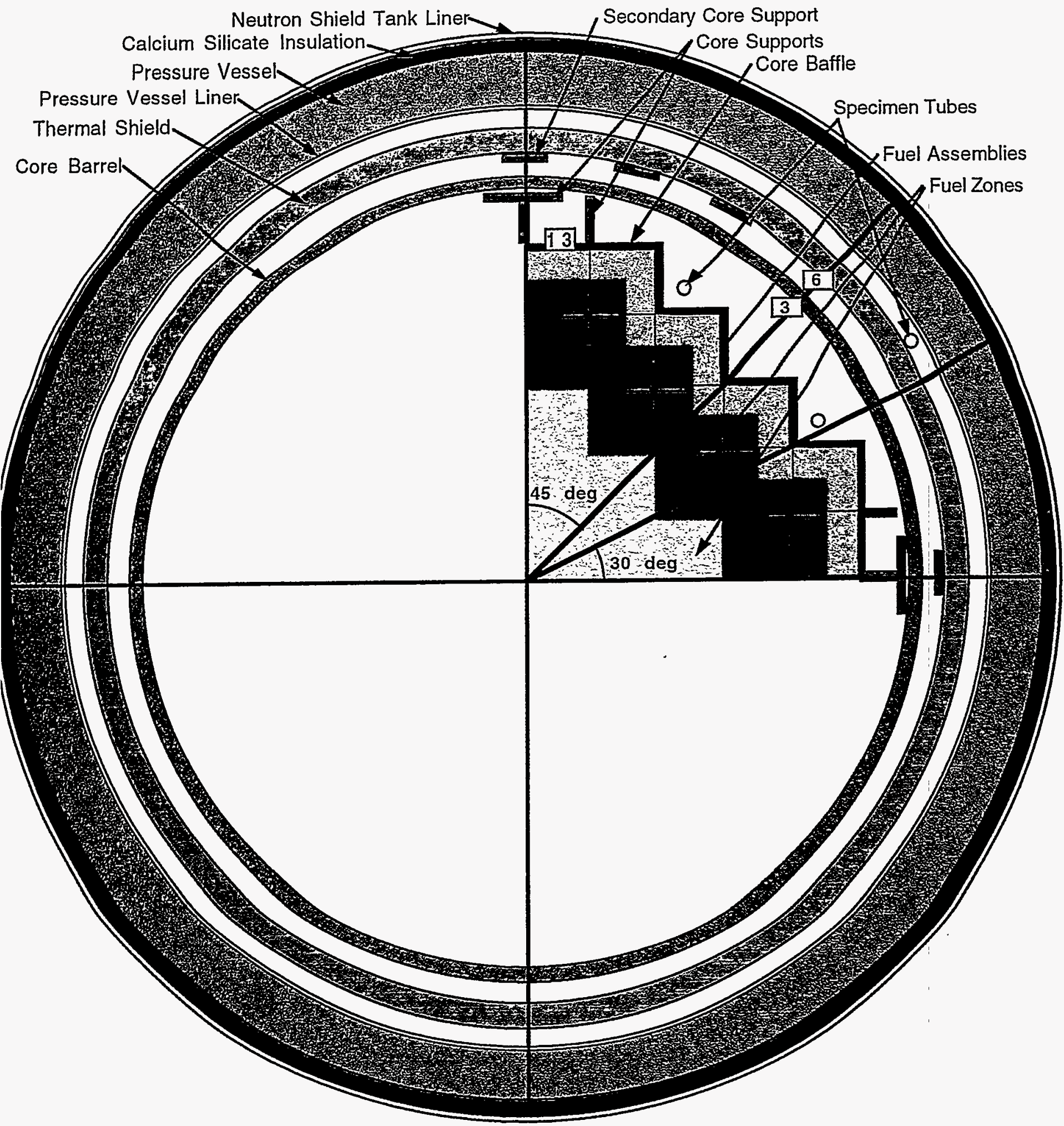

Figure B-2. Yankee Rowe radial view-50\% above active core mid-plane. 


\section{Called $\mathbf{A}$ \\ Yankee Rowe Atomic Station \\ North \\ Fuel Assembly Level Cross-Section - Top of Active Core}

Neutron Shield Tank Liner Secondary Core Support

Calcium Silicate Insulation Core Supports

Pressure Vessel 7 Core Baffle
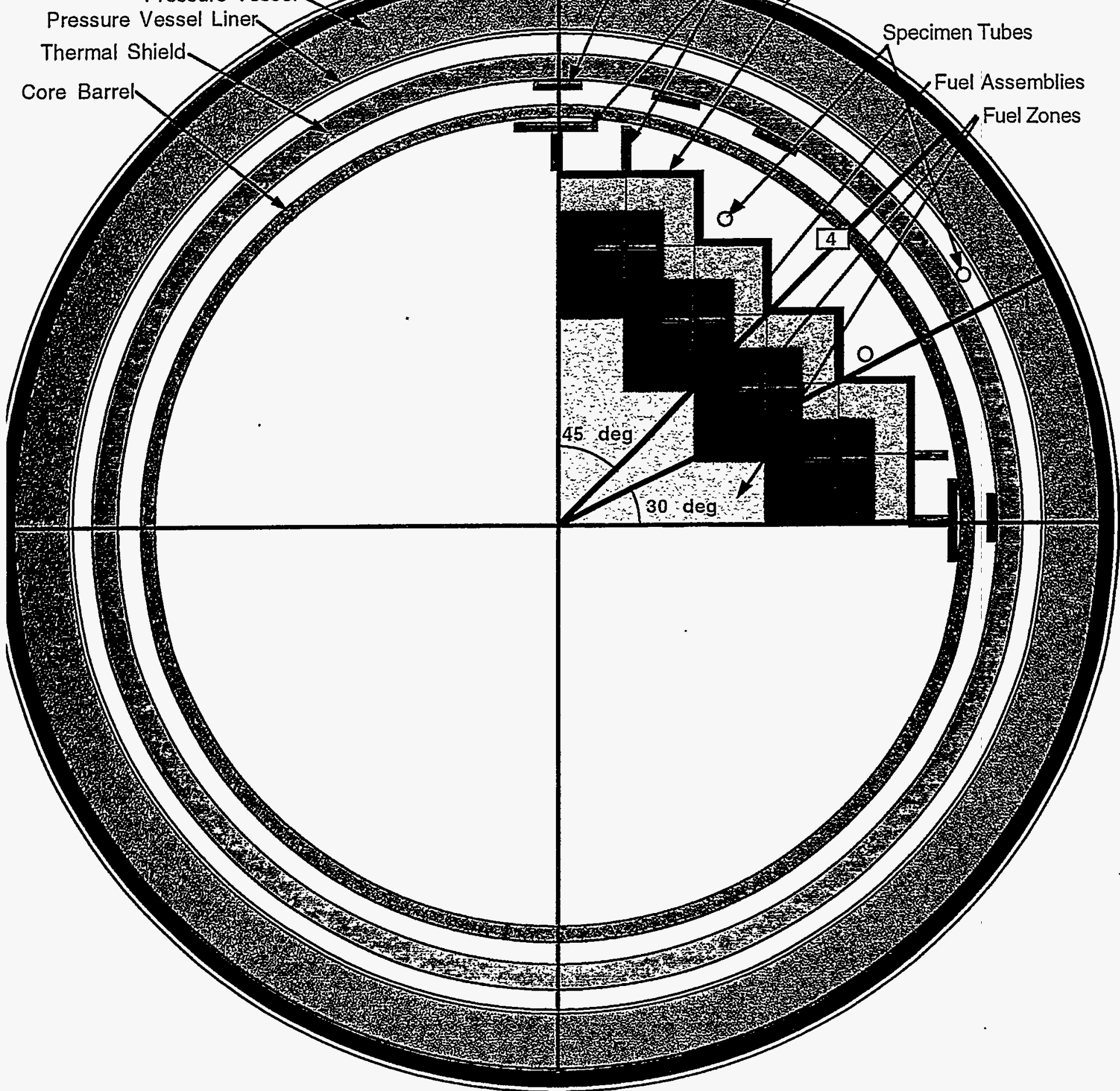

Figure B-3. Yankee Rowe radial view-top of active core. 
Yankee Rowe Atomic Station

Pressure Vessel Cut-Away

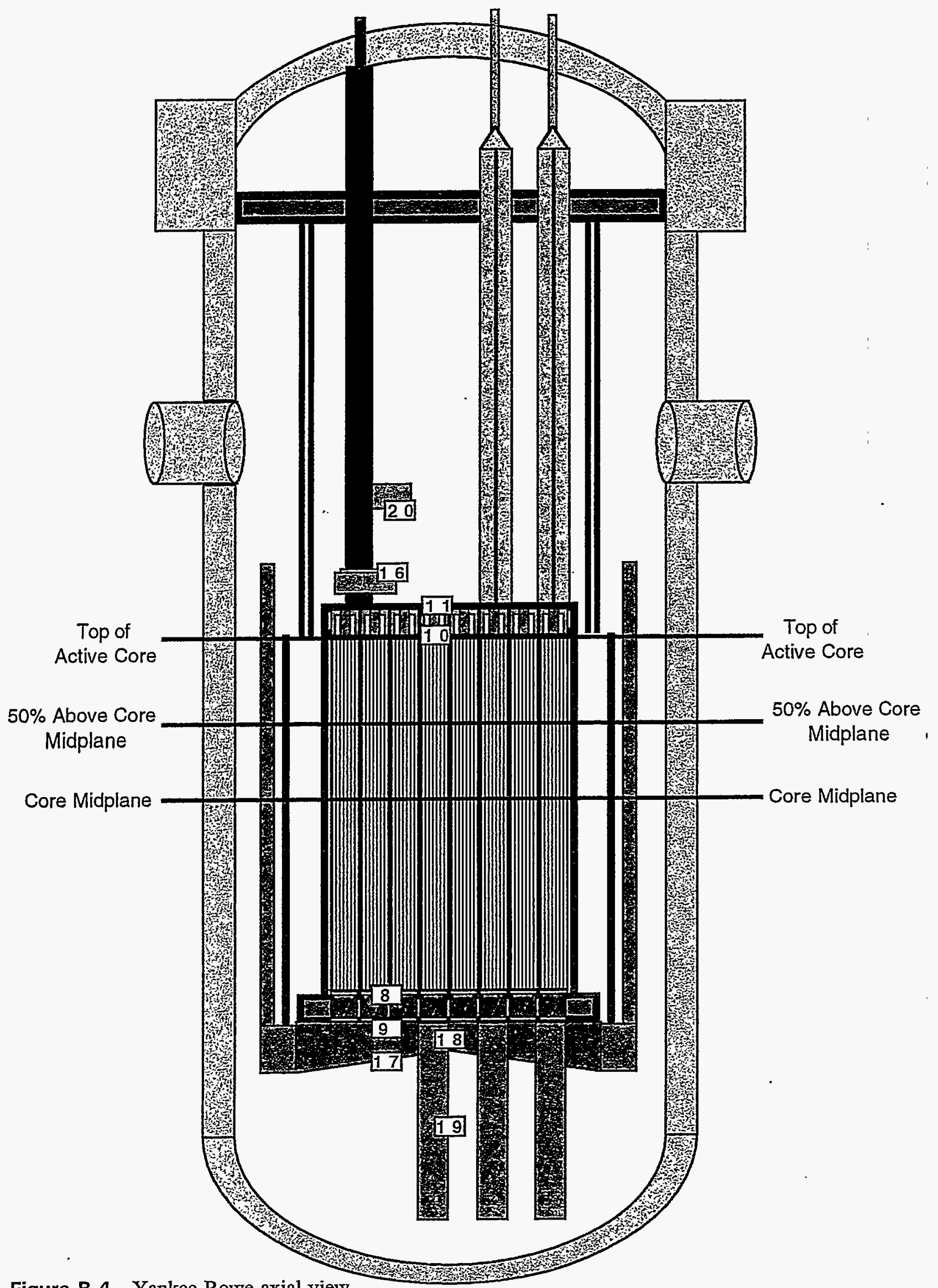

Figure B-4. Yankee Rowe axial view. 
Table B-1. Proposed sample location list and location description for the Yankee Rowe reactor.

\begin{tabular}{|c|c|c|c|c|}
\hline Sample ID & Component & Axial height & Radial distance & Description \\
\hline PNL-CIS-001 & Core baffle & $\begin{array}{l}\text { Active core } \\
\text { midplane }\end{array}$ & Outer surface & $\begin{array}{l}\text { Intersection of Baffle } \\
\text { Plates on } 45 \text { degree } \\
\text { azimuth from } \\
\text { Designated North }\end{array}$ \\
\hline PNL-CIS-002 & Core barrel & $\begin{array}{l}\text { Active core } \\
\text { - midplane }\end{array}$ & Outer surface & $\begin{array}{l}\text { On } 45 \text { degree azimuth } \\
\text { from Designated } \\
\text { North }\end{array}$ \\
\hline PNL-CIS-003 & Core barrel & $\begin{array}{l}50 \% \text { above active } \\
\text { core midplane }\end{array}$ & Outer surface & $\begin{array}{l}\text { On } 45 \text { degree azimuth } \\
\text { from Designated } \\
\text { North }\end{array}$ \\
\hline PNL-CIS-004 & Core barrel & $\begin{array}{l}\text { Top of active } \\
\text { core }\end{array}$ & Outer surface & $\begin{array}{l}\text { On } 45 \text { degree azimuth } \\
\text { from Designated } \\
\text { North }\end{array}$ \\
\hline PNL-CIS-005 & Thermal shield & $\begin{array}{l}\text { Active core } \\
\text { midplane }\end{array}$ & Outer surface & $\begin{array}{l}\text { On } 45 \text { degree azimuth } \\
\text { from Designated } \\
\text { North }\end{array}$ \\
\hline PNL-CIS-006 & Thermal shield & $\begin{array}{l}50 \% \text { above active } \\
\text { core midplane }\end{array}$ & Outer surface & $\begin{array}{l}\text { On } 45 \text { degree azimuth } \\
\text { from Designated } \\
\text { North }\end{array}$ \\
\hline PNL-CIS-007 & Core barrel & $\begin{array}{l}\text { Active core } \\
\text { midplane }\end{array}$ & outer surface & $\begin{array}{l}\text { At point at which } \\
\text { core baffle is closest } \\
\text { to the core barrel }\end{array}$ \\
\hline PNL-CIS-008 & $\begin{array}{l}\text { Lower core } \\
\text { nozzle }\end{array}$ & Top surface & $\begin{array}{l}\text { Any position not } \\
\text { on core center } \\
\text { line }\end{array}$ & - \\
\hline PNL-CIS-009 & $\begin{array}{l}\text { Lower core } \\
\text { nozzle }\end{array}$ & Bottom surface & $\begin{array}{l}\text { Same radial } \\
\text { position as } \\
\text { PNL-CIS-008 }\end{array}$ & - \\
\hline PNL-CIS-010 & $\begin{array}{l}\text { Upper core } \\
\text { support plate }\end{array}$ & Bottom surface & $\begin{array}{l}\text { At core center } \\
\text { line }\end{array}$ & - \\
\hline PNL-CIS-011 & $\begin{array}{l}\text { Upper core } \\
\text { support plate }\end{array}$ & Top surface & $\begin{array}{l}\text { At core center } \\
\text { line }\end{array}$ & - \\
\hline PNL-CIS-012 & Core baffle & $\begin{array}{l}\text { Active core } \\
\text { midplane }\end{array}$ & Outer surface & $\begin{array}{l}\text { At midpoint of the } \\
\text { single assembly flat }\end{array}$ \\
\hline PNL-CIS-013 & Core baffle & $\begin{array}{l}50 \% \text { above active } \\
\text { core midplane }\end{array}$ & Outer surface & $\begin{array}{l}\text { At midpoint of the } \\
\text { single assembly flat }\end{array}$ \\
\hline
\end{tabular}


Table B-1. (continued).

\begin{tabular}{cllll}
\hline Sample ID & \multicolumn{1}{c}{ Component } & \multicolumn{1}{c}{ Axial height } & Radial distance & \multicolumn{1}{c}{ Description } \\
\hline PNL-CIS-014 & Core barrel & $\begin{array}{l}\text { Active core } \\
\text { midplane }\end{array}$ & Outer surface & $\begin{array}{l}\text { Along Designated } \\
\text { North }\end{array}$ \\
PNL-CIS-015 & Thermal shield & $\begin{array}{l}\text { Active core } \\
\text { midplane }\end{array}$ & Inner surface & $\begin{array}{l}\text { Along Designated } \\
\text { North }\end{array}$ \\
PNL-CIS-016 & $\begin{array}{l}\text { Upper core } \\
\text { support column }\end{array}$ & $\begin{array}{l}\text { Upper surface of } \\
\text { support assembly }\end{array}$ & Any position & $\begin{array}{l}\text { Support assembly as } \\
\text { shown on drawing } \\
\text { W646J692 }\end{array}$ \\
PNL-CIS-017 & $\begin{array}{l}\text { Lower core } \\
\text { support plate }\end{array}$ & Lower surface & Any position & - \\
PNL-CIS-018 & $\begin{array}{l}\text { Lower core } \\
\text { control rod } \\
\text { shroud }\end{array}$ & $\begin{array}{l}\text { 12 inches below } \\
\text { lower core nozzle }\end{array}$ & Any position & - \\
PNL-CIS-019 & $\begin{array}{l}\text { Lower core } \\
\text { control rod } \\
\text { shroud }\end{array}$ & $\begin{array}{l}\text { 24 inches below } \\
\text { lower core nozzle }\end{array}$ & $\begin{array}{l}\text { Same shroud } \\
\text { assembly as } \\
\text { PNL-CIS-018 }\end{array}$ & - \\
& $\begin{array}{l}\text { Upper core } \\
\text { support column }\end{array}$ & $\begin{array}{l}\text { Lower surface of } \\
\text { support assembly }\end{array}$ & Any position & $\begin{array}{l}\text { Support assembly as } \\
\text { shown on drawing }\end{array}$ \\
\hline PNL-CIS-020 & W646J692 \\
\hline
\end{tabular}

\section{B-2. SPECIFIC STRATEGY}

Once the general strategy for choosing samples was determined, specific sample locations were chosen from the Yankee Rowe drawings provided by YAEC. Because of their bulk and their possibility of being classified as GTCC LLW, the sample locations should provide good characterization of the core baffle, core barrel, and thermal shield as a first priority. The upper support plate and lower nozzles are also considered important components. These five components, therefore, account for 15 of the 20 proposed sample locations.

To identify the specific purpose of each specific sample, a discussion is presented below about groups of samples, their relation to each other, and the specific phenomena that the samples are intended to verify. Note that a specific sample may be cited more than once. Specific sample locations have been chosen to provide the maximum amount of information using the minimum number of samples. Therefore, several samples are proposed that serve to illustrate more than one effect.

It should be noted that the samples are numbered according to the importance placed on the sample location, i.e., location 5 is believed to be more important than location 7 , and location 7 more important than location 12 . However, the difference in priority for the first 11 samples is very small. 
Together, they form a core set of data that is significantly reduced in value if any one sample is omitted.

\section{B-3. SAMPLE LOCATIONS}

Locations 1, 2, and 5: These midplane locations are chosen to characterize the radial activation profile at locations farthest from the fuel source. This group of locations serves to verify the effects of modeling assumptions.

Locations 2, 3, and 4: These locations are chosen on the core baffle to characterize the axial activation profile on a component that is calculated to be activated to levels above Class $\mathrm{C}$ limits. This group of locations serves to verify the effects of modeling assumptions.

Locations 3 and 6: These sample locations are chosen to supplement the information from samples 1,2 , and 5 concerning the radial activation profile. They are designed to illustrate the relative differences between the activation at mid-plane and at other axial locations.

Location 4: This location is chosen because it is relatively far from the core and may be difficult to accurately model.

Locations 5 and 6: These locations are chosen on the thermal shield to characterize the axial activation profile on a component that is calculated to be activated to below Class $C$ limits, but serves to verify the effects of modeling assumptions.

Location 7: This location is at the point of minimum distance between the fuel and the core barrel. The location is chosen to investigate the radial activation differences between points closer to and farther from (such as sample 2) the fuel source. Analytical comparisons between location 2 and location 7 can be evaluated.

Locations 8 and 9: These locations are chosen to evaluate the code capability in order to predict activation in the complicated nozzle region. The nozzle region has a potential for being activated to above Class $C$ limits, so this evaluation is highly useful. Note that these samples are not at core centerline so that asymmetric effects can be analyzed.

Locations 10 and 11: These locations are chosen to evaluate the difference in activation on opposite sides of a relatively thick plate. This region has a high potential for being activated to above Class $C$ limits. Information gathered here can also be related to data from locations 8 and 9 for above- and below-core comparisons.

Locations 12 and 13: These locations are chosen to allow for investigation of the differences in activation between component sections "on the flats" of the baffle and component sections in a corner, such as sample 1. An axial profile is also desired in this region. Analytical comparisons between location 12 and location 1 can be evaluated.

Locations 12, 14, and 15: This region in the Yankee core is thought to be difficult to model analytically because of the streaming path that is provided by the steel core supports. Location 12 
provides a regional location without streaming for accuracy comparison, and locations 14 and 15 are in areas of maximum neutron streaming.

Location 16: This location on the instrument trunk support will allow for evaluation of a large component above the core that will have significant activation and may be above Class $\mathrm{Climits.}$ Because of the various components between the support column and the core, it is believed that analytical prediction may be more difficult here than in other locations.

Location 17: This location on a lower core support will allow for evaluation of a large component below the core that will have significant activation. Because of the various components between the support and the core and the thickness of the plate, it is believed that analytical prediction may be more difficult here than in other locations.

Locations 18 and 19: These locations allow for the characterization of the axial activation profile below the core. The control rod shrouds provide a uniform vertical component from which to establish the axial trend.

Location 20: This location on the instrument trunk support will allow for evaluation of a large component above the core that lies a significant distance from the core itself. Because of the various components between the support column and the core, it is believed that analytical prediction may be more difficult here than in other locations. Data from this location can be related to location 16 to provide an axial characterization above the core.

A number of PWR facilities are significantly different from Yankee Rowe, and therefore some sample locations have been chosen to investigate spatial effects that may concern other facilities. An example of this type of sample is the locations on the control rod shroud. While other reactors do not have shrouds below the core, other component structures may exist below the core that may be of concern. Since it is anticipated that samples from other facilities may not be available, and that verification of the axial activation profile below the core is considered important, the locations on the shroud were chosen. To the maximum extent possible, attempts are made to verify all aspects of the code model.

The proposed sampling plan is sufficient to validate the code model with respect to the prediction of components that may be activated to levels above Class $\mathrm{C}$ limits. While they are listed in order of relative importance, all the locations are considered important for code validation. Careful consideration should be given before the number of samples is reduced.

\section{B-4. SAMPLE PLAN QUALITY ISSUES}

The actual sampling analysis plan would be developed in detail prior to the extraction of samples from a candidate reactor. Development of such a detailed plan will require extensive participation of the subject utility and is not in the scope of this report. There are quality assurance issues, however, that need to be addressed in any sampling plan which is developed. 
The intent of this section is to identify these issues, and to provide possible resolutions. Since the subject of this report is the Yankee Rowe reactor facility, these issues are addressed specifically with Yankee Rowe in mind. The issues should be pertinent to any other facilities of interest as well.

The following items have been identified as quality issues associated with the plan to obtain and analyze samples from the Yankee Rowe reactor. The issues are identified, and a means for resolving the issues is provided. In most cases, the quality assurance issues identified can be addressed through procedures used to perform the work.

\section{B-4.1 Sample Constraints}

The cutting method that will be used to remove samples from the reactor should be chosen at the convenience of the utility. However, guidance from the analytical laboratory needs to be provided so that the method chosen is appropriate for the size and location of the sample.

The actual samples to be taken need to have a minimum mass to support the analytical chemistry analysis. The mass of each sample should be at least 5 to $10 \mathrm{~g}$ to allow enough material for all of the isotope analyses that are to be performed.

The actual physical size and shape of the samples depends on two things. First, the shape should be large enough and convenient to handle in the laboratory. The sample will have to be manipulated and sampled remotely in a hot cell after it is received. A square or rectangular shape of about 1 in. $^{3}$ would therefore be preferred over smaller or round samples. Secondly, the size and shape of the sample will depend somewhat on the method used to cut the sample from the reactor. It is desirable to analyze metal that has not been affected by the heat of the cutting tool used to remove it. Different cutting tools affect metal at different distances from the cut. For example, use of a welding torch may affect several inches to either side of the cut, whereas the use of a plasma arc might only affect $1 / 4$ in. to either side. Because of the sample considerations, guidance should be provided to the utility so that they adjust the sample size in accordance with the method chosen.

To ensure the accuracy of the sample locations relative to the location specifications defined in the sampling plan, a quality assurance procedure for the cutting process should be developed. The sampling plan will only give the relative region where the sample should be taken since, for the purposes of this project, the locations are somewhat flexible. Once the sample is taken, however, the exact sample location (including whether it is from the inside or outside of a component) must be recorded, probably by using measurements. The procedure should include some form of independent verification of the region and the measurement at the time the cut is made. Photographs or video tape of the cutting procedure showing the region of each cut at the time of the cut would be an excellent method of verification, and a quality assurance check of the measurements would be appropriate.

\section{B-4.2 Sample Tracking}

A procedure that specifies a method for marking and tracking the samples to their origin once they are removed from the reactor must be developed. It is expected that each sample will have its own container. At the minimum, a unique identifier should be given to each sample, and the sample 
and/or its container should be marked with this identifier. A written correlation should be completed that indicates the sample identifier and the origin of the sample in the reactor. The container will be sealed after the sample is placed inside, and the sample should not be removed until arrival at the analytical laboratory.

Procedures must be implemented to track the samples once they reach the laboratory location. These procedures should assign a unique number to each sample. When subsamples are removed, the subsamples should be identified with the sample number plus a unique subsample suffix. All samples should be logged into an administrative database for tracking. The results of laboratory analysis should be recorded in association with the sample numbers.

\section{B-4.3 Laboratory Analysis Methods}

Radiochemical analysis will be performed to determine the concentrations of Carbon-14, Nickel-59, Nickel-63, Niobium-94, Technetium-99, and Cobalt-60 in the samples. With the exception of ${ }^{60} \mathrm{Co}$, each of the above radionuclides has concentration limits specified in $10 \mathrm{CFR} 61$ for Class $\mathrm{C}$ waste. The ${ }^{60} \mathrm{Co}$ concentration is relatively easy to accurately measure in activated metals and provides a good data point for validation of the MCNP computations.

Elemental analysis will be performed to determine the concentrations of elemental nitrogen, nickel, niobium, molybdenum, carbon, copper, and cobalt. These elements are the parent elements for the radionuclides that are measured in the radiochemical analysis.

The following summaries provide very brief descriptions of radiochemical procedures which can be used to determine the concentration of each radionuclide of interest. These summaries are adapted from detailed procedures that are available at the Pacific Northwest Laboratory.

Carbon-14 quantities are determined by a total combustion method, using an induction furnace in the hot cell to fuse the metal sample in pure oxygen with a metal flux. The gas stream exiting from the combustion tube is passed over a catalytic heater mounted on the furnace for conversion of any $\mathrm{CO}$ to $\mathrm{CO}_{2}$, as well as $\mathrm{H}_{2}$ to $\mathrm{H}_{2} \mathrm{O}$. The efficiency of conversion is determined by comparison with documented carbon standards. The gas is routed out of the shielded hot cell through a drying column for removal of any $\mathrm{H}_{2} \mathrm{O}$. The gas is then sparged through a $\mathrm{NaOH}$ caustic bubbler for collection of ${ }^{14} \mathrm{CO}_{2}$. Collection efficiency of the caustic bubbler is determined prior to first-time use. Measurement of ${ }^{14} \mathrm{C}$ in the bubbler solution is by liquid scintillation counting.

Measurement of the ${ }^{59} \mathrm{Ni}$ and ${ }^{63} \mathrm{Ni}$ isotopes will be performed by a combination of liquid scintillation counting, low-energy photon spectrometry, and inductively coupled atomic emission spectroscopy (ICP/AES). The nickel is separated from the solution and prepared for liquid scintillation counting by electroplating it on a disk. Stable nickel is used as a carrier, the concentration of which is determined by ICP/AES.

The separation of ${ }^{93 \mathrm{~m}} \mathrm{Nb}$ and ${ }^{94} \mathrm{Nb}$ from the aqueous samples is accomplished by precipitation of hydrated niobium pentoxide (niobic acid) that is collected by filtration and converted to $\mathrm{Nb}_{2} \mathrm{O}_{5}$ in air. Yield is determined from a known quantity of ${ }^{95} \mathrm{Nb}$ tracer that is evaluated by gamma-ray spectroscopy. The ${ }^{94} \mathrm{Nb}$ and ${ }^{93 m} \mathrm{Nb}$ activities are also both determined by gamma-ray spectroscopy. A low-energy photon detector is used to measure the x-rays produced from the internal transition decay 
from the $30.4 \mathrm{keV}$ state of ${ }^{93 \mathrm{~m}} \mathrm{Nb}$. One limitation to this procedure is the incomplete separation of $\mathrm{Nb}$ from $\mathrm{Sb}$. The results of this procedure are interpreted by considering the amount of ${ }^{93 \mathrm{~m}} \mathrm{Nb}$ and ${ }^{125} \mathrm{Sb}$ present and the required sensitivity for ${ }^{93 m} \mathrm{Nb}$.

The concentration of ${ }^{99} \mathrm{Tc}$ is determined by adding a known quantity of ${ }^{95 \mathrm{~m}} \mathrm{Tc}$ tracer to the aqueous sample. The sample is converted to the pertechnetate form and cations are removed using a cation column. The technecium is further purified using a technicium-specific column resin. The ${ }^{99} \mathrm{Tc}$ and ${ }^{95 \mathrm{~m}} \mathrm{Tc}$ relative concentrations are then determined using liquid scintillation counting.

To determine the ${ }^{60} \mathrm{Co}$ concentration, an aliquot of dissolved metal is placed in a specific $10 \mathrm{ml}$ geometry in a side-looking $\mathrm{Ge}(\mathrm{Li})$ gamma detector. The $\mathrm{Ge}(\mathrm{Li})$ detector is used in association with the appropriate electronics, to separate the gamma photons by energy. The ${ }^{60} \mathrm{Co}$ concentration is determined based on the peak areas at $1173.2 \mathrm{keV}$ and $1332.5 \mathrm{keV}$ and the detector efficiency at these regions.

\section{B-4.4 Validity of Data}

To establish the validity of the data and identify the uncertainties associated with each procedure, a stainless steel standard or spiked sample is also prepared with each batch of subsamples as a laboratory control. The standard serves as a known quantity that allows for screening of systematic variations in the analysis process (i.e., background radiations in the hot cell).

The process procedures must contain quality control instructions that must be followed. The data from the analysis must also be evaluated by a cognizant scientist. In addition, quality control audits of the procedures must be made. 
Appendix C

Comparison to DORT/ACTIV Calculations

C-1 
C-2 


\section{Appendix C}

\section{Comparison to DORT/ACTIV Calculations}

In early 1994, the Yankee Atomic Electric Company (YAEC) began decommissioning the Yankee Rowe reactor. The reactor core internals were sectioned and categorized for waste disposal. The waste was classified according to the isotopic concentration of various radionuclides in accordance with 10 CFR 61 (see Table 1). Components or combinations of components classified as Class $C$ waste or lower were shipped to the Barnwell disposal site in South Carolina. The disposal of material that was determined to be GTCC LLW is ultimately the responsibility of the United States government and is currently being stored in the Yankee Rowe spent fuel pool.

YAEC contracted with Waste Management Group (WMG), Inc., to section the internal components and estimate the waste classification. In conjunction with the waste disposal activities, YAEC performed calculations to estimate the activity content and therefore the waste classification of the components which were to be removed.

Activation estimates were provided by YAEC for inclusion into this appendix to provide some basis of comparison for the MCNP calculations. The specific data which will be discussed here are the specific activities for each component and the scaling factors used to determine the activities. Additionally, the resulting differences in the sum-of-the-fractions will be discussed.

\section{C-1. ACTIVATION COMPARISON}

The MCNP method used to calculate the activation of the Yankee Rowe components is detailed in the body of this report. YAEC used a different code methodology to calculate activation as part of their work supporting Yankee Rowe decommissioning. The YAEC calculations use the DORT code with the SAILOR library to calculate neutron fluxes at various radial and axial locations. DORT is a discrete ordinates neutron transport code. The calculations were performed in two dimensions using $\mathrm{R}-\theta$ and R:Z geometric representations. The resultant fluxes from the DORT results were then used as inputs to the ACTIV code to perform the activation analysis on individual components. ACTTV is a multi-group, one-dimensional code used for radionuclide activation and depletion calculations. The ACTIV code calculates pointwise activation in 47 energy groups using cross-sections derived from ENDF/B-VI data. The inputs for this code methodology were essentially the same as that provided for the MCNP calculations.

The MCNP calculation results of the Yankee Rowe component activation were compared to the DORT/ACTIV results. The two sets of results are presented in Table C-1. The MCNP results are the same as the base results with decay in Tables 5 and 6, however; they have been converted to units of curies per gram for comparison to YAEC results. Additionally, the MCNP activities were adjusted for decay to January 1, 1994 (March 1, 1994 was used for the base results) to be consistent with the estimates provided by YAEC. 
Table C-1. Activation calculations for long-lived isotopes $(\mathrm{Ci} / \mathrm{g})$.

\begin{tabular}{|c|c|c|c|c|c|c|c|c|c|c|c|c|}
\hline \multirow[b]{2}{*}{ Component } & \multicolumn{2}{|c|}{${ }^{94} \mathrm{Nb}$} & \multicolumn{2}{|c|}{${ }^{59} \mathrm{Ni}$} & \multicolumn{2}{|c|}{${ }^{14} \mathrm{C}$} & \multicolumn{2}{|c|}{${ }^{00} \mathrm{Tc}$} & \multicolumn{2}{|c|}{${ }^{63} \mathrm{Ni}$} & \multicolumn{2}{|c|}{${ }^{\infty} \mathrm{Co}$} \\
\hline & $\begin{array}{c}\text { DORT/ACTIV } \\
\text { estimate }\end{array}$ & $\begin{array}{c}\text { MCNP } \\
\text { estimate } \\
\text { w/decay }\end{array}$ & $\begin{array}{c}\text { DORT/ACTIV } \\
\text { estimate }\end{array}$ & $\begin{array}{c}\text { MCNP } \\
\text { estimate } \\
\text { w/decay }\end{array}$ & $\begin{array}{c}\text { DORT/ACTIV } \\
\text { estimate }\end{array}$ & $\begin{array}{c}\text { MCNP } \\
\text { estimate } \\
\text { w/decay }\end{array}$ & $\begin{array}{c}\text { DORT/ACTIV } \\
\text { estimate }\end{array}$ & $\begin{array}{c}\text { MCNP } \\
\text { estimate } \\
\text { w/decay }\end{array}$ & $\begin{array}{c}\text { DORT/ACTIV } \\
\text { estimate }\end{array}$ & $\begin{array}{c}\text { MCNP } \\
\text { estimate } \\
\text { w/decay }\end{array}$ & $\begin{array}{c}\text { DORT/ACTIV } \\
\text { estimate }\end{array}$ & $\begin{array}{l}\text { MCNP } \\
\text { estimate } \\
\text { W/decay }\end{array}$ \\
\hline Core baffle & $3.00 e-07$ & $1.51 \mathrm{e}-07$ & $1.22 \mathrm{e}-04$ & $4.09 \mathrm{e} \cdot 05$ & $4.40 e-05$ & $4.07 e-07$ & N/A & $1.70 \mathrm{e}-09$ & $1.28 \mathrm{e}-02$ & $2.86 \mathrm{e} \cdot 04$ & $6.63 e-02$ & $2.82 \theta-02$ \\
\hline Core barrel & $1.11 \mathrm{e}-08$ & 8.330 .09 & $7.62 \mathrm{e}-06$ & $3.05 \theta-06$ & $2.610-06$ & $3.03 e-08$ & N/A & $9.67 e-11$ & 8.290 .04 & $2.15 e-05$ & $4.190-03$ & $1.91 \mathrm{e}-03$ \\
\hline $\begin{array}{l}\text { Thermal } \\
\text { shield }\end{array}$ & $1.14 \mathrm{e}-09$ & $1.82 \theta-09$ & $3.73 e-07$ & $4.85 e-07$ & 1.370 .07 & $4.88 \mathrm{e}-09$ & N/A & $1.64 \mathrm{e}-11$ & $3.97 e-05$ & $3.40 \mathrm{e}-06$ & $2.66 \mathrm{e}-04$ & $3.34 \mathrm{e}-04$ \\
\hline
\end{tabular}


The YAEC analysis contains results for a variety of components, including most of the components analyzed in this report. However, due to differences in modeling assumptions, the data comparison will be limited to the radial components: the baffle, barrel, and thermal shield.

Two key differences should be noted between the YAEC calculations and the calculations made for this report. First, the YAEC assumptions indicate that the core barrel and thermal shield were 1 in. and 3.25 in. thick, respectively. The data made available for this report (from physical measurements or design drawings) indicated that these thicknesses were $1.25 \mathrm{in}$. and $1.5 \mathrm{in}$., respectively. As noted in Appendix A, differences in material thickness of just $1.27 \mathrm{~cm}(0.5$ in.) can alter the neutron spectrum and significantly alter the calculated activation results.

Second, the coolant boron concentration assumption is different. As noted in the main report, the MCNP model includes an average 1,000 ppm boron in the water. The YAEC results were generated assuming that the boron concentration in water was zero. This was done to provide conservative estimates for the actual decommissioning activity. Since boron is a large thermal neutron absorber, significant differences could result from large concentration differences.

The results received from YAEC are given in terms of total cobalt concentrations and associated scaling factors. For ease of comparison, the scaling factors have been multiplied by the cobalt concentrations to determine the associated isotopic activities. The specific scaling factors used by YAEC are presented in Table C-2.

The concentration comparisons indicate that MCNP generally predicts lower activation levels than DORT/ACTIV for all of the isotopes. The exception is the thermal shield, where the MCNP results indicate higher activation for some isotopes. The inconsistent thermal shield comparison is likely influenced by the difference in thermal shield thicknesses used in the code models. Some of the activities calculated by the codes compare rather well and are only 20-70\% different. This is true of ${ }^{94} \mathrm{Nb},{ }^{59} \mathrm{Ni}$ and ${ }^{60} \mathrm{Co}$. Activities for ${ }^{14} \mathrm{C}$ and ${ }^{63} \mathrm{Ni}$, however, differ by up to two orders of magnitude. One reason the MCNP calculations are generally lower may be due to the differing boron

Table C-2. Comparison of DORT/ACTIV and MCNP scaling factors (i.e., ratios of activation products relative to ${ }^{60} \mathrm{Co}$ ).

\begin{tabular}{lcccccccc}
\hline & \multicolumn{2}{c}{ Core baffle } & & \multicolumn{2}{c}{ Core barrel } & & \multicolumn{2}{c}{ Thermal shield } \\
\cline { 2 - 3 } Isotope & DORT/ACTIV & MCNP & & DORT/ACTIV & MCNP & & DORT/ACTIV & MCNP \\
\hline${ }^{94} \mathrm{Nb}$ & $4.52 \mathrm{e}-06$ & $5.34 \mathrm{e}-06$ & & $2.64 \mathrm{e}-06$ & $4.37 \mathrm{e}-06$ & & $4.27 \mathrm{e}-06$ & $5.43 \mathrm{e}-06$ \\
${ }^{59} \mathrm{Ni}$ & $1.84 \mathrm{e}-03$ & $1.45 \mathrm{e}-03$ & & $1.82 \mathrm{e}-03$ & $1.60 \mathrm{e}-03$ & & $1.40 \mathrm{e}-03$ & $1.45 \mathrm{e}-03$ \\
${ }^{14} \mathrm{C}$ & $6.64 \mathrm{e}-04$ & $1.44 \mathrm{e}-05$ & & $6.23 \mathrm{e}-04$ & $1.59 \mathrm{e}-05$ & & $5.16 \mathrm{e}-04$ & $1.46 \mathrm{e}-05$ \\
${ }^{99} \mathrm{TC}$ & $\mathrm{N} / \mathrm{A}$ & $6.01 \mathrm{e}-08$ & & $\mathrm{~N} / \mathrm{A}$ & $5.07 \mathrm{e}-08$ & & N/A & $4.90 \mathrm{e}-08$ \\
${ }^{63} \mathrm{Ni}$ & $1.93 \mathrm{e}-01$ & $1.01 \mathrm{e}-02$ & & $1.98 \mathrm{e}-01$ & $1.13 \mathrm{e}-02$ & & $1.49 \mathrm{e}-01$ & $1.02 \mathrm{e}-02$ \\
${ }^{60} \mathrm{Co}$ & $1.00 \mathrm{e}+00$ & $1.00 \mathrm{e}+00$ & & $1.00 \mathrm{e}+00$ & $1.00 \mathrm{e}+00$ & & $1.00 \mathrm{e}+00$ & $1.00 \mathrm{e}+00$ \\
\hline
\end{tabular}


concentrations used. Higher boron concentrations lead to increased capture of thermal neutrons by boron, and therefore fewer thermal neutrons available to activate the metal components. The boron incorporated in the MCNP model would therefore result in a lower metal activation compared to the DORT/ACTIV calculations, which do not include boron.

The calculations performed by YAEC were knowingly designed to be conservatively high. Measurements made during the Yankee Rowe decommissioning confirmed this. Radially outward from the active fuel region, the actual activities were about 30-70\% lower than the DORT/ACTTV estimates. This would appear to indicate that those MCNP results which are 20-70\% lower than the DORT/ACTIV results may be close to the actual metal activation. It is of particular note that the ${ }^{60} \mathrm{Co}$ is one of the isotopes whose results are in this $20-70 \%$ range. Since ${ }^{60} \mathrm{Co}$ is the predominant isotope measured during component profiling, calculations of ${ }^{80} \mathrm{Co}$ are particularly important.

The large differences in the ${ }^{14} \mathrm{C}$ and ${ }^{63} \mathrm{Ni}$ calculations can only be explained reasonably by crosssection or calculation differences. Both the ${ }^{14} \mathrm{~N}$ and the ${ }^{62} \mathrm{Ni}$ cross-sections are $1 / \mathrm{v}$; however, the magnitudes of the cross-sections used by each code may be different. The isotopic cross-sections of nickel in particular are not well known, and the data used by the codes may be from different sources. Differences are also possible in the neutron spectrum calculations. It is possible that the multi-group calculational approach used by DORT/ACTIV may skew the activation results if the groups were not optimized for the activation calculations being performed. Without significant crosssection and code comparisons, however, the reason the ${ }^{14} \mathrm{C}$ and ${ }^{63} \mathrm{Ni}$ calculations show such large differences cannot be well understood.

Since results from YAEC are based on the use of scaling factors and the measured activities are determined by a similar process, it is instructive to provide a comparison of those factors with "scaling factors" generated from MCNP.' The MCNP code methodology does not use scaling factors to arrive at results; however, the MCNP results can be manipulated into "scaling factors" by normalizing all the activation results to ${ }^{60} \mathrm{C}$. These factors can then be compared to those provided by YAEC. This comparison is shown in Table C-2.

In addition to these scaling factors, comparison of other isotope production ratios can be instructive. Table C-3 shows comparisons of several activation ratios. Note that Table C-3 may have slightly different ratios than Table 8 since the decay times are different and the ratios change slightly with additional decay.

An observation which can be made from Tables C-2 and C-3 is that distinct neutron spectrum changes occur radially outside the core. Relative activation of ${ }^{93} \mathrm{Nb}$ in particular, and ${ }^{59} \mathrm{Co}$ to a lesser extent, varies significantly in relation to other parent isotopes in the core barrel. For example, the ratio of ${ }^{14} \mathrm{C}$ and ${ }^{59} \mathrm{Ni}$ with ${ }^{94} \mathrm{Nb}$ increases $30-60 \%$ (depending on the code calculation) in the core barrel relative to the baffle or thermal shield (Table C-3). The ratio of ${ }^{60} \mathrm{Co}$ with ${ }^{14} \mathrm{C}$ and ${ }^{59} \mathrm{Ni}$ consistently changes by about $10 \%$ when the MCNP core barrel results are compared to the MCNP baffle or thermal shield results in Table C-2. The DORT/ACTIV results in Table C-2 are less consistent with respect to this comparison. The table results generally indicate, however, that the ${ }^{93} \mathrm{Nb}$ and ${ }^{59} \mathrm{Co}$ captures are relatively lower in the barrel compared to the other isotopes.

The reason for the drop in captures may be due to spectral effects. To understand the possible effect, the isotopic cross-sections involved should be understood. The ${ }^{58} \mathrm{Ni}$ cross-section is $1 / \mathrm{v}$ to at 
Table C-3. Comparison of production ratios of activation products.

\begin{tabular}{|c|c|c|c|c|c|c|c|c|c|c|}
\hline \multirow[b]{2}{*}{ Component } & \multicolumn{2}{|c|}{${ }^{59} \mathrm{Ni} /{ }^{94} \mathrm{Nb}$} & \multicolumn{2}{|c|}{${ }^{63} \mathrm{Ni} /{ }^{14} \mathrm{C}$} & \multicolumn{2}{|c|}{${ }^{59} \mathrm{Ni} /{ }^{14} \mathrm{C}$} & \multicolumn{2}{|c|}{${ }^{63} \mathrm{Ni} /{ }^{59} \mathrm{Ni}$} & \multicolumn{2}{|c|}{${ }^{14} \mathrm{C} /{ }^{94} \mathrm{Nb}$} \\
\hline & DORT/ACTIV & MCNP & DORT/ACTIV & MCNP & DORT/ACTIV & MCNP & DORT/ACTIV & MCNP & DORT/ACTIV & MCNP \\
\hline Core baffle & 407.1 & 271.3 & 290.7 & 701.1 & 2.8 & 100.3 & 104.9 & 7.0 & 146.9 & 2.7 \\
\hline Core barrel & 689.4 & 366.6 & 317.8 & 707.9 & 2.9 & 100.7 & 108.8 & 7.0 & 236.0 & 3.6 \\
\hline $\begin{array}{l}\text { Thermal } \\
\text { shield }\end{array}$ & 327.9 & 267.3 & 288.8 & 696.9 & 2.7 & 99.4 & 106.4 & 7.0 & 120.8 & 2.7 \\
\hline
\end{tabular}


least $4 \mathrm{KeV}$ and the ${ }^{14} \mathrm{~N}$ cross-section is $1 / \mathrm{v}$ through $10 \mathrm{KeV}$. However, both ${ }^{93} \mathrm{Nb}$ and ${ }^{59} \mathrm{Co}$ have significant absorption resonances in the $10 \mathrm{Kev}$ to $10 \mathrm{KeV}$ range. If all captures were of thermal neutrons, all of the production ratios would be constant as all captures would be in the $1 / \mathrm{v}$ range of the cross-sections. Since the ratios change, this may indicate that the spectrum is more thermal in the barrel region, as that would allow for fewer resonance captures in ${ }^{93} \mathrm{Nb}$ and ${ }^{59} \mathrm{Co}$, thereby changing the ratio. The fast-to-thermal flux ratios in the baffle and thermal shield appear to be similar to each other, while the ratio appears to be different in the barrel. Detailed analysis of the spectrum would be required to verify this.

For waste classification purposes, the comparison which is of highest value is the resulting sumof-the-fractions calculation. The sums-of-the-fractions are shown in Tables C-4 and C-5. The tables clearly show differences in the sums of factors of two or more. However, for these components both methodologies would predict the same waste classification. DORT/ACTIV show more conservative results for most of the components, which is to be expected.

\section{C-2. CONCLUSIONS}

In general, many of the MCNP and DORT/ACTIV results compare well when the 30-70\% conservatism built into the DORT/ACTIV calculations is considered. The results for ${ }^{14} \mathrm{C}$ and ${ }^{63} \mathrm{Ni}$ may be different by one or two orders of magnitude, however. Those differences may be due to cross-section differences or calculational effects.

Both code methodologies would predict the same waste classification for all the components that were compared. However, DORT/ACTIV predicts a much higher sum-of-the-fractions than MCNP. This is partially due to the conservative nature of the DORT/ACTIV calculations. If the DORT/ACTIV results were to be extrapolated to other reactors, it would be desirable to remove some of the conservatisms used. If they are not, it would be likely that some core barrels would be predicted to be well over the Class $C$ limit when in fact they were not. 
Table C-4. Comparison of sums-of-the-fractions calculations for long-lived isotopes.

\begin{tabular}{|c|c|c|c|c|c|c|c|c|c|c|}
\hline \multirow[b]{2}{*}{ Component } & \multicolumn{2}{|l|}{${ }^{91} \mathrm{Nb}$} & \multicolumn{2}{|l|}{${ }^{59} \mathrm{Ni}$} & \multicolumn{2}{|l|}{${ }^{14} \mathrm{C}$} & \multicolumn{2}{|l|}{${ }^{99} \mathrm{Tc}$} & \multicolumn{2}{|c|}{ Total } \\
\hline & DORT/ACTIV & MCNP & DORT/ACTIV & MCNP & DORT/ACTIV & MCNP & DORT/ACTIV & MCNP & DORT/ACTIV & MCNP \\
\hline Core baffle & 11.982 & 6.022 & 4.434 & 1.486 & 4.400 & 0.041 & N/A & 0.005 & 20.816 & 7.553 \\
\hline Core barrel & 0.442 & 0.333 & 0.277 & 0.111 & 0.261 & 0.003 & $\mathrm{~N} / \mathrm{A}$ & 0.000 & 0.980 & 0.448 \\
\hline $\begin{array}{l}\text { Thermal } \\
\text { shield }\end{array}$ & 0.046 & 0.073 & 0.014 & 0.018 & 0.014 & 0.000 & N/A & 0.000 & 0.073 & 0.091 \\
\hline
\end{tabular}


Table C-5. Comparison of sums-of-the-fractions calculations for short-lived isotopes.

\begin{tabular}{lccccc}
\hline & \multicolumn{2}{c}{${ }^{63} \mathrm{Ni}$} & & \multicolumn{2}{c}{ Total } \\
\cline { 2 - 3 } \cline { 5 - 6 } Component & DORT/ACTIV & MCNP & & DORT/ACTIV & MCNP \\
\hline Core baffle & 14.617 & 0.326 & & 14.617 & 0.326 \\
Core barrel & 0.947 & 0.025 & & 0.947 & 0.025 \\
Thermal shield & 0.045 & 0.004 & & 0.045 & 0.004 \\
\hline
\end{tabular}

